\title{
Review
}

\section{Oxidative Stress in Non-Alcoholic Fatty Liver Disease}

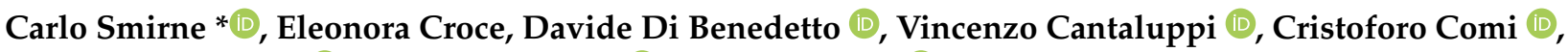 \\ Pier Paolo Sainaghi (D), Rosalba Minisini (1), Elena Grossini (1) and Mario Pirisi
}

\author{
Department of Translational Medicine, Università del Piemonte Orientale, Via Solaroli 17, 28100 Novara, Italy; \\ ec.croce@gmail.com (E.C.); davidedibenedetto304@gmail.com (D.D.B.); \\ vincenzo.cantaluppi@med.uniupo.it (V.C.); cristoforo.comi@med.uniupo.it (C.C.); \\ pierpaolo.sainaghi@med.uniupo.it (P.P.S.); rosalba.minisini@med.uniupo.it (R.M.); \\ elena.grossini@med.uniupo.it (E.G.); mario.pirisi@med.uniupo.it (M.P.) \\ * Correspondence: carlo.smirne@med.uniupo.it; Tel.: +39-03213733889
}

Citation: Smirne, C.; Croce, E.; Di Benedetto, D.; Cantaluppi, V.; Comi, C.; Sainaghi, P.P.; Minisini, R.; Grossini, E.; Pirisi, M. Oxidative Stress in Non-Alcoholic Fatty Liver Disease. Livers 2022, 2, 30-76. https://doi.org/livers2010003

Academic Editor: Kenichi Ikejima

Received: 12 November 2021

Accepted: 14 January 2022

Published: 1 February 2022

Publisher's Note: MDPI stays neutral with regard to jurisdictional claims in published maps and institutional affiliations.

Copyright: (C) 2022 by the authors. Licensee MDPI, Basel, Switzerland. This article is an open access article distributed under the terms and conditions of the Creative Commons Attribution (CC BY) license (https:// creativecommons.org/licenses/by/ $4.0 /)$.

\begin{abstract}
Non-alcoholic fatty liver disease (NAFLD) is a challenging disease caused by multiple factors, which may partly explain why it still remains an orphan of adequate therapies. This review highlights the interaction between oxidative stress (OS) and disturbed lipid metabolism. Several reactive oxygen species generators, including those produced in the gastrointestinal tract, contribute to the lipotoxic hepatic (and extrahepatic) damage by fatty acids and a great variety of their biologically active metabolites in a "multiple parallel-hit model". This leads to inflammation and fibrogenesis and contributes to NAFLD progression. The alterations of the oxidant/antioxidant balance affect also metabolism-related organelles, leading to lipid peroxidation, mitochondrial dysfunction, and endoplasmic reticulum stress. This OS-induced damage is at least partially counteracted by the physiological antioxidant response. Therefore, modulation of this defense system emerges as an interesting target to prevent NAFLD development and progression. For instance, probiotics, prebiotics, diet, and fecal microbiota transplantation represent new therapeutic approaches targeting the gut microbiota dysbiosis. The OS and its counter-regulation are under the influence of individual genetic and epigenetic factors as well. In the near future, precision medicine taking into consideration genetic or environmental epigenetic risk factors, coupled with new OS biomarkers, will likely assist in noninvasive diagnosis and monitoring of NAFLD progression and in further personalizing treatments.
\end{abstract}

Keywords: non-alcoholic fatty liver disease; oxidative stress; antioxidants; metabolic syndrome; inflammation; gut microbiota; mitochondrial dysfunction; lipotoxicity; lipid metabolism; reactive oxygen species

\section{Introduction}

Non-alcoholic fatty liver disease (NAFLD) is the most widespread and emerging chronic liver disease both in Western and developing countries. It has an estimated prevalence of about $23-25 \%$ in the general adult population. The burden varies between and within regions, with the highest prevalence in the Middle East (32\%) and South America $(30 \%)$, and the lowest in Africa (13\%) [1]. Additionally, the prevalence rates in North America, Europe, and Asia were reported to be 24.1\%, 23.7\%, and 27.4\%, respectively [2], and increased up to $55.5 \%$ in type 2 diabetes subjects [3]. NAFLD is a metabolic disorder with no history of excessive drinking (i.e., less than 14 and 21 standard drinks per week on average for women and men, respectively) [4] and is characterized by hepatocyte steatosis and fat accumulation. The disease presents with a broad spectrum of histological alterations, ranging from simple steatosis (SS) to the appearance of steatohepatitis (NASH), which is characterized by the presence of lobular inflammation, hepatocyte damage, and ballooning and that can ultimately lead, in a minority of subjects, to hepatic fibrosis [5]. SS is considered one benign condition with no or little active inflammation and without 
fibrosis that does not lead to aggravation and progression of the disease. On the contrary, in a small percentage of patients, namely, those with NASH, the disease can be progressive and ultimately evolve towards cirrhosis with its increase in liver-related mortality and/or hepatocellular carcinoma (HCC). Nowadays, NASH represents the second most common indication for liver transplantation in Europe and the US and it is expected within a short time period to overcome hepatitis C [6]. In addition, it is a matter of concern the growing number of non-cirrhotic subjects in which NASH can progress directly towards HCC [7].

The diagnosis of NAFLD is usually made through abdominal ultrasound, which, in the studies that have compared it with the gold standard exam (i.e., liver biopsy), has been shown to have good sensitivity and high specificity for the diagnosis of steatosis [8]. More recently, especially in the research field, the assessment of steatosis is performed by means of magnetic resonance imaging [9]. Otherwise, the diagnosis of NASH is made through liver biopsy, using standardized criteria based on the evaluation of the NAS (NAFLD activity score) - which takes into account separate scores for steatosis, balloon-shaped degeneration and inflammation-and fibrosis [10]. However, most patients with NAFLD do not require a liver biopsy, mainly for ethical reasons. As a matter of fact, biopsy is not indicated especially in those who do not present significant liver disease.

Both SS and NASH are often associated with the presence of common metabolic alterations such as abdominal obesity, atherogenic dyslipidemia, type 2 diabetes, and metabolic syndrome: Indeed, it has been suggested that they represent the hepatic component of all these processes [3].

The pathogenesis of NAFLD and NASH is multifactorial, and numerous pathophysiological mechanisms have been proposed to explain the process of excessive fat accumulation in the liver and the subsequent possible induction of inflammation and fibrosis [11].

Among the main biological players and pathways of NAFLD, hepatic steatosis (the first "hit") has an obvious central role. This is the consequence of an excessive lipid accumulation within the liver, largely resulting from the excessive importation, diminished exportation, and/or reduced breakdown of free fatty acids (FFA) in the liver itself. During periods of excess macronutrient intake, the liver will convert unused carbohydrates and proteins to triglycerides and then store them. During later periods of diminished macronutrient intake or heightened caloric use, these lipids may be broken down and released. Complications of obesity may include hyperlipidemia leading to increased levels of circulating triglycerides and increased delivery and storage of triglycerides in the liver [12].

On the basis of the traditional "two hits" theory [13], it is believed that increased insulin resistance is the basis of the first stages of fatty liver, mainly through profound changes to normal systemic lipid metabolism such as increased mobilization of the aforementioned fatty acids (FA) from visceral adipose tissue to the liver. Insulin affects the intestinal-liver-fat axis by regulating blood glucose levels and guiding nutrients from the bloodstream to cells after meals through a complex pathway in which nuclear receptors such as liver $\mathrm{X}$ receptor (LXR), farnesoid X receptor (FXR), and nuclear factor erythroid 2-related factor 2 (Nrf2) play an important role [14]. The development of insulin resistance occurs primarily in muscle and adipose tissue, while liver tissue remains largely spared. When muscle and adipose tissue develop decreased sensitivity to the effects of insulin, less glucose is delivered to these tissues and a catabolic state occurs in which peripheral adipose tissue is broken down and free FA are released into the systemic circulation. To compensate for the elevated blood glucose levels, pancreatic beta cells secrete increasing levels of insulin, resulting in hyperinsulinemia. The liver, having remained largely insulin sensitive and being exposed to increasing levels of blood glucose, serum triglycerides, and insulin, enters a hyperanabolic state, continuing to synthesize and store lipids [15]. However, there is currently much debate as to whether insulin resistance and the consequent hyperinsulinemia are only possible causes of steatosis or rather that NAFLD itself promotes a condition of hyperinsulinemia as a result of its degradation slowing down [16-18]. Moreover, some believe that the effects of insulin resistance alone are insufficient to explain the development of true NASH. This is because it is still a matter of debate how lipid accumulation in the liver 
leads to the hepatocellular damage seen in NASH (which occurs in one out of 10 patients who develop NAFLD) [19]. Instead, increased oxidative stress (OS) seems to be one of the additional main drivers in the promotion of NAFLD liver damage, playing a fundamental role in the progression from SS to NASH $[20,21]$. This would occur, in particular, as a consequence of the induction of oxygen radical forming cytochrome p-450 microsomal lipoxygenases [22] and consequent increased lipid peroxidation in which chain reactions between oxygen free radicals and lipids can damage mitochondrial DNA and membrane structures required for beta-oxidation $[23,24]$. As a matter of fact, patients with NASH have been shown to have significant mitochondrial structural abnormalities within their hepatocytes. Whether lipid peroxidation alone is sufficient to produce these abnormalities is not known. In the setting of mitochondrial abnormalities, it has been theorized that the transition to beta-oxidation of FFA seen in NASH produces a further increase in free radical production with consequent hepatocellular damage, inflammation, and eventual fibrosis due to the activation of hepatic stellate cells (HSC) [25]. In addition, reactive oxygen species (ROS) are also able to inhibit the hepatic secretion of very-low-density lipoproteins (VLDL), thus promoting a further intrahepatic accumulation of lipids [26]. Antioxidants protect liver tissue from the damaging effects of oxygen radicals and lipid peroxidation by donating electrons and neutralizing these molecules before they react with DNA or proteins. However, they can be depleted in cases of continued OS or insufficient dietary intake. Glutathione (GSH), vitamin E (VitE), vitamin C (VitC), and beta-carotene may all be reduced in the setting of NASH $[27,28]$. Hepatic iron content may also contribute to the oxygen free radical damage seen in NASH. Moreover, hepatic iron levels correlate with insulin resistance and the severity of fibrosis [29,30]. However, homozygosity for the homeostatic iron regulator (HFE) gene, which leads to the development of hereditary hemochromatosis, has not been shown to increase the risk of NAFLD [31]. In addition, no improvement in NAFLD was observed in a study, where participants underwent 6 months of phlebotomy to lower serum ferritin levels. Even those patients with hyperferritinemia at baseline showed no significant difference in the endpoints of hepatic steatosis, alanine aminotransferase (ALT) levels, or insulin sensitivity [32].

More recently, alongside this traditional theory, a "multiple hits" hypothesis has been proposed, which, in addition to insulin resistance and OS, identifies as possible pathogenic factors in NAFLD development several other conditions including low-grade chronic inflammation, some genetic and epigenetic mutations, and factors derived from the intestinal microbiota. These elements may be variously associated with NAFLD in the presence or absence of the metabolic syndrome [11].

In low-grade chronic inflammation—strictly linked to overweight/obesity—lipids and their derivatives contribute to inflammatory liver by the production of abnormal cytokines and adipokines such as interleukin (IL)-6, tumor necrosis factor (TNF)- $\alpha$, IL-1, leptin, and resistin. These factors inhibit insulin signaling in hepatocytes by activating a suppressor of cytokine signaling (SOCS) proteins, several kinases [such as c-Jun $\mathrm{N}$-terminal kinase (JNK), inhibitor of nuclear factor kappa-B kinase subunit beta (IKK- $\beta$ ), and protein kinase $C$ $(\mathrm{PKC})$ ] and protein tyrosine phosphatases [such as protein tyrosine phosphatase 1B (PTP1B) and phosphatase and tensin homolog (PTEN)] that, in turn, impair insulin signaling at the insulin receptor and insulin receptor substrate (IRS) level. Hepatic insulin resistance, in turn, causes impaired suppression of glucose production by insulin in hepatocytes, leading to hyperglycemia. An important and early complication is the induction of hepatic VLDL production, via changes in the rate of apoB synthesis and degradation, de novo lipogenesis, or increased FFA flux from adipose tissue into the liver. Insulin resistance also stimulates the production of C-reactive protein and plasminogen activator inhibitor-1 (PAI-1), both markers of an inflammatory state, and interacts with other complex mechanisms such as hypercholesterolemia, hypertension, hemostatic factors, lipoproteins and their associated receptors structure, homocysteine processing/metabolism, and lipoprotein(a) levels [33,34].

Additionally, a role for genetics has been demonstrated, for instance, in twin studies where it contributed roughly to $50 \%$ of hepatic fat content and fibrosis [35]. Genetic 
variations in hepatic lipid metabolism and insulin signaling have also been demonstrated to contribute to development and progression of NAFLD [36-38]. Obviously, a variety of factors then affects individuals with a genetic predisposition to NAFLD.

The gut microbiome may also contribute to the pathogenesis of NAFLD. One study showed significantly increased intestinal permeability and small intestinal bacterial overgrowth in patients with NAFLD. These patients were shown to have compromised intestinal tight junction integrity $[39,40]$. Colon bacteria can damage intestinal tight junctions through endogenous production of alcohol and acetaldehyde [41]. Increased intestinal permeability allows endotoxins produced by intestinal bacteria to enter the portal circulation and activate toll-like receptor (TLR)-4 signaling in Kupffer cells, leading to downstream increases in pro-inflammatory cytokines [42,43]. TLR-4 can trigger myeloid differentiation primary response 88 (MyD88)-dependent or MyD88-independent pathways, with MyD88dependent signaling playing a more critical role in the pathogenesis of NASH than in that of alcoholic liver disease $[44,45]$. Both pathways lead to nuclear factor kappa B (NF- $\mathrm{B}$ ) activation, with further activation of pro-inflammatory cytokines (being characteristic of MyD88-dependent signaling) and type I interferon (IFN) induction (being characteristic of MyD88-independent signaling) [46].

All this complexity may partly explain why the development of potential new drugs for NASH has been carried out across multiple channels, such as lipid metabolism regulation, anti-inflammation, and anti-fibrosis, even though this disease basically still remains an orphan of an adequate therapeutic strategy [47]. Herein, in this review, we try to shed light on some of these mechanisms, focusing in particular on the interplay between OS and other causative pathogenic factors.

\section{Evidences on the Presence of Oxidative Stress in NAFLD}

According to the previously reported "two-hits" and "multiple hits" theories, OS seems to be one of the most important mechanisms leading to hepatic injury in NAFLD, playing a fundamental role in the progression from SS to NASH [48-50]. Briefly, it has been demonstrated that the augmented generation of ROS can induce lipid peroxidation leading to inflammation and fibrogenesis through the activation of HSC. Moreover, ROS inhibit hepatocytes' secretion of VLDL, inducing liver fat accumulation. ROS can also promote hepatic insulin resistance and necro-inflammation and activate several intracellular pathways that can lead to hepatocyte apoptosis [26]. At the same time, sound evidence has been generated that OS centrally contributes to atherothrombosis and is involved at all stages of atherosclerotic plaque evolution, reasonably representing the missing link between NAFLD and cardiovascular disease [20].

The term OS or "redox imbalance" generically indicates the set of biochemical alterations that occur in tissues, cells, and biological macromolecules when they are exposed to an excess of oxidizing agents: The effect consists of metabolic alterations, damage, and cell death. The stress originates from an imbalance in the ratio between the production of free radicals [both ROS and reactive nitrogen species (RNS)] and their relative metabolic neutralization. Focusing on liver, epidemiological, clinical, and experimental studies has shown that NAFLD is closely associated with alterations in redox status and subsequent increased metabolic risk [51-55].

Interestingly, OS may be a consequence but also a cause of NAFLD. Chronic overnutrition, high fat content - especially saturated fats (SFAs) and trans FA-and carbohydrate content in the diet-particularly at low glycemic index-stimulate intracellular liver pathways, leading to OS through multiple biochemical mechanisms, such as superoxide generation by reduced nicotinamide adenine dinucleotide phosphate (NADPH)-oxidases (NOX), mitochondrial oxidative phosphorylation, glyceraldehyde auto-oxidation, PKC activation, and polyols' and hexosamines' pathways [56-59]. NAFLD has also been shown to directly induce systemic OS; indeed, liver fat accumulation increases NOX activity and endoplasmic reticulum (ER) stress both in hepatocytes and adipocytes, resulting in enhanced ROS production [60-63]. Other factors contributing to OS in NAFLD include abnormal 
postprandial ROS generation [64], hyperleptinemia [65], chronic inflammation [66], and tissue dysfunction [59] with reduced antioxidant defenses [61,67,68].

As demonstrated in other diseases, OS and inflammation seem to be closely related also to obesity, although it remains difficult to establish the exact temporal sequence of their contribution. Systemic OS and inflammation are also key factors in the pathogenesis of other diseases more or less closely related to fat accumulation and/or obesity, including atherosclerosis, insulin resistance, type 2 diabetes, and cancer [69,70]. It has recently been hypothesized that the increased OS and inflammation in NAFLD also promote the processes of aging [71,72]. On the contrary, it is known that caloric restriction and the consequent weight reduction have the effect of reduction of oxidation markers, increase of antioxidant defenses, and improvement of cardiovascular risk associated with obesity [73,74] (Figure 1).

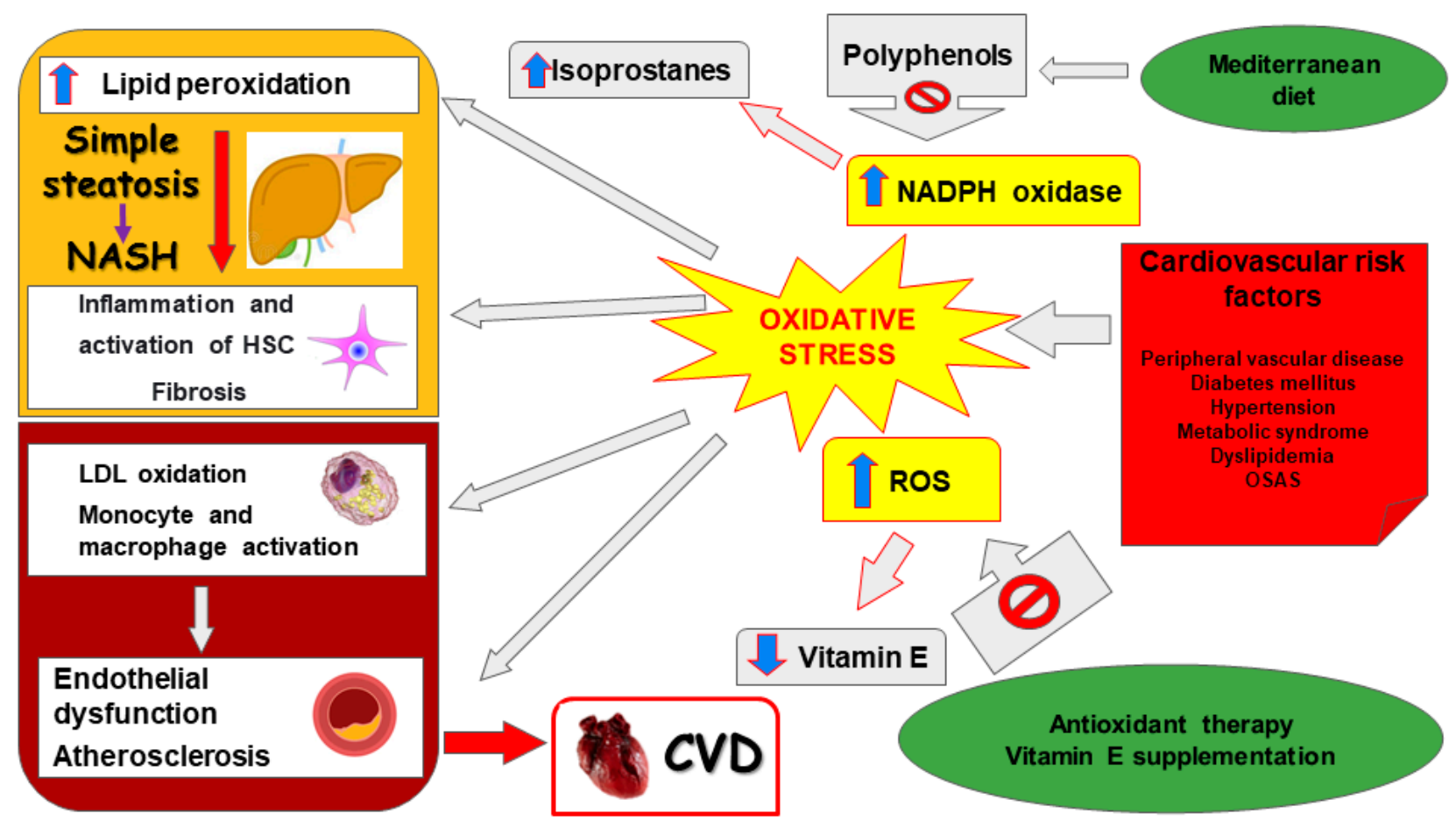

Figure 1. Possible pathophysiological effects of oxidative stress in NAFLD and cardiovascular diseases. NAFLD: non-alcoholic fatty liver disease; NASH: non-alcoholic steatohepatitis; HSC: hepatic stellate cells; LDL: low-density lipoprotein; ROS: reactive oxygen species; NADPH: nicotinamide adenine dinucleotide phosphate; OSAS: obstructive sleep apnea syndrome; CVD: cardiovascular disease.

\subsection{Evidence for a Role of Oxidative Stress in NAFLD}

In NAFLD, OS promotes also the activation of enzymatic- or non-enzymatic-mediated antioxidant mechanisms that counteract the aforementioned ROS production. This is an indirect further confirmation of the central role that OS plays in the disease pathogenesis. As a matter of fact, both clinical and experimental studies show that these antioxidant pathways are modulated during NAFLD progression. In fact, activity of the antioxidant enzymes superoxide dismutase (SOD) and glutathione peroxidase (GPX) increases in patients with NAFLD [75]. In vitro, HSC deficient for the GPX7 isoform present increased expression of pro-fibrotic and pro-inflammatory genes in response to FFA exposure. Consistent with these results, overexpression of GPX7 in these cells decreases ROS generation and expression of pro-fibrotic and pro-inflammatory genes. In vivo, GPX7 deficiency exacerbates choline-deficient, L-amino-defined, high-fat diet (HFD)-induced NASH fibrosis [76].

The expression of glutaminase 1 (GLS1) is increased in both NASH preclinical mouse models and clinical NASH liver biopsies. GLS1 promotes glutamine fueling of anaplerotic mitochondrial metabolism, resulting in increased ROS production. In methionine/cholinedeficient diet (MCD)-fed mice, GLS1 inhibition decreases hepatic triglyceride accumulation 
by restoring VLDL export and diminishes OS by reducing ROS production. GLS1 deficiency in this model is also associated with decreased lipid peroxidation [77].

Paraoxonase- 1 is a liver antioxidant enzyme that hydrolyses peroxide and lactones associated with lipoproteins. In a cohort of 81 patients with NAFLD, the serum paraoxonase1 concentration was decreased, which could reflect higher OS in these patients [78].

The peroxisomal antioxidant enzyme catalase plays a key role in protecting cells from oxidative damage by reducing $\mathrm{H}_{2} \mathrm{O}_{2}$ concentration. In HFD-fed mice deficient for catalase, lipid accumulation and OS are exacerbated [79]. In fact, these mice develop an imbalanced redox status in peroxisomes because of increased $\mathrm{H}_{2} \mathrm{O}_{2}$ levels, which, in turn, induce ER stress in the liver. Catalase inhibition in HepG2 cells increases ROS production by peroxisomes, causing ER stress and FA accumulation [80]. In line with this observation, human liver cells with impaired peroxisome biogenesis show decreased ER stress, OS, and apoptosis [81].

\subsection{Redox Regulation of Lipid Metabolism in NAFLD}

During OS, the most important oxidizing factors are ROS, i.e., singlet oxygen, superoxide anion, hydrogen peroxide $\left(\mathrm{H}_{2} \mathrm{O}_{2}\right)$, and hydroxyl radical, whose production is due to an alteration of the electronic flow along the respiratory chain and subsequent interaction of intermediates with oxygen. Even under physiological conditions, there is a certain production of ROS. Indeed, about $0.15-5 \%$ of total oxygen consumption is used for the production of superoxide anion, which, however, is captured by cell antioxidant systems [catalase, SOD, GSH] [82]. ROS toxicity is due to their ability to rapidly interact with several cellular structures. First of all, they interact with liver cellular lipids, resulting in the formation of aldehydes, in particular 4-hydroxynonenal (HNE) and malondialdehyde (MDA). Both have a longer half-life than ROS and are able to damage even more distant cellular structures. More in detail, HNE and MDA are able to attack mainly polyunsaturated fatty acids (PUFA) $[83,84]$. Mitochondrial membranes do contain large amounts of these PUFA for the proper assembly of respiratory complexes; so, the production of aldehydes in the ultimate end compromises cellular respiration. HNE and MDA are also able to increase the proteolysis of apolipoprotein B, leading to a reduced secretion of VLDL and-thus-aggravation of the already existing liver steatosis [83].

Another important finding is the ability of ROS to directly attack liver mitochondrial DNA. This damage, which is responsible for a reduced biosynthesis of polypeptides constituting the respiratory chain, was confirmed by the reduction of mitochondrial DNA content in the hepatocytes affected by NASH [85]. In the same patients, ROS production can be also promoted by TNF- $\alpha$, causing electrons to be retained along cytochrome $b$ and leading to further defects in the hepatic mitochondrial respiratory chain [86].

Hepatic ROS production is also related to the mitochondrial membrane potential $(\Delta \Psi)$. As a matter of fact, a hyperpolarization of the mitochondrial membrane slows down electron transport, favoring the interaction of electrons with oxygen and, thus, ROS production. However, this effect can be limited by the presence of an uncoupling agent that allows the return of protons in the mitochondrial matrix, reducing the membrane potential difference and, therefore, the production of ROS. The cellular reduction-oxidation (redox) state can influence the activity of several enzymes involved in lipid metabolism, which are responsible for post-translational modifications (glutathionylation, carbonylation) or which, through the modulation of phosphatases/kinases, act as second messengers or induce conformational changes in nuclear receptors $[87,88]$.

The intracellular redox state is established by different redox pairs such as oxidized/reduced nicotinamide adenine dinucleotide (NAD+/NADH), oxidized/reduced GSH $[89,90]$. These ratios serve as an index of the availability of reducing equivalents required for lipogenesis. In steatotic liver, lipid oxidation and tricarboxylic acid cycling increase, whereas ketogenesis is not altered, suggesting that hepatocytes attempt to counteract excess lipids by increasing oxidation [91]. More in detail, liver $\beta$-oxidation involves four individual reactions that generate reducing equivalents [NADH or the hydroquinone 
form of flavin adenine dinucleotide (FADH2)]. The energy produced is stored in the form of adenosine triphosphate (ATP) by an oxidative phosphorylation system coupled to electron transfer along the mitochondrial respiratory chain, resulting in increased free radical generation [92]. Peroxisomal $\beta$-oxidation generates $\mathrm{H}_{2} \mathrm{O}_{2}$ and is not coupled with phosphorylation systems [93]. Microsomal oxidation also participates in the adaptive response induced by lipid accumulation and redox balance disorder; in particular, cytochromes P4502E1 (CYP2E1) and P4504A are the major microsomal sources of OS in NAFLD [94]. Therefore, in NAFLD there is an increased fat oxidation at the level of microsomes and peroxisomes and this contributes to OS $[95,96]$.

\subsection{Oxidative Stress and Antioxidant Markers in NAFLD and Other Metabolic Diseases}

Increased OS, as previously reported, represents a pathophysiological condition commonly reported in NAFLD. The same imbalance is observed in numerous chronic diseases often associated with NAFLD, such as arteriosclerosis [20], hypercholesterolemia [97], obesity [98], metabolic syndrome [99], and obstructive sleep apnea syndrome [100]; all these conditions are-in turn-associated with an increased cardiovascular risk. In fact, on the one hand, an excessive production of ROS is responsible for low-density lipoprotein (LDL) oxidation, which promotes the transformation of macrophages into foam cells, i.e., the process that represents the first phase of the development of the arteriosclerotic lesion. On the other hand, the liver peroxidation of lipids by ROS can induce inflammation and fibrosis by activation of the HSC compartment [101].

NOX is considered the most important cellular source of OS and its activation has been associated with the possible development of liver damage [102]. The isoforms of NOX, which include NOX1, NOX2, and NOX4, regulate HSC activation and hepatic apoptosis, two central aspects in the early stages of fibrogenesis $[103,104]$. Experimental studies have demonstrated that in a NOX2 knockout mouse with a defect in p47phox (i.e., the phagocyte NADPH oxidase/NOX2 organizer) [105], after induction of liver damage by means of bile duct ligation or a methionine-deficient diet, a reduction of steatosis but not of fibrosis was observed, thus suggesting that NOX2 may represent a possible target for countering NASH [106].

Few studies have evaluated the antioxidant and pro-oxidant status in NAFLD. Among the most relevant ones, a large case series can be cited, demonstrating an increased OS in vivo. This effect was documented by measuring the urinary levels of 8 -iso-prostaglandin F $2 \alpha$ (8-iso-PGF $2 \alpha$ ), which is derived from the non-enzymatic oxidation of arachidonic acid, and the serum levels of soluble NOX2-derived peptide (sNOX2-dp), which represents an indicator of NOX2 activation (i.e., the main NOX isoform responsible for ROS production). In this study, the increased 8-iso-PGF2 $\alpha$ and sNOX2-dp concentrations observed in NAFLD patients were independent from obesity, diabetes, and metabolic syndrome, and were positively associated with disease severity at liver ultrasound. Furthermore, in the same case series, the urinary levels of 8-iso-PGF2 $\alpha$ were independently associated with the serum levels of cytokeratin-18, a validated hepatic marker of apoptosis, thus also hinting at a possible role of liver damage on systemic OS [101]. More recently, in a larger cohort of subjects with NAFLD, a significant reduction in plasma levels of VitE was demonstrated, both in subjects with SS and in those with NASH, thus suggesting the presence of increased OS even in the earliest stages of the disease. As a matter of fact, VitE is an important fat-soluble antioxidant vitamin that protects cell membranes and lipoproteins from peroxidation: Its circulating levels are considered a good index of antioxidant status and have an inverse correlation with the markers of OS. It is thus possible to hypothesize that the presence of an increased OS in NAFLD may, in turn, induce a reduction of natural antioxidants as a consequence of their excessive consumption [107].

In further studies it was demonstrated that NAFLD patients exhibit less brachial flow-mediated dilation (FMD), which is considered a key marker of atherosclerosis and endothelial function. This result was particularly evident in the subgroup of patients with NASH. The pathophysiological rationale is that-together with low-grade systemic 
inflammation-OS is one of the main factors that can compromise endothelial function, with a consequent relative reduction of FMD. This could be one of the explanations of why, in many prospective studies, the reduction of FMD has been shown to be an important predictor also of cardiovascular events [108,109]. In other words, the increase in OS can be implicated both in the development of NASH and of cardiovascular diseases, representing a possible link between the two conditions. An increased production of ROS can, in fact, modify coagulation and platelet functionality with consequent alteration of endothelial function and increase of thrombosis risk in any district, including liver [110]. Indeed, in the initial stages of atherogenesis, the greatest damage towards the endothelium is that caused by ROS and other pro-oxidant molecules which, in turn, are associated with the presence of metabolic syndrome risk factors and are produced by various types of cells, including platelets. An excessive ROS production is responsible, among other things, for LDL oxidation, which, in turn, promotes the transformation of macrophages into foamy cells. Likewise, ROS can induce the expression of scavenger receptors also on smooth muscle cells, promoting their transformation into foam cells. Furthermore, they can induce changes in the extracellular matrix by promoting release of metalloproteinases [111,112].

\section{Evidences on the Role of Oxidative Stress on NAFLD Progression}

We already reported that SS may progress to NASH with apparent inflammation, advanced fibrosis, and cirrhosis. In 1965, increased lipid peroxidation levels were reported in carbon tetrachloride- (CCl4-) treated rats, with increased production of ROS. However, it was only in 1972 that ROS started to be hypothesized with a causative role in the progression of liver damage [113]. There is now a large body of evidence that, in the context of NAFLD, impaired redox status and consequent ROS accumulation are indeed the origins of hepatic maladaptive responses to fat accumulation, thereby leading to hepatic metabolic impairment and NASH progression [61]. Moreover, OS-related oxidized phospholipids accumulate and induce mitochondrial dysfunction in hepatocytes [114]. The mitochondrial GSH depletion is also induced by cholesterol accumulation in the progression of SS to NASH [115]. Mitochondrial DNA (mtDNA) released from fatty liver-damaged hepatocytes then causes liver inflammation by TRL-9 activation [116] and its levels tend to decrease in patients with more advanced forms of NAFLD [117]. Thus, increased OS triggers hepatic stress pathways; therefore, maintaining cellular redox homeostasis is a promising strategy for NASH therapy [118].

The hepatocytes are the primary cells affected by lipotoxicity-induced oxidative stress in the liver. However, also non-parenchymal cells (NPC), including HSC, liver sinusoidal endothelial cells (LSEC), and Kupffer cells, are involved in OS-induced liver damage [119]. HSCs are notoriously responsible for extracellular matrix deposition in the development of liver fibrosis. CYP2E1-induced free radicals can activate the transdifferentiating of HSC. On the contrary, antioxidants could prevent the effect of ROS on increasing collagen production [120]. The NOX1- and NOX2-deficient mice exhibited improved ROS production and hepatic fibrosis in $\mathrm{CCl} 4$ or bile duct ligation-treated models [121]. In addition, mice deficient in antioxidant cytoglobin $(\mathrm{Cyg} b)$ are susceptible to OS, inflammation, and fibrosis under diethylnitrosamine (DEN) or a choline-deficient diet [122]. Specifically, LSEC govern the regenerative process initiation, but OS damages their typical phenotype. Aberrant LSEC activation in chronic liver injury can ultimately induce fibrosis [123]. Moreover, OS increases macrophage M1 (i.e., classically activated) polarization and promotes pro-inflammatory cytokines in Kupffer cells [124]. Therefore, a promising line of research for treating NASH progression is to investigate OS targeting, possibly even with cell type-directed strategies.

During liver injury, oxidative stress induces the activation of redox-sensitive transcription factors, such as nuclear factor kappa-light-chain-enhancer of activated B cells (NF- $\mathrm{kB}$ ) and activator protein-1 (AP-1), leading to an inflammatory response and the activation of cell death pathways in hepatocytes. In NAFLD, ROS regulates NF-kB activation by increasing the expression of pro-inflammatory cytokine TNF- $\alpha$ [125]. NF- $\mathrm{kB}$, a significant regulator of the inflammatory response, plays a vital role in regulating the transcription 
of genes involved in the establishment of the immune and inflammatory responses [126]. Reduced NF- $\mathrm{KB}$ activity by antioxidants has been proposed as a therapeutic target in NASH due to its anti-inflammatory properties [127]. Moreover, in the development of steatohepatitis, Nrf2 acts as a significant regulator of the redox balance and mediates anti-inflammatory and antiapoptotic effects of antioxidants [128]. Upon oxidative stress, the cytoplasmatic transcription factor Nrf2, which regulates the expression of genes encoding antioxidant enzymes and regulators of the GSH (such as glutamate-cysteine ligase catalytic subunit, glutamate-cysteine ligase modifier subunit, GPX7), translocates into the nucleus, where it interacts with specific DNA sequences called antioxidant response elements (ARE) in the promoter of its target antioxidant enzyme genes [129]. Nrf2 expression is increased in the first stage of NAFLD in preclinical models, and pharmacological activation of Nrf2 in mice fed a high-fat and high-fructose diet decreases NASH parameters (insulin resistance, weight, triglycerides, ALT levels) via the transcriptional regulation of genes involved in inflammation, apoptosis, fibrosis, ER stress, and OS [130]. Consistently, Nrf2-knockout mice treated with MCD show exacerbation of liver inflammation and steatosis, compared to control mice [84]. In addition, Nrf2-deficient mice fed a HFD develop a more severe NASH phenotype than their wild-type counterparts [131]. Other evidence has shown that the dysfunctional Nrf2 in patients with NASH is tightly involved in the grade of inflammation but not of steatosis [132]. In addition, upregulated Nrf2 in senescent hepatocytes is related to the activation of cocultured HSC. The Nrf2 agonist sulforaphane remarkably inhibits the effect of lipid accumulation-induced hepatocyte senescence on activation of HSC by the Nrf2-ARE pathway [133]. Nrf2 also directly affects lipid metabolism by the activation of genes involved in FA oxidation (acyl-CoA oxidase 2, carnitine palmitoyltransferase 1), triglyceride export (apolipoprotein $\mathrm{B}$ ), and the lipogenic transcription factor sterol regulatory element binding transcription factor 1 (SREBP-1) [130]. Nfr2 deficiency in HFD-fed mice diminishes phosphorylation of acetyl-CoA carboxylate (ACC), a rate-limiting enzyme of hepatic FA synthesis, and, thus, increases its activity [131]. A further study reported that the dysfunction of redox homeostasis induces hepatocytes to be highly susceptible to proteasome-associated metabolic stress. In comparison, insufficient peroxisome proliferator activating ligand receptors (PPAR) $\gamma / \mathrm{Nrf2}$-driven antioxidative response is the main factor [134]. Moreover, the interaction between NF- $\mathrm{KB}$ and Nrf2 is also a noticeable target for NAFLD progression. Evidence showed that NF- $\mathrm{BB}$ p65 subunit represses the Nrf2/ ARE system at the transcriptional level by competitive interaction with the binding domain of the CREB-binding protein (CBP) [135]. NF- $\mathrm{kB}$ dissociates from inhibitor kappa B (IкB) and then translocates to the nucleus. Nrf2 negatively controls the NF- $\mathrm{kB}$ signaling pathway by multiple mechanisms, including inhibiting nuclear translocation of NF- $\mathrm{KB}$ and blocking the degradation of IKB- $\alpha$ [136].

Collectively, these data indicate that alterations in antioxidant pathways are associated with NAFLD, suggesting a role of oxidative stress in disease progression.

\subsection{Markers of Immunological Responses to Inflammation and Oxidative Stress during NAFLD Evolution}

OS in NASH results not only in an inappropriate activation of monocytes/macrophages at the endothelial and atherosclerotic plaque level, as previously mentioned, but also directly in the liver itself. As a matter of fact, a large body of evidence indicates that hepatic macrophages play a key role in directing the evolution of the disease [137]. During chronic liver diseases, liver macrophages consist of ontogenically distinct populations that include liver resident Kupffer cells and monocyte-derived macrophages (MoMFs) [137]. These latter are the main elements responsible for producing pro-inflammatory mediators responsible for the perpetuation for hepatocyte injury and liver inflammation and also for supporting the activation of HSC and extracellular matrix deposition during OS-induced NASH progression to fibrosis and cirrhosis [137]. Consistently, interfering with liver MoMF recruitment ameliorated experimental NASH and reduced fibrosis evolution in a phase 2 clinical trial [138]. What is less clear is how MoMFs interact with other inflammatory cells 
within the liver and particularly with lymphocytes. In this respect, several studies have demonstrated that lymphocyte-derived cytokines such as IFN- $\gamma$, IL-17, and tumor necrosis factor superfamily member 14 (TNFSF14 or LIGHT) can stimulate pro-inflammatory responses of MoMFs [139-141]. However, the presence of more specific interactions between liver lymphocytes, particularly T-cells and MoMFs, has so far received little attention.

Among the signals involved in the OS-elicited interaction of T-cells with other myeloid cells, a new promising field of research is represented by the co-stimulatory molecules' inducible T-cell co-stimulator (ICOS; CD278) and its ligand ICOSL (CD275, also named B7h, B7-H2, B7RP-1, and LICOS) [142]. ICOS belongs to the CD28 family of co-stimulatory molecules and is selectively expressed by activated T cells, while its ligand ICOSL/ICOSL is constitutively present on the surface of a variety of myeloid cells including dendritic cells, macrophages, and B-cells, but also on endothelial cells, lung epithelium cells, and fibroblasts. The triggering of ICOS on T-cells by ICOSL/ICOSL has been shown to modulate their cytokine secretion pattern [142] and favor regulatory T cell (Treg) differentiation [143]. In addition, ICOS/ICOSL interaction plays an important role in the development and differentiation of follicular T-helper cells (Tfh) in the germinal centers of lymphatic nodes [142]. This action is critical in the selection and survival of B cells expressing high-affinity B cell receptors, as well as in facilitating their differentiation into memory B cell and plasma cells [142]. However, recent reports have shown that ICOS/ICOSL interaction can also trigger reverse signals able to modulate the functions of ICOSL-expressing cells. For instance, in dendritic cells, ICOSL-mediated signals favor maturation and stimulate cytokine secretion and antigen presentation $[144,145]$, while in monocytes they prevent the differentiation to osteoclasts stimulated by receptor activator of nuclear factor KB (RANK) ligand [146]. A recent study has also shown that by binding to $\alpha \mathrm{v} \beta 3$ integrin on podocytes, ICOSL ameliorates kidney injury and the development of proteinuria [147]. From these observations, some preliminary data have emerged on the possible involvement of ICOS/ICOSL dyad in the evolution of liver inflammation, OS, and fibrosis in NASH [148].

\subsection{Mitochondrial Oxidative Injury as a Key Pathway That Links Saturated Fat Intake to the Development and Progression of NAFLD}

\subsubsection{Mitochondrial Dysfunction and Oxidative Stress in NAFLD/NASH}

Liver is an organ that consumes as much as $15 \%$ of the body's oxygen, since it has a huge amount of mitochondria (from 500 to 4000 per hepatocyte), which have a high turnover and are responsible for ATP production [142]. One of the key mechanisms for the genesis and progression of NAFLD is, indeed, mitochondrial dysfunction [149-152].

High dietary fat consumption and genetic obesity lead to the accumulation of triglycerides and FA in hepatocytes, inducing a compensatory increase in oxidative phosphorylation, tricarboxylic acid cycling, and mitochondrial respiratory chain function. In particular, increased mitochondrial carnitine palmitoyltransferase (CPT)-1 and mitochondrial uncoupling protein (UCP)-2 activity resulting from a HFD reduces the levels of serum markers of liver damage and ROS, playing a protective role against the onset of NAFLD [153]. Nevertheless, in the long term, the liver is no longer able to adaptively compensate for the hepatocyte accumulation of FA, as the increase in mitochondrial respiration becomes bioenergetically inefficient. This leads to structural and functional mitochondrial alterations that determine the onset of NAFLD and, with the perpetuation of oxidative damage, the progression to NASH. As a matter of fact, literature evidence indicates that ROS production, lipid peroxidation, alterations in mitochondrial respiratory chain activity, and changes in mitochondrial membrane composition are all present in individuals with hepatic steatosis and drive NAFLD progression [154]. The progression to advanced stages of NAFLD, including NASH and cirrhosis, is complex, and the role of SFAs in mitochondrial dysfunction is undoubtedly less studied than that of unsaturated FA. However, there is an increasing evidence that also SFAs play a key role in the development of hepatic steatosis and NAFLD progression through changes in mitochondrial function and structure [154]. 
One of the mechanisms most involved in mitochondrial dysfunction associated with hepatic steatosis is the production of ROS, precisely at the mitochondrial level. ROS are formed when electrons escape from the electron transport chain complexes, interacting with oxygen and forming superoxides. The latter ones damage mitochondria by peroxidizing mitochondrial DNA, phospholipid acyl chains, and respiratory transport chain enzymes. Under normal conditions, redox molecules within the mitochondria matrix neutralize most ROS by converting them to water. However, chronic activation of mitochondrial function in lipid overload leads to excessive electron leakage that exposes the liver to high amounts of OS [154-157]. Additionally, the results obtained on Huh7.5 cells treated with plasma of NAFLD patients would confirm those issues. Hence, in those cells, an increased mitochondrial ROS release was observed in association with changes of mitochondrial membrane potential [158]. Furthermore, along with the increased mitochondrial ROS production, decreased expression and activity of ROS detoxification mechanisms (e.g., SOD2, catalase, or GSH) have also been reported in in vitro and in vivo experiments. Thus, levels of ROS, lipid peroxidation, and apoptosis are increased in fatty liver disease and are even more so in NASH, suggesting that these processes drive the progression of NAFLD to NASH $[72,153,159]$.

In addition to inducing ROS production, SFAs can also alter the composition of mitochondrial membranes. In this regard, one of the most studied target molecules is cardiolipin, which constitutes approximately $20 \%$ of the total phospholipid content in the inner mitochondrial membrane (IMM). Cardiolipin is critical in many mitochondrial functions. It maintains the fluidity and osmotic stability of the IMM and is crucial in the assembly and stabilization of the enzymatic supercomplexes of the electron transport chain involved in ATP production [154,160,161]. The most widely represented cardiolipin species in hepatic mitochondria - constituting approximately 55\% of hepatic cardiolipin species-is tetralinoleoyl-cardiolipin, in which all four acyl groups are derived from linoleate (linoleic acid methyl ester, C18:2). Linoleate-rich cardiolipin is able to bind with high affinity to a multitude of proteins and enzymes within the IMM, including key enzymes in the mitochondrial respiratory chain, such as cytochrome c [154,160,162]. Evidence in the literature shows that the linoleate percentage in the IMM cardiolipin pool is lower in subjects with NASH. The precise mechanisms by which changes in cardiolipin content and structure occur, affecting mitochondrial function, are complex and still under investigation. However, it is known that when the acyl chain composition of cardiolipin changes, cytochrome $\mathrm{c}$ detaches from cardiolipin. The latter, in turn, translocates to the outer mitochondrial membrane (OMM) [154], destabilizing its lipid composition and promoting pore formation [163]. The final result is an altered mitochondrial function.

A further important characteristic of cardiolipin molecules is that they are very susceptible also to direct ROS attacks [164-166]. Because a HFD increases the levels of ROS and of modified hepatic cardiolipin [167-169], it is reasonable to hypothesize that this is an additional mechanism of mitochondrial damage with regard to NAFLD.

Structural changes in the IMM indirectly reflect on the ER. This is because approximately $80 \%$ of mitochondria are in contact with the ER via mitochondria-associated membranes (MAMs) in order to allow exchanges in metabolites and calcium (the latter one critical for cellular homeostasis and signaling). Structural damage of MAM induced by a HFD has been shown to lead to increased calcium influx into mitochondria. This promotes NADH production by tricarboxylic acid cycle enzymes and increases ATP synthesis and ROS production. In addition, increased levels of calcium in the mitochondrial matrix induce further mitochondrial permeability transition pore (mPTP) opening, promoting apoptotic processes in the long term [154,170].

Ceramides are also another key element linking SFAs to the progression of NAFLD through mitochondrial dysfunction. These are sphingolipids synthesized from SFAs. Under conditions of hepatic steatosis (and even more so in NASH) when SFA levels are elevated, the production of ceramide substrates is increased. According to several clinical studies, the resulting accumulation of ceramides then induces hepatocyte apoptosis through increased 
ER stress and formation of mPTPs. In addition, ceramides inhibit mitochondrial function by interacting with the mitochondrial fragmentation factor (MFF), resulting in mitochondrial (and peroxisomal) fragmentation [142].

Finally, another actor involved in the progression of NAFLD to NASH through mitochondrial dysfunction is cholesterol, which determines mitochondrial GSH depletion and sensitizes hepatocytes (in mouse models) to TNF and Fas cell surface death receptor (FAS)-induced apoptosis [171].

Thus, the mechanisms responsible for mitochondrial dysfunction in hepatic steatosis and NAFLD progression are diverse and still not perfectly understood. It is likely that the functional and structural mitochondrial alterations induced by the aforementioned mechanisms mutually interact and reinforce, in a vicious circle leading to a constant evolution of NAFLD [154].

\subsubsection{Diagnostic Tools for Mitochondrial Dysfunction in NAFLD}

The importance of assessing mitochondrial function in chronic liver diseases, such as NAFLD and its evolved forms, is, therefore, evident, thanks also to new diagnostic tools. One test recently introduced, although still in the process of implementation, is the $13 \mathrm{C}$ breath test (BT) [170]. This is a "dynamic" liver function test based on the use of substrates labeled with the sTable ${ }^{13} \mathrm{C}$ isotope, which is a natural, non-radioactive element. The substrate, inhaled and metabolized at the hepatocellular level, is excreted in breath as ${ }^{13} \mathrm{CO}_{2}$, which is measured by mass spectrometry or infrared spectroscopy. Thus, respiratory levels of ${ }^{13} \mathrm{CO}_{2}$ can be used as biomarkers of specific metabolic processes (occurring in the cytosol, microsomes, and mitochondria of hepatocytes) and consequently of several chronic liver diseases, including simple hepatic steatosis, NASH, liver fibrosis, cirrhosis, and HCC, and also drug- or alcohol-related hepatitis [172]. In particular, the substrates used in 13C-BT for NAFLD are alpha-ketoisocaproic acid, methionine, and octanoic acid, i.e., substrates capable of measuring mitochondrial oxidation capacity, which is impaired already at an early stage of the disease [173]. Therefore, 13C-BT represents an indirect, convenient, and easy method to evaluate the dynamic liver function in NAFLD with particular concern for the altered mitochondrial function. This may be particularly useful to guide early treatments, with the potential to limit disease progression, but could also be applied during secondary prevention. On the other hand, experimental studies indicate that mitochondrial dysfunction may precede the onset and progression of NAFLD, suggesting a potential use of 13C-BTs also in primary disease prevention [174].

\subsection{Gut Microbiota and Oxidative Stress in NAFLD, with Possible Therapeutic Implications}

\subsubsection{Role of Microbiota in Hepatic Steatosis and Oxidative Stress}

Great interest has recently been addressed by the scientific community to the characterization of the intestinal microbial flora (microbiota) by means of sequencing its genome (microbiome), as its composition has often been found to have important implications in numerous pathological states, including NAFLD. Some observations demonstrated, in fact, quantitative and qualitative differences in the gut microbiota between subjects with or without NAFLD, even more so if the latter is associated with obesity and its related complications such as insulin resistance and diabetes $[175,176]$. More in detail, increased Proteobacteria at the phylum level was seen in NAFLD patients compared to control subjects. Increased Enterobacteriaceae and decreased Rikenellaceae and Ruminococcaceae at the family level were found in NAFLD patients. Increased Escherichia and Dorea and decreased Anaerosporobacter, Coprococcus, Eubacterium, Faecalibacterium, and Prevotella were observed at the genera level in NAFLD patients [177]. Studies in animal models demonstrated a direct role for the intestinal microbiota in the development of NAFLD. Inoculation of B. thetaiotaomicron and M. smithii strains into adult germ-free (GF) C57BL/ 6 mice increased host adiposity regardless of the amount of dietary intake. These microbial strains promoted monosaccharide uptake from the intestinal lumen, which resulted in the induction of lipogenesis [178]. In a similar study, most wild-type mice fed a HFD developed 
insulin resistance, OS, and systemic inflammation; however, some mice remained sensitive to insulin and developed lower levels of systemic inflammation and liver FA oxidation (non-responders). GF mice were then inoculated with responder and non-responder gut microbiota and then fed with HFD. Interestingly, mice that received microbiota from a non-responder developed less steatosis and insulin resistance than mice that received the responder microbiota [179]. Following these premises, translational studies were conducted, with particular regard to NAFLD disease. In one study the intestinal microbiota collected from obese donors before and after weight loss was transplanted into GF mice: Mice that received intestinal microbiota before weight loss had higher triglycerides and cholesterol liver levels than mice that received intestinal microbiota after weight loss [180]. Moreover, donor fecal microbiota transplantation studies performed in human subjects confirmed that the gut dysbiosis can per se cause hepatic steatosis mainly by means of weight gain, insulin resistance, and increased OS $[67,181,182]$. The hypothesized mechanisms are greater efficiency in energy absorption from food, modification of the intestinal permeability, release of intestinal hormones, and inflammation, with a relevant role for OS induction [183-189].

\subsubsection{Modulation of Gut-Liver Axis: Effects on Oxidative Stress}

A very promising line of research is that the microbiota is a dynamic entity that can change over time as a result of the modulation from various factors. In this respect, it can be considered not only as a causative agent of NAFLD, but also as a protective one, leading to possible future therapeutic implications (as regrading expected benefits on the evolution of NAFLD itself). For instance, the microbial composition of the intestinal flora is, first of all, influenced by body weight and some components of the diet, such as fiber, polyphenols, and lipids. The most represented phyla in the gut are Bacteroidetes (50-60\%) and Firmicutes (25-30\%). While bacteria of the first group feed mainly on vegetable fibers and are able to assimilate few fats from the diet, those of the second group are characterized by their ability to obtain nourishment mainly from dietary fats and sugars while promoting their absorption by the host organism. In obese subjects, weight loss reduces the Firmicutes/Bacteroidetes ratio [190], whereas a diet rich in fat and caloric load increases it [191]. This is true also for NAFLD patients, where the Firmicutes/Bacteroidetes ratio is positively correlated with liver steatosis, too, at least in obese individuals [192-194]. A relatively high abundance of Firmicutes is associated with metabolic endotoxemia due to increased uptake of lipopolysaccharide (LPS), which reaches the circulation and induces OS, inflammation, and impaired insulin signaling [177,195-198]. As a counterevidence, some preliminary studies reported that probiotics (i.e., living microorganisms including Bifidobacterium spp. and Lactobacillus spp.) and prebiotics (i.e., nonviable food components including "insulin-like" fructans) may confer a health benefit that is directly associated with the modulation of the microbiota $[199,200]$. As a matter of fact, in healthy subjects, the daily consumption for 3 weeks of $150 \mathrm{~g}$ of goat milk fermented with Lactobacillus fermentum increased the total antioxidant capacity (TAC) and decreased the oxidative markers in human blood and urine (oxidized LDL, F2-isoprostanes, and oxidized/reduced GSH ratio) [201]. Similarly, results were reproduced in individuals with obesity and obesityrelated disorders $[198,199,202,203]$. Translating the evidence from these researches, it can now be assumed that prebiotics and probiotics are capable of regulating the metabolism also of NAFLD subjects [204-209]. For example, studies conducted to identify the effect of novel probiotics on NAFLD induced by a fructose-rich diet underlined the ability of intestinal flora to improve OS. Human subjects fed with such a diet developed hepatic steatosis, and a relevant proportion acquired the clinical features of the true metabolic syndrome [210-213]. Compared to controls, many individuals indeed presented an increase in plasma concentrations of glucose, insulin, triglycerides, cholesterol, and total levels of markers of OS, as well as in liver mass and lipids. Probiotic treatment lowered almost all of these parameters and reduced lipogenesis [214,215].

Other studies emphasized the positive role of probiotics also in modulating the redox state. In NAFLD patients, the consumption of $300 \mathrm{~g} /$ day of probiotic yogurt containing 
Lactobacillus acidophilus and Bifidobacterium lactis significantly improved AST and ALT when compared with the placebo group, generally in parallel with a lowering of cholesterol, triglycerides, and LDL-cholesterol levels; in some cases, there was also an improvement in the intrahepatic fat content and/or waist circumference [216-219]. The pathophysiological rationale probably resides in an increase in TAC [220], SOD levels [221], and GPx activity [222], which are accompanied by a reduction in lipid oxidation (detected through MDA serum concentrations) [223].

Gut microbiota has a demonstrated beneficial effect on NAFLD/NASH-related OS not only by a direct effect, as previously described, but also through its modulation of other dietary compounds with antioxidant activity. For instance, interesting observations have been made concerning the relationship between microbiota and polyphenols. The composition of the intestinal microbial flora, in fact, seems to be able to act directly on the bioactivity of such substances, which are normal components of the diet, known for their antioxidant effect in vitro, but also for their low bioavailability in vivo [224]. The presence or absence of intestinal germs capable of metabolizing polyphenols could, at least in part, explain the inter-individual variability of the beneficial effects on NAFLD observed as a result of polyphenol dietary supplementations. Because these agents, by changing the intestinal redox state, are, in turn, able to control the different subpopulations of the microbiota, it may well be believed that the microbiota-polyphenol interconnection may represent a new target for studies centered on diseases mediated by OS such as NAFLD $[225,226]$.

In NAFLD patients, intestinal microbiota may be modulated also by physical exercise, and this could elicit its antioxidant activities. Lifestyle modifications are indeed one of the traditional treatments in obesity-related diseases and have a proven beneficial role also in the NAFLD context, all the more in patients with excess weight. Apart from dietary interventions, physical exercise interventions are, in fact, a valid way to reach weight loss. With regard to liver disease, physical exercise is capable of modulating hepatic steatosis, improving insulin sensitivity, or affecting body composition independently of weight loss [227]. Only a few studies have considered that the effect of exercise on the metabolic state may be at least partially driven by intestinal microbiota modulation and no clear relation to NAFLD has been yet established. To the best of our knowledge, the impact of exercise specifically on the gut microbiome and its subsequent effects on NAFLD has not been studied in humans. Thus, when researchers suggest that exercise might affect NAFLD (in part) due to modulation of the intestinal microbiome, this is attributed to effects seen mainly on obesity, an important contributor to NAFLD [228-231]. Interestingly, there is only one rodent study indirectly addressing the modulatory effect of exercise on NAFLD through gut microbiome [232]. In this research, the effect of a controlled exercise program was thoroughly investigated on the gut-liver axis in juvenile rats with promising results, when the mice were introduced to an exercise program after the development of features for obesity and NAFLD induced by a HFD. Exercise effectively counteracted HFD-induced microbial imbalance, leading to intestinal barrier preservation. This, in turn, prevented deregulation of the gut-liver axis and improved bile acid homeostasis, determining the clinical outcomes of NAFLD. It is noteworthy that the exercise protocol also positively increased the citrate synthase enzymatic activity, suggesting an improvement in the oxidative metabolism capacity. In parallel, exercise performance caused a distinct reduction in the HFD-induced hepatic Cyp2e1 expression involved in OS development and derived lipotoxicity. These reports are confirmed also by others: A high-intensity exercise training can reduce postprandial circulating lipid peroxidation levels [233], suggesting that hepatic OS is reduced by aerobic exercise [234]. Thus, with the aforementioned metabolic antioxidant activities (i.e., modulatory capacity over dysbiosis and gut-liver axis activation) at least in part attributable to the action of the microbiota itself, physical exercise may have the potential to be considered as an alternative, indirect microbiome-based therapy for NAFLD, at least for what concerns its obesity-associated variant [209,235]. 


\subsection{Relationship of Oxidative Stress and the Development and/or Progression of NAFLD-HCC}

Taking into account the aforementioned epidemiological data that clearly indicate that NAFLD/NASH is causing a dramatic increase in the prevalence of HCC development, with NASH being a recognized etiological cause of HCC, it is quite understandable why many studies have attempted to unravel the possible role of OS also in the development of HCC, similarly to what happened for NAFLD and NASH. While increased OS in liver parenchymal cells has been observed and linked to HCC, both the detailed mechanisms and the overall impact of this specific problem have yet to be fully clarified [236]. It is well known that ROS, such as H202, can cause point mutations or larger lesions in the genome [237]. A recent study investigated in detail the role of OS-related enzymes and receptors in liver carcinogenesis, identifying three factors (thioredoxin reductase- 1 , glutathione reductase, and the transcription factor Nrf2) as major players in the development of HCC [238]. The authors concluded that this process is the result of a complex interaction between several factors. Indeed, although it is well known that anti-oxidant systems constitute an integrated and finely tuned network capable of effectively preventing carcinogenesis by protecting healthy cells, the role of OS is controversial in existing cancers, where ROS are definitely part of the tumor microenvironment (TME) [239] and the antioxidant network probably plays both anti- and pro-cancer roles. In this context, ROS are active players in cancer development, exerting apparently contradictory effects, i.e., stimulation of tumorigenesis and cancer cell proliferation or induction of cell death. Focusing on NAFLD/NASH, an indirect confirmation of the tumorigenic role of $\mathrm{OS}$ is the adaptation of cancer cells to antioxidant insults, e.g., by increasing NADPH through the pentose phosphate pathway (PPP), which is also an emerging mechanism of drug resistance exploited by cancer cells [240]. In this context, dissecting the role of NOX (such as NOX1, NOX2, and NOX4), which are both NADPH consumers and ROS generators, would be of great interest.

In any case, an exhaustive analysis of all ROS involved in the transition from NASH to HCC far exceeds the aims of this review. Briefly, the most well-established signaling cascade regulated by ROS is Nrf2. When active in neoplastic cells, Nrf2 signaling restricts ROS damage and favors cancer cell survival under chronic OS. It is believed that some cancer cells actually use Nrf2 signaling as an adaptive mechanism to promote tumor growth [241]. Recently, it was proposed that Nrf2 activation due to the microenvironment could be one of two hits required for HCC, while a mutation in the gene encoding $\beta$-catenin, a major genetic aberration observed in a significant subset of NAFLD-associated HCC, provides the second hit [242]. NF- $\mathrm{kB}$ is another important pathway in this context. It can have both pro- and antioxidant roles by affecting the expression of target enzymes involved in ROS scavenging and generation [243]. Despite this role of NF- $\mathrm{KB}$ in maintaining antioxidant defenses and reducing liver damage, obese and NAFLD patients display increased pro-inflammatory cytokine levels, hepatic NF- $\mathrm{kB}$ activation, and risk for HCC development [244]. ROS can also indirectly and directly affect the tumor suppressor p53 activity (with higher expressions causing liver inflammation and NAFLD progression) [245] and hypoxia-inducible factors (HIF) (with a positive correlation with HCC development and resistance to chemotherapeutic agents) [246]. In addition to classical ROS pathways, B-cell lymphoma 2 (BCL-2) proteins are emerging as physiological- and pathophysiological-associated redox molecules in cell survival and death, with a possible role in NAFLD/NASH tumorigenesis. As a matter of fact, BCL-2 proteins can contribute to NAFLD hepatic ROS formation; in addition, ROS levels can trigger cell death through BCL-2 protein modulation [247]. Protein tyrosine phosphatase (PTP) oxidation is another key mechanism of downstream ROS production with a proposed role in the transition from SS to NASH and HCC [248]. Briefly, OS stress inhibition of PTPs serves as a mechanism by which optimal tyrosine phosphorylation is maintained under physiological conditions but, if dysregulated, can contribute to liver dysfunction and HCC development, especially in obese subjects [249].

Among other possible, interesting new molecular mechanisms linking OS and NAFLD tumorigenesis there is the Notch signaling pathway. Selective blocking of Notch homolog 1 , translocation-associated (Notch1), inhibits cancer cell growth and deregulates angiogene- 
sis [250]. By performing RNA sequencing of HFD-fed mice, Zhu et al. demonstrated that Notch-active hepatocytes show transcriptional enrichment of ECM-related genes, which may represent a mechanism that persists in the tumorigenic process. Furthermore, the same animal model with Notch active mutation spontaneously forms fully developed liver tumors [251]. Therefore, it can be inferred that the continuous activation of the Notch signaling pathway promotes the occurrence of NAFLD-related HCC. A further indirect evidence comes from the potential inhibition of HCC invasion and metastasis by $\delta$-tocotrienol, an isomer of VitE, via downregulating the Notch1 signaling pathway with reduced biochemical markers of hepatocellular injury and steatosis [252], and by silymarin via inhibiting factors such as Notch intra-cellular domain (NICD), recombining binding protein suppressor of hairless (RBP-JK) (i.e., the central player in the transcriptional regulation of Notch target genes and functions) and hairy and enhancer of split-1 (Hes1) [253].

\subsection{Biomarkers of Oxidative Stress in NAFLD/NASH}

A further interesting and innovative line of research is the investigation of possible new biomarkers that have a diagnostic/prognostic role in relation to OS in NAFLD/NASH and that go alongside those already more validated regarding liver fibrosis. Though not well defined, circulating factors in NAFLD patients could modulate intracellular pathways in the direction predicted by current hypotheses on NAFLD pathogenesis, which has been recently evidenced by an in vitro study. Hence, exposure of primary human hepatocytes and Huh7.5 cells to plasma of NAFLD patients was able to cause triglycerides' accumulation and OS through mechanisms involving SREBP-1c, inflammasome nucleotide-binding oligomerization domain-containing protein (NOD), leucine-rich repeats (LRR), pyrin domain-containing protein 3 (NLRP3), and PPAR $\gamma$, as a starting point [158]. (Figure 2).

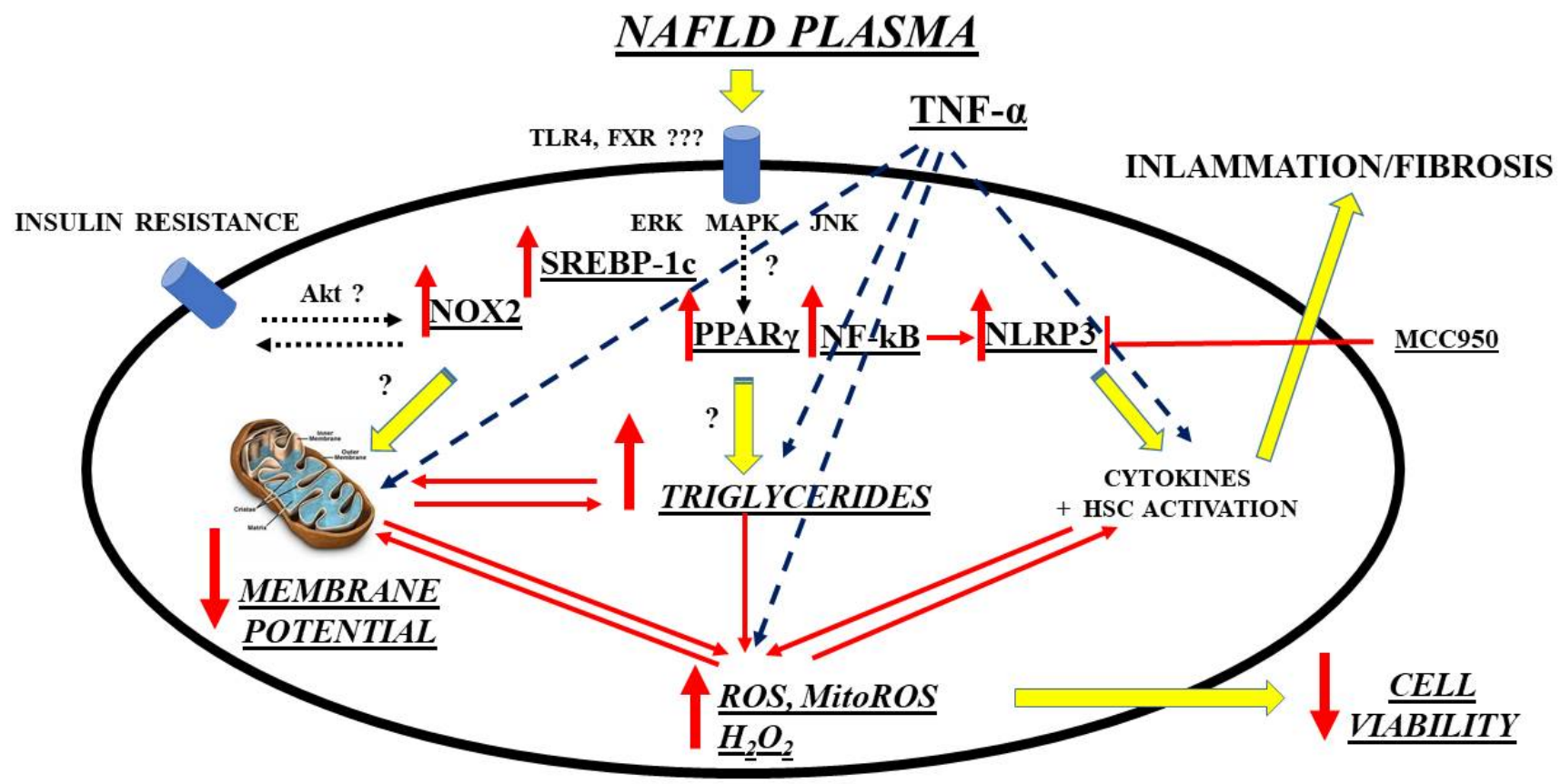

Figure 2. Mechanisms of damage elicited by NAFLD plasma on hepatocytes. ERK: extracellular signal-regulated kinases; FXR: farnesoid X receptor; HSC: hepatic stellate cells; MAPK: mitogenactivated protein kinase; ROS: reactive oxygen species; MitoROS: mitochondrial $\mathrm{ROS}_{3} \mathrm{H}_{2} \mathrm{O}_{2}$ : hydrogen peroxide; NF-kB: nuclear factor kappa-light-chain-enhancer of activated B cells; NLRP3: NOD-LRR-and pyrin domain-containing protein 3; MCC950: a specific, small-molecule inhibitor of NLRP3 inflammasome; NOX: nicotinamide adenine dinucleotide phosphate (NADPH) oxidases; Akt: Ak strain transforming factor; PPAR: peroxisome proliferator activating ligand receptors; SREBP: sterol regulatory element binding protein; TLR: toll-like receptor; TNF: tumor necrosis factor; JNK: c-Jun N-terminal kinase. 
Following these premises, a promising, novel, systemic marker of OS, but also of inflammation and cellular aging, is represented by growth differentiation factor-15 (GDF-15) [254-256]. This is a cytokine upregulated in multiple pathological conditions where OS, endothelial dysfunction, tissue aging, and chronic inflammation are the hallmarks. As a matter of fact, GDF-15 is rapidly produced by various cell types, including hepatocytes, cardiomyocytes, macrophages, adipocytes, and endothelial and smooth cells, among others, in response to pro-inflammatory cytokines or ROS, cellular stress, tissue injury, hypoxia, and/or oncogene activation [257]. More in detail, this factor has been identified as a mitochondrial unfolded protein response (UPR $\left.{ }^{\mathrm{mt}}\right)$-associated cell non-autonomous mitokine that regulates systemic energy homeostasis and feeding behavior [258]. Due to the link between mitochondrial dysfunction and liver injury, GDF15 is currently considered a biomarker of diverse chronic liver diseases [259]. First of all, this factor has been demonstrated, as expected, to be a possible prognostic HCC marker because its upregulation as a consequence of mitochondrial oxidative phosphorylation defects and ROS production is associated with liver cancer development, progression, and metastasis [260]. Taking into consideration the same physiopathological considerations, it is not surprising that the factor has also a potential prognostic role in hepatitis B and C chronic viral hepatitis, with an increasing degree of diagnostic accuracy in compensated and decompensated liver cirrhosis [261-263]. Finally, its pathogenic role was recently demonstrated also in the development and progression of NAFLD. With concern to the latter condition, GDF15 increased the risk of NASH and advanced fibrosis among biopsy-proven NAFLD patients, independently of known metabolic risk factors [(such as age, gender, body mass index (BMI), insulin resistance, and low skeletal muscle mass)]; moreover, the factor was associated with the severity of lobular inflammation and ballooning [264,265].

Among other promising biomarkers of OS in NAFLD, the growth arrest-specific gene 6 (Gas6) serum protein and its family of tyrosine kinase receptors, namely, Tyro3, Axl, and MERTK (TAM), can be cited. The Gas6/TAM system (mainly, Axl and MERTK) is already a well-known important player in the progression of liver fibrosis in various hepatic diseases, including NAFLD/NASH [266]. Focusing on OS, it is necessary to go back for a moment to the aforementioned "two hits" theory of NASH. Briefly, steatosis is the first hit that generally is recognized to increase hepatocyte vulnerability to any secondary insult, eliciting an inflammatory response, characterized by lobular inflammation, elevated local and systemic cytokines, activation of HSC, and expansion of liver progenitor cells (LPC). Most probably, both events are strictly interconnected since fat accumulation per se induces OS, inflammatory cytokine synthesis, and LPC expansion [267]. Well, the Gas6/TAM system could be a key element in this interplay [268,269]. What is already known is that in the liver, Gas6 and at least its high-affinity receptor Axl, are expressed by many of the previously cited inflammatory elements, such as macrophages, HSC in their myofibroblastic phenotype [270], and LPC [271]. Moreover, in murine models, Gas6 deficiency reduced inflammation and activation of Kupffer cells and myofibroblasts, causing, among other things, delayed liver repair in response to acute injury [272]. Based on these preliminary studies, which suggested a prominent role of Gas6 in the pathogenesis of chronic liver diseases including NAFLD/NASH, new studies followed, still analyzing the possible roles of Gas6 deficiency but this time focusing more on the possible changes in the oxidative state at the hepatic level. For instance, Gas6-deficient mice fed a choline deficient, ethionine-supplemented diet (CDE) showed not only, as expected, reduced liver inflammation and fibrosis, but also attenuated hepatic steatosis. More in detail, Gas6 ${ }^{-/-}$ mice fed with the CDE diet showed a reduced downregulation of some crucial rate-limiting enzymes of mitochondrial FA $\beta$-oxidation, such as PPAR $\alpha$ and its target genes acyl-CoA oxidase-1 (ACOX1) and carnitine palmitoyltransferase-1 (CPT1). Moreover, Gas6 deficiency reversed the CDE-induced repression of stearoyl-CoA desaturase-1 (SCD1), the rate-limiting step in the biosynthesis of monounsaturated FA. Moreover, Gas6 deficiency at least partially mitigated the increased expression of CD36 hepatic fatty acid translocase (CD36), an enzyme that mediates uptake and intracellular transport of long-chain FA in 
hepatocytes and that is known to be abnormally increased in NAFLD. All these mechanisms ultimately accounted for the more efficient FA catabolism and delayed steatosis found in Gas6 knockout mice [273]. On the other hand, CDE diet is long known to promote intrahepatic lipid accumulation because of increased FA uptake and decreased triglycerides synthesis, in addition to the already mentioned inhibition of FA oxidation, and so can be a useful model if NAFLD-associated processes are the study focus [274-276]. This happens probably because the $\mathrm{CDE}$ diet has been demonstrated to induce CD36 expression, favoring FA uptake, and to suppress the SCD1 mRNA, preventing synthesis of unsaturated FA [277-279]. Concerning the latter point, a possible explanation for the higher SCD1 expression observed in $\mathrm{Gas6}^{-/-}$mice is that they have a decreased expression of Kupffer cells-derived TNF- $\alpha$, which, in turn, has been demonstrated to downregulate SCD1 [277]. Moreover, Gas6-deficient mice showed also reduced IL-1 $\beta$ expression, again produced from Kupffer cells. This a cytokine that promotes triglycerides' storage in hepatocytes by reducing the expression of PPAR $\alpha$ and its target genes involved in hepatocyte FA oxidation [280]. Therefore, it can be assumed that reduced IL-1 $\beta$ expression revealed in Gas ${ }^{-/-}$ mice is an additional mechanism that prevents early CDE-induced downregulation of genes involved in $\beta$-oxidation in hepatocytes and steatosis. Of interest, a role of Gas6 in fat accumulation has been reported also in adipogenesis. After exposure to a HFD, fat accumulation in adipose tissues was reduced in Gas6 knockout mice, with no effect on hepatic steatosis. In this study, Gas6 directly promoted the proliferation of Axl-positive preadipocytes and their differentiation into mature adipocytes [281]. For what concerns the liver, it was previously demonstrated that Gas6 and its receptor Axl are not expressed in hepatocytes. Therefore, the contribution of Gas 6 to CDE-induced FA accumulation in these cells may not be direct but mediated by Axl-positive cells, such as macrophages, LPC, and HSC in their myofibroblastic phenotype $[270,271]$. By the way, the total content of Axl was higher than in wild-type mice [273]. New insights to the importance of the Gas6/TAM system pathway in the progression of NASH came also from studies involving the Gas6 receptor MERTK. In the metabolic syndrome, and more specifically in NAFLD, accumulation of excess lipoprotein-derived cholesterol in macrophages was shown to activate nuclear liver $\mathrm{X}$ receptors (LXR) that, in turn, triggered the induction of the ATP-binding cassette (ABC) transporter, mediating cholesterol efflux [282] and the upregulation of MerTK both in mice [283] and in humans [284]. Both LXR and the aforementioned PPAR influence, among other things, the transcription of genes regulating lipid homeostasis and inflammation. More in detail, PPAR $\gamma$ can be activated by metabolic signals (i.e., polyunsaturated FA and lipoproteins) [285], resulting in lipid uptake through the scavenger receptor CD36 and $\beta$-oxidation [286]. LXRs are, in turn, oxysterol-activated transcription factors that sense elevated cellular cholesterol [287]. PPAR $\gamma$ and LXR activities are generally coordinated and control the transcription of many receptors, including MerTK. In MERTK and LXRs, double knockout mice amplified pro-inflammatory responses, and increased susceptibility to OS and atherosclerosis were observed, suggesting that the LXR-dependent regulation of MerTK is important for normal homeostasis including FA metabolism [288-290]. However, further studies are needed to confirm these preliminary data.

Mac-2 binding protein (M2BP), a known important player in cell adhesion, is another NAFLD biomarker candidate [291]. For what concerns liver, a source of M2BP is HSC; since Kupffer cells have an increased M2BP production after autocrine or paracrine stimulation, it was suggested that M2BP secreted from HSC may be taken up by Kupffer cells [292]. Based on these premises, the factor is mainly known as a liver fibrosis marker through inflammation in the extracellular matrix $[291,293,294]$. However, there is now increasing evidence for a promising role also, as in the metabolic syndrome context. For instance, serum M2BP levels were higher in subjects with hypertension, dyslipidemia, or abnormal glucose metabolism compared to subjects without such risk factors. Moreover, the protein levels were associated with severity of cardiovascular risk. Subdivision of M2BP levels into quartiles revealed that M2BP was significantly associated with OS and, in particular, with reactive oxygen metabolites [295]. Other studies confirmed that, in normal subjects, 
M2BP concentrations were not only associated with OS marker derivatives of reactive oxygen metabolites, but also with LDL-cholesterol and triglyceride levels. Furthermore, increased LDL-cholesterol was an independent determinant of M2BP high concentrations and, vice versa, increase in LDL-cholesterol was significantly greater in subjects in whom M2BP concentrations increased during the follow-up period [296]. When focusing on NAFLD patients, there was an indirect association between M2BP levels and subclinical atherosclerosis as determined by brachial-ankle pulse wave velocity [297]. A direct link between OS and M2BP was instead provided in a cohort of Japanese obese men with NAFLD. Independent of the effect of weight loss, a 3-month exercise regimen significantly reduced liver steatosis (by $9.5 \%$ ) as determined by transient elastography. Moreover, an important decrease in OS parameters during the intervention was observed: Among other parameters, there was also serum M2BP (until $-62.4 \%$ in the exercise group and $-37.7 \%$ in the weight-loss group). These reductions paralleled with less significant decreases in insulin resistance (HOMA-IR) and lipid profile (triglycerides and non-esterified FA). Taken together, these data suggest that, in NAFLD, M2BP may be more a marker of organokine balance and systemic inflammation and OS than a surrogate liver steatosis parameter [298] and could find a clinical application primarily in NAFLD patients with obesity and/or metabolic syndrome.

A new line of research in NAFLD biomarkers concerns extracellular vesicles (EVs). Several mechanisms implicated in NAFLD progression, such as inflammation, fibrosis, and angiogenesis, but also OS, all related to metabolic syndrome-associated lipotoxicity, trigger EV production and release by the liver [299]. On the one hand, EVs mediate local intercellular communications between the liver cells, thereby driving disease pathogenesis and, on the other, liver-derived EVs could affect distant tissues and organs upon their release to the bloodstream. Thus, liver-derived EVs have been suggested as biomarkers both for diagnostic (potentially including early stages) and prognostic purposes in NAFLD patients (the so-called liquid biopsy) [300,301]. However, the identification of liver-derived EVs in circulation as indicative of metabolic alterations in this organ is still a challenge for basic and clinical researchers. As previously cited, NAFLD is not an isolated condition and generally occurs as a complication of other metabolic disorders. Therefore, multiple tissues may be affected and, consequently, the contribution of extrahepatic EVs during NAFLD cannot be excluded (i.e., adipocyte- or immune cell-derived EVs). Furthermore, most liver cell types produce EVs including hepatocytes, cholangiocytes, HSC, and liver sinusoidal endothelial cells [302]. Nonetheless, as $80 \%$ of the liver volume is composed by hepatocytes, their participation to the total pool of liver-derived EVs is likely the most relevant. Based on these premises and focusing on EVs of hepatocyte production, several protein-based EV biomarkers have been introduced for NAFLD liver damage [303] or NASH [304,305] with particular regard to the lipotoxicity link with inflammation, although, to date, most studies have focused on characterizing EVs-associated nucleic acids, especially microRNAs (miRNAs). For what concerns OS, some preliminary data exist precisely for EVs-derived miRNAs. It was demonstrated that liver firstly responds to lipid overload and thereafter sends hepatocyte-derived EVs (in particular, let-7e-5p), targeting adipocytes to regulate adipogenesis and lipogenesis. More in detail, these EVs positively correlated with BMI and enhanced adipocyte lipid deposition by increasing lipogenesis and inhibiting lipid oxidation through an axis involving also the peroxisome proliferator-activated receptor gamma coactivator 1-alpha $\left(P_{g c 1} \alpha\right)$. Moreover, taking into account that lipid overload enhances liver geranylgeranyl diphosphate synthase (Ggpps) expression, which, in turn, regulates EVs' secretion through Rab27A geranylgeranylation, liver-specific Ggpps-deficient mice had reduced fat adipose deposition because of reduced EVs' secretion [306]. Thus, this pilot study highlighted an inter-organ mechanism whereby the liver during NAFLD senses different metabolic states and sends corresponding signals to remodel adipose tissue to adapt to metabolic changes in response to lipid overload. In any case, future studies aiming to examine additional molecular mechanisms possibly involved in EVs' biogenesis, release, and dysregulation of target cells as well as to identify cargos with potential 
value as biomarkers for noninvasive diagnosis and monitoring of NAFLD progression are much desirable.

There are many other biomarkers of OS that have been evaluated, or that are under evaluation, in animal and clinical models of NAFLD/NASH $[61,68,75,307]$. These factors were detected primarily in the liver, plasma, and serum, although a few studies analyzed whole blood samples. Major approaches to measure these biomarkers included ELISA, colorimetry, and immunohistochemistry. Biomarkers of OS measured in experimental models of NAFLD/NASH included lipid oxidation products [thiobarbituric acid reactive substances (TBARS), which were used as MDA, 4-HNE, and 8-isoprostanes], DNA damage products [8-hydroxy-2'-deoxyguanosine (8-OH-dG)], and protein damage products (protein carbonyl, dityrosine, hydroxyproline, and nitrotyrosine) (Table 1). Among these biomarkers, MDA was the most measured marker of OS. The level or activity of these factors was generally increased in most animal models, with a few exceptions [308,309].

Table 1. Oxidative stress markers in animal models of NAFLD/NASH.

\begin{tabular}{|c|c|c|c|c|c|}
\hline $\begin{array}{c}\text { Oxidative Stress } \\
\text { Markers }\end{array}$ & Disease Status & $\begin{array}{c}\text { Experimental } \\
\text { Model and Species }\end{array}$ & Sample & $\begin{array}{c}\text { Changes in } \\
\text { Concentration/ } \\
\text { Activity/Expression }\end{array}$ & Reference(s) \\
\hline TBARS/MDA & Steatosis, NASH & $\begin{array}{c}\text { HFD, HF-HSD, MCD, } \\
\text { ob/ob mice, CDHF } \\
\text { diet } \\
\text { HCD } \\
\text { HFD, MCD }\end{array}$ & Liver & $\begin{array}{c}\uparrow \\
\downarrow \\
\text { NS }\end{array}$ & {$[310,311]$} \\
\hline 4-HNE & Steatosis, NASH & $\begin{array}{c}\text { HFD, MCD, HF-HSD, } \\
\text { CDHF diet }\end{array}$ & Liver & $\uparrow$ & {$[312,313]$} \\
\hline 8-OH-dG & $\mathrm{NASH}$ & $\begin{array}{c}\text { MCD, ob/ob mice } \\
\text { HFMCD }\end{array}$ & Liver & $\begin{array}{l}\uparrow \\
\downarrow\end{array}$ & [314] \\
\hline 8-isoprostane & $\mathrm{NASH}$ & HFMCD & Liver & $\uparrow$ & [315] \\
\hline Protein carbonyl & Steatosis, NASH & $\begin{array}{c}\text { HFD, MCD } \\
\text { HFD }\end{array}$ & Liver & $\begin{array}{c}\uparrow \\
\text { NS }\end{array}$ & [316] \\
\hline Nitrotyrosine & $\mathrm{NASH}$ & HFD, ob/ob mice & Liver & $\uparrow$ & [317] \\
\hline Periostin & NASH & HFD, ob/ob mice & Serum, liver & $\uparrow$ & [318] \\
\hline CYP2E1 & Steatosis, NASH & HFD, HF-HSD, CDHF & Liver & $\uparrow$ & {$[311,319]$} \\
\hline Dityrosine & Steatosis & HFD & Liver & $\uparrow$ & [320] \\
\hline Hydroxyproline & NASH & $\mathrm{MCD} / \mathrm{WD}$ & Liver & $\uparrow$ & [321] \\
\hline $\mathrm{H}_{2} \mathrm{O}_{2}$ & NASH & MCD & Liver & $\uparrow$ & [309] \\
\hline Lipid peroxide & $\mathrm{NASH}$ & MCD & Liver & $\uparrow$ & [322] \\
\hline NADPH oxidase & NASH & $\mathrm{ob} / \mathrm{ob}$ mice & Liver & $\uparrow$ & [323] \\
\hline Xanthine oxidase & Steatosis & HFD & Liver & $\uparrow$ & [324] \\
\hline
\end{tabular}

NS: no significant change; TBARS/MDA, thiobarbituric acid reactive substances/malondialdehyde; 4-HNE: 4-hydroxynonenal; 8-OH-dG: 8-hydroxy-2'-deoxyguanosine; $\mathrm{H}_{2} \mathrm{O}_{2}$ : hydrogen peroxide; NADPH oxidase: nicotinamide adenine dinucleotide phosphate-oxidase; MCD: methionine/choline-deficient diet; HFD: high-fat diet HCD: high-cholesterol diet; CDHF: choline-deficient, high-fat diet; HFMCD: high-fat, methionine choline-deficient diet; HF-HSD: high-fat, high0sucrose diet; WD: Western diet.

For what concerns biomarkers of OS frequently determined in NAFLD/NASH patients, the most studied ones were quite similar to those previously mentioned for experimental models (Table 2). Overall, the concentrations or activities of these biomarkers were increased in all data examined, although the rise was not significant in some cases [117,325-327]. 
Table 2. Oxidative stress markers in NAFLD/NASH patients.

\begin{tabular}{|c|c|c|c|c|}
\hline $\begin{array}{c}\text { Oxidative Stress } \\
\text { Markers }\end{array}$ & Disease Status & Sample & $\begin{array}{c}\text { Changes in } \\
\text { Concentration/ } \\
\text { Activity/Expression }\end{array}$ & Reference(s) \\
\hline TBARS/MDA & Steatosis, NASH & $\begin{array}{l}\text { Serum, liver, blood } \\
\text { Serum }\end{array}$ & $\begin{array}{c}\uparrow \\
\text { NS }\end{array}$ & {$[87,117,328]$} \\
\hline 4-HNE & NASH & Liver & $\uparrow$ & [329] \\
\hline Hydroperoxides & NASH & Liver & $\uparrow$ & [330] \\
\hline 8-OH-dG & Steatosis, NASH & $\begin{array}{l}\text { Liver, plasma } \\
\text { Liver }\end{array}$ & $\begin{array}{c}\uparrow \\
\text { NS }\end{array}$ & [331] \\
\hline 8-isoprostane & NASH & Plasma & NS & [326] \\
\hline Protein carbonyl & Steatosis, NASH & Liver & $\uparrow$ & [327] \\
\hline Nitrotyrosine & Steatosis, NASH & $\begin{array}{l}\text { Liver } \\
\text { Blood }\end{array}$ & $\begin{array}{c}\uparrow \\
\text { NS }\end{array}$ & [25] \\
\hline Periostin & Steatosis, NASH & $\begin{array}{l}\text { Serum, plasma, liver } \\
\text { Serum, plasma }\end{array}$ & $\begin{array}{c}\uparrow \\
\text { NS }\end{array}$ & [332-335] \\
\hline Nitric oxide & Steatosis, NASH & Serum, blood & $\uparrow$ & {$[336,337]$} \\
\hline CYP2E1 & Steatosis, NASH & Liver & $\begin{array}{c}\uparrow \\
\text { NS }\end{array}$ & {$[338]$} \\
\hline
\end{tabular}

NS: no significant change; TBARS/MDA: thiobarbituric acid reactive substances/malondialdehyde; 4-HNE: 4-hydroxynonenal; 8-OH-dG: 8-hydroxy-2'-deoxyguanosine.

In addition, many studies, both in human and experimental models of NAFLD/NASH, also measured enzymatic and nonenzymatic liver antioxidant biomarkers [e.g., catalase, SOD, GSH peroxidase (GPx), GSH, thioredoxin reductase (TrxR), $\alpha$-tocopherol, and ubiquinone], and their activities were decreased in most liver samples, consistently with a loss of their protective abilities due to high OS, while blood, serum, and plasma had more conflicting results [316,324,326,339-345] (Tables 3 and 4).

Table 3. Antioxidant markers in animal models of NAFLD/NASH.

\begin{tabular}{|c|c|c|c|c|c|}
\hline $\begin{array}{l}\text { Antioxidant } \\
\text { Marker }\end{array}$ & $\begin{array}{l}\text { Disease } \\
\text { Status }\end{array}$ & $\begin{array}{c}\text { Experimental } \\
\text { Model and Species }\end{array}$ & Sample & $\begin{array}{c}\text { Changes in } \\
\text { Concentration/ } \\
\text { Activity/Expression }\end{array}$ & Reference(s) \\
\hline SOD & $\begin{array}{l}\text { Steatosis, } \\
\text { NASH }\end{array}$ & $\begin{array}{c}\text { HF, HFD, OLETF rats, MCD } \\
\text { HFD, MCD } \\
\text { HFD }\end{array}$ & Liver & $\begin{array}{c}\downarrow \\
\uparrow \\
\text { NS }\end{array}$ & {$[344,346]$} \\
\hline Catalase & $\begin{array}{l}\text { Steatosis, } \\
\text { NASH }\end{array}$ & $\begin{array}{l}\text { HFD, MCD, HCD } \\
\text { MCD }\end{array}$ & Liver & $\begin{array}{l}\downarrow \\
\uparrow\end{array}$ & {$[117,343]$} \\
\hline GPx & $\begin{array}{l}\text { Steatosis, } \\
\text { NASH }\end{array}$ & $\begin{array}{c}\text { HFD, MCD, HF } \\
\text { MCD } \\
\text { HFD }\end{array}$ & Liver & $\begin{array}{c}\downarrow \\
\uparrow \\
\text { NS }\end{array}$ & {$[326,327]$} \\
\hline GSH & $\begin{array}{l}\text { Steatosis, } \\
\text { NASH }\end{array}$ & $\begin{array}{c}\text { HFD, HCD, MCD, ob /ob mice } \\
\text { OLETF rats, HF MCD }\end{array}$ & Liver & $\begin{array}{l}\downarrow \\
\uparrow\end{array}$ & [346] \\
\hline GR & NASH & MCD & Liver & $\downarrow$ & [340] \\
\hline
\end{tabular}

NS: no significant change; SOD: superoxide dismutase; GPx: glutathione peroxidase; GSH: glutathione; GR: glutathione reductase; HF: high-fructose diet; HFD: high-fat diet; OLETF: Otsuka Long-Evans Tokushima Fatty; MCD: methionine/choline-deficient diet; HCD: high-cholesterol diet; ob/ob: obese leptin-deficient; HFMCD: high-fat, methionine choline-deficient diet. 
Table 4. Antioxidant markers in NAFLD/NASH patients.

\begin{tabular}{|c|c|c|c|c|}
\hline Antioxidant Marker & Disease Status & Sample & $\begin{array}{c}\text { Changes in } \\
\text { Concentration/ } \\
\text { Activity/Expression }\end{array}$ & Reference(s) \\
\hline SOD & Steatosis, NASH & $\begin{array}{c}\text { Serum, plasma, liver } \\
\text { Blood, serum } \\
\text { Serum }\end{array}$ & $\begin{array}{c}\downarrow \\
\uparrow \\
\text { NS }\end{array}$ & {$[344,346]$} \\
\hline Catalase & Steatosis, NASH & $\begin{array}{c}\text { Plasma, blood, liver } \\
\text { Serum }\end{array}$ & $\begin{array}{c}\downarrow \\
\text { NS }\end{array}$ & {$[117,343]$} \\
\hline GPx & Steatosis, NASH & $\begin{array}{c}\text { Liver, serum } \\
\text { Blood } \\
\text { Serum }\end{array}$ & $\begin{array}{c}\downarrow \\
\uparrow \\
\text { NS }\end{array}$ & {$[326,327]$} \\
\hline GSH & Steatosis, NASH & $\begin{array}{l}\text { Liver, blood } \\
\text { Serum }\end{array}$ & $\begin{array}{l}\downarrow \\
\uparrow\end{array}$ & [346] \\
\hline GR & Steatosis, NASH & Serum, blood & $\uparrow$ & [344] \\
\hline TRX & Steatosis & Serum & $\uparrow$ & [345] \\
\hline$\alpha$-Tocopherol & Steatosis, NASH & Serum & $\begin{array}{c}\downarrow \\
\text { NS }\end{array}$ & [333] \\
\hline $\begin{array}{l}\text { Ubiquinone } \\
\text { Bilirubin }\end{array}$ & $\begin{array}{c}\text { Steatosis } \\
\text { Steatosis, NASH }\end{array}$ & $\begin{array}{l}\text { Serum } \\
\text { Serum }\end{array}$ & $\begin{array}{l}\downarrow \\
\downarrow\end{array}$ & $\begin{array}{l}{[347]} \\
{[337]}\end{array}$ \\
\hline Ascorbic acid & Steatosis, NASH & Serum & $\begin{array}{c}\downarrow \\
\text { NS }\end{array}$ & [346] \\
\hline
\end{tabular}

NS: no significant change; SOD: superoxide dismutase; GPx: glutathione peroxidase; GSH: glutathione; GR: glutathione reductase; TRX, thioredoxin.

Data derived from the measurement of all these markers clearly indicate that the presence of OS is strongly associated with NAFLD/NASH. However, these biomarkers provide very limited information on the type, amount, and localization of ROS as well as their targets and involvement in specific pathophysiological processes. Indeed, the cause-and-effect relationship between OS and pathogenesis has not yet been established with certainty, although many studies have provided possible mechanisms supporting the crucial role of OS in the pathogenesis of NAFLD.

\section{Genetic Polymorphisms and Oxidative Stress in NAFLD/NASH}

\subsection{General Premises}

Among the pathophysiological factors that cause NAFLD, both genetic and environmental factors can be found, affecting the increase in inflammation and the OS degree. In particular, the latter plays an important role due to excessive ROS production following the hyperoxidation of FFA by mitochondria, peroxisomes, and microsomes, as previously reported [348].

There is compelling evidence that genetic factors influence the NAFLD natural history. In particular, a demonstration of how genetics could condition the development of advanced fibrosis in NAFLD comes from family clustering studies showing that approximately one-fifth of NASH patients have a first-degree parent with severe liver disease $[37,336,349,350]$. In high-risk populations, such as the obese and diabetics, the NAFLD distribution and its evolution to NASH is not uniform: With the same risk factors, hepatic involvement is different, suggesting that, at the basis of this difference, there may be also a genetic influence affecting susceptibility not only to the development of NAFLD but also to the severity of liver damage. In the Literature, several examples have confirmed the relationship between genetic predisposition and the NAFLD/NASH development. For example, there are studies on family aggregation, on the different prevalence of these conditions based on ethnic groups, and on the higher NAFLD prevalence in some rare genetic syndromes, such as Prader-Willi, lipodystrophy, and abetalipoproteinemia [349,351]. In recent years, genetic studies have looked for differences in gene or protein expression between healthy and NAFLD/NASH individuals to assess whether these differences may later have a significance in influencing the disease expression [348,352]. 


\subsection{Single Nucleotide Polymorphisms}

Based on these premises, one of the most accredited explanations is that, for example, single nucleotide polymorphisms (SNPs) can modify the expression of genes involved both in the FFA oxidation and in mitochondrial function, making the former excessive and the latter inefficient [353]. In particular, with regard to mitochondrial OS increase, it is likely that polymorphisms involving the SOD2 gene can reduce mitochondrial antioxidant defenses, compromising hepatocyte function [348,354]. Indeed, the mitochondrial manganese-dependent SOD (MnSOD), encoded by SOD2, is essential for the ROS clearance [355]. A common SNP (C47T, rs4880) determines a single amino acid (Ala16Val) replacement in the signaling sequence of the enzyme, reducing its function in the mitochondrial matrix. In this way, MnSOD can influence the genetic susceptibility to NASH, due to a lack of cell detoxification from the superoxide anion and an increased hepatocellular exposure to oxidative damage $[356,357]$. Evidence of the relationship between C47T SNP and NAFLD evolution came from a study that demonstrated how the increase in mitochondrial OS, resulting from this genetic predisposition, increases the fibrosis stage and, therefore, is associated with a more advanced NAFLD [358]. These data were confirmed also in another research, highlighting that NASH patients had a higher incidence of the SOD2 T/T genotype [359].

Another example of genetic polymorphism associated with increased OS and greater incidence and severity of liver damage involves the mitochondrial uncoupling protein 3 (UCP3) gene, which codes for a mitochondrial transport protein implied in the decoupling of oxidative phosphorylation through the loss of IMM protons [354]. UCP3, which is expressed mainly at the skeletal muscle level and in liver only under conditions of high FA catabolism, promotes thermogenesis, lipid metabolism, and BMI reduction [360]. A SNP in the UCP3 promoter (rs1800849) has been associated with insulin resistance, low adiponectin levels, and moderate/severe NAFLD or NASH [357,361].

Mitochondrial uncoupling protein 2 (UCP2) is involved in the regulation of mitochondrial lipid efflux and oxidative metabolism. In patients with NASH, the UCP2 hepatic expression is increased and this leads to the loss of a proton and a reduced redox pressure on the mitochondrial respiratory chain, thus exerting a protective role on the liver damage progression [92]. In later studies, it was shown that the homozygosity for the $866 \mathrm{G}>\mathrm{A}$ variant (rs695366) of the UCP2 gene was protective against NASH and insulin resistance, being associated to an increased UCP2 hepatic expression [354,362].

Sirtuins (SIRTs), which are a family of NAD+-dependent deacetylases involved in cellular metabolism, can modify the OS together with the aforementioned UCPs, thus influencing the risk of atherosclerosis and cardiovascular disease. In a study conducted on a large cohort of patients without stroke and who underwent a high-definition carotid ultrasound, it was shown that the SIRT6 rs107251 and SIRT5 rs12216101 polymorphisms were associated with an increased risk for carotid plaque, while the $\mathrm{T}$ carriers of mitochondrial uncoupling protein 5 (UCP5) SNP rs5977238 had a reduced risk [363]. However, the impact of the SIRTs' polymorphisms on the NAFLD development, with particular regard to the risk of acquiring a metabolic syndrome-like phenotype and its relative risk of cardiovascular complications, has not yet been thoroughly studied and deserves further investigation [357].

Previously, a SNP related to a reduction in the hepatocyte antioxidant defenses of NASH patients was also described: the $-129 \mathrm{C} / \mathrm{T}$ polymorphism in the promoter region of the glutamate-cysteine ligase $(G C L C)$ gene. This is a gene that catalyzes the heterodimeric subunit of glutamate-cysteine ligase (GCL), which is the first enzyme in the production of the GSH, a very important endogenous antioxidant, as previously described. The SNP of the GCLC promoter results in a $50-60 \%$ decrease in the promoter activity. The NASH prevalence was shown to be significantly higher among patients with CT and TT genotypes than among those with CC genotypes. However, a further study found no significant differences in this SNP prevalence between NAFLD patients and control 
subjects, suggesting the need to implement studies with larger populations to confirm or deny this hypothesis [364,365].

\subsection{Other Genetic Variants}

Connor et al. described a missense variant (A165T) of the gene encoding the mitochondrial amidoxime-reducing component 1 (MARC1). This variant is associated with protection against all causes of cirrhosis in the general population [366]. The mutation, in fact, results in a truncated protein, which probably causes a MARC1 loss of function and is associated with lower levels of hepatic steatosis and various liver disease biomarkers [357]. In any case, the precise MARC1 function is not fully known, but, according to previous studies, the variant plays a role in the ROS neutralization during OS, by reducing nitric oxide production and detoxifying trimethylamine N-oxide [367,368]. Therefore, further studies would be useful to clarify the MARC1 exact role both in its native and in its mutated forms, in particular as regards its involvement in the OS regulation and liver inflammation [354].

CYP2E1 is an endoplasmic monooxygenase, activated by ethanol, diet, and endogenous FA. In the NAFLD pathophysiological context, CYP2E1 causes a ROS increase following an incomplete transfer of electrons to molecular oxygen, with a subsequent increase in OS. Excessive CYP2E1 activation in perivenular hepatocytes causes an increase in the area of hepatocyte damage, at least in CYP2E1 transgenic murine models. In particular, the variant CYP4502E1*5B (RsaI, $-1053 C>$ T) seems to increase the enzyme transcription and activity, resulting in an increase in the ROS production in alcoholic cirrhotic patients, but evidence is not yet available for NAFLD patients [369].

Another potential NAFLD genetic predictor is the HFE gene implicated in the hereditary hemochromatosis genesis. Gene mutations, especially C282Y (rs1800562) and H63D (rs1799945), can increase the levels of iron duodenal uptake and subsequent hepatic deposition which, in the context of liver steatosis, promote OS [29]. Despite this, the data on the HFE actual contribution to the NAFLD worsening are still conflicting [348].

For what concerns the pediatric population affected by NAFLD, the OS mechanisms seem to be influenced also by other polymorphisms rarely seen in adult-onset forms [370]. Various genes are involved, such as the G protein-coupled receptor 120 (GPR120) [371], uridine-5'diphosphoglucuronosyltransferase 1A1 (UGT1A1) [372,373], heme oxygenase1 (HO-1) [374], PPAR gamma coactivator 1-alpha (PPARGC1A) [375,376], cannabinoid receptor type 2 (CB2) [370], and beta-Klotho rs17618244 gene variant $(K L B)$ [362].

\subsection{Conclusive Remarks}

In conclusion, although the molecular mechanisms of OS, lipotoxicity, and abnormal adipocytokine release caused by gene polymorphisms in NAFLD/NASH have been gradually elucidated, most studies meet with the absence of statistical power, replication in various cohorts, well-matched samples, and the presence of heterogeneities in disease stages. This stresses the complexity and limitation of gene polymorphism research in NAFLD and is a possible explanation why investigators still do not completely understand the physiopathological mechanisms of NAFLD caused by gene variants.

Based on existing studies, it is clear that the discovery of genetic and environmental associations robust enough to direct the treatment and to trace specific prevention strategies would only be possible with studies examining the susceptibility of NAFLD in a number of individuals considerably higher than assessed so far. These studies rely on a large number of well-phenotyped cases and controls and certainly require national and international collaborations. Moreover, given the role of FFA oxidation and ROS [348], future research should address also many other genes (i.e., glutathione-s-transferase isoforms GSTM1, GSTT1, and GSTP1; myeloperoxidase; and microsomal epoxide hydrolase) already known to be involved in the ROS generation or degradation and consequently to potentially influence the progression to cirrhosis of other liver diseases (such as alcoholic liver disease, chronic hepatitis C, or HCC) [247,377-381]. In any case, with the technological development and applications of disease gene location, the authors believe that a further breakthrough 
studying NAFLD gene polymorphisms will be achieved to help identify also potentially effective treatments for NAFLD [36].

\section{Therapeutic Potential of Targeting Oxidative Stress in NAFLD Patients}

Because lipotoxicity, as discussed above, plays a central role in the progression of NAFLD and is closely related to redox balance and OS in the liver, new therapeutic targets aimed at improving redox balance are under investigation. Clinical evidence shows that dietary supplementation with different types of polyphenols significantly improves the prognosis of NAFLD in individuals at high cardiometabolic risk [382]. These data suggest that their antioxidant effect might be beneficial against hepatic fat accumulation, hepatic inflammation, and fibrosis. In addition, several signaling pathways have been described to explain the therapeutic effects of antioxidants such as polyphenols in NAFLD [383]. Activation of the Nrf2 pathway and attenuation of NF-kB signaling are the most studied. In addition, natural dietary antioxidants may also contribute to ameliorate some OS-related phenomena, such as altered lipogenesis, mitochondrial dysfunction, insulin resistance, inflammation, and intestinal microbial dysbiosis (see also Section 3.3.2) [384].

Therefore, Nrf2 activators, whether natural or synthetic compounds, have been proposed as potential therapeutics, and some of them (e.g., oltipraz) have been evaluated for their therapeutic effect in NAFLD patients. However, due to their electrophilic nature, some side effects are to be expected and more specific and less electrophilic potential compounds are also being developed. Natural compounds such as resveratrol and quercetin have also been reported as modulators of Nrf2 and candidates for the treatment of NAFLD [385]. However, other antioxidant molecules, such as compounds found in green tea, have demonstrated Nrf2-independent mechanisms, as described in HFD mice [386]. Incidentally, some experimental evidence, derived mainly from in vitro models, suggests that these antioxidants also prevent lipid accumulation through alternative molecular mechanisms, like the phosphorylation of $5^{\prime}$ AMP-activated protein kinase (AMPK) [387].

Clinical and experimental evidence links OS to NAFLD, and there is evidence that antioxidants may protect against NAFLD/NASH [388]. Many natural compounds are known to exhibit antioxidant effects in vitro and in vivo. In addition, some of these compounds have been shown to have a therapeutic effect in several liver diseases, including NAFLD. However, in many of these cases, the mechanism of action remains unclear and is not always related to antioxidant activity [389]. In this section, we will discuss some experimental evidence on classical and novel antioxidants, including natural compounds and their potential therapeutic effect in NAFLD (for prebiotics and probiotics please refer to Section 3.3.2).

\subsection{Classical Antioxidants: Vitamin $C$ and Vitamin $E$}

VitC and VitE are classical antioxidant molecules that protect against OS by eliminating free radicals. These vitamins have been proposed as a potential therapy in NAFLD, and there is evidence that consumption of VitE/C combinations is beneficial in NAFLD/NASH. In addition, it has been reported that dietary intake of VitE and VitC is inversely associated with the severity of NAFLD. VitE/C supplementation has been reported to improve the antioxidant status of NAFLD patients treated with statins, but no significant alterations in serum lipid markers have so far been reported [390].

VitE is a fat-soluble vitamin that is normally stored in the liver and adipose tissue. It is synthesized by plants as several isoforms, but $\alpha$-tocopherol is the most common isoform in human plasma and tissues. Tocopherols are direct scavengers of ROS and RNS; however, they also modulate the antioxidant response by increasing the expression of detoxifying enzymes such as SOD, GPX, and catalase. In addition, anti-inflammatory and anti-apoptotic effects have been reported that might be related to protection against cellular damage [391]. VitE treatment slows the progression of NAFLD and decreases NAFLDassociated inflammation in clinical trials [392], and experimental models have shown that VitE supplementation can effectively decrease intrahepatic lipid accumulation [393]. In 
fact, several studies have shown that both serum VitE levels and VitE/cholesterol ratioadjusted levels are inversely correlated with NAFLD severity [107]. A negative correlation between VitE levels and VitE/cholesterol ratio with NAFLD outcome was observed only in nondiabetic patients. Diabetic patients showed higher VitE levels, probably due to hyperlipidemia, which may lead to higher levels of lipoprotein transporters. In addition, it has been reported that VitE treatment alone improves steatosis but is not able to significantly improve the histological outcome in NASH diabetic patients [247]. The explanation for this observation remains unclear, which is why, according to current guidelines, VitE supplementation is not recommended to treat NASH diabetic patients.

Whether the protective effect of VitE in NAFLD is related to its antioxidant potential is still a matter of debate. Recent evidence has shown that VitE reduces hepatic de novo lipogenesis (DNL) through mechanisms dependent on its antioxidant capacity by preventing the maturation and translocation of SREBP-1 to the nucleus [394]. Furthermore, the hydroxyl groups and lipophilic side chain of VitE are required to observe DNL inhibition in HepG2 cells, suggesting that this mechanism is related to its antioxidant activity.

The antioxidant effect of VitE has been linked to the modulation of Nrf2 in several experimental models [395] but has not been fully explored in NAFLD models. For example, VitE has been reported to protect against OS-related liver damage in cadmium-treated rats by promoting the expression of Nrf2 pathway genes and proteins. In addition, recent evidence shows that VitE treatment reduces hepatic steatosis in rats with NAFLD induced by fructose feeding, and this therapeutic effect seems to depend on the activation of Nrf2/carboxylesterase 1 (CES1) signaling, which has also been observed in vitro [396]. However, further studies are needed to explore the effect of VitE on Nrf2 activation and the therapeutic potential of VitE in NAFLD.

VitC is an essential water-soluble vitamin that must be obtained from the diet and cannot be stored in mammals. The therapeutic effect of VitC is not completely cleared. Some studies suggest a moderate association between VitC intake and protection against NAFLD, particularly in men and non-obese patients [397]. Other researchers have demonstrated a therapeutic effect of VitC in NAFLD. In an experimental model of NAFLD, VitC significantly reduced liver histological changes, steatosis, and hepatocellular ballooning. However, the model of NAFLD used (choline-deficient diet) was unable to reflect the hepatic inflammation and histological features of NASH. Therefore, the value of VitC supplementation in NASH currently remains unclear [398]. Guinea pigs, like humans, are unable to synthesize VitC: In these animals, an association between VitC deficiency and the development of NAFLD has been observed [399]. Ascorbic acid supplementation in a HFD model of NAFLD led to a reduction in visceral obesity, inflammation, and apoptosis, most likely by increasing the expression of PPAR $\alpha$ and genes encoding $\beta$-oxidation enzymes. Moreover, studies of the efficacy of VitE/C in NAFLD have demonstrated a clinical response and improved biochemical and histological markers [400]. In any case, whether the reported beneficial effects of VitE/C in NAFLD patients are related to their antioxidant mechanisms remains to be clarified.

\subsection{Coffee Components: Caffeine and Coffee Polyphenols}

Coffee is among the most widely consumed beverages in the world. It contains hundreds if not thousands of different compounds: Many have been proposed to have beneficial effects on human health. Recent epidemiological studies suggest that coffee consumption protects against several chronic liver diseases, including NAFLD [401]. This beneficial effect is partly explained by the presence of caffeine (1,3,7-trimethylxanthine), one of the most abundant components in coffee: As a matter of fact, there is abundant experimental evidence to support its therapeutic effect in the prevention of liver diseases. However, several reports have also demonstrated an inverse association between decaffeinated coffee consumption and hepatic disease, suggesting that the protective effect of coffee is in part due also to its non-caffeine components [402]. 
The molecular mechanisms of the protective effects of coffee are not yet fully elucidated. Evidence suggests a link with the antioxidant response: Coffee consumption has been shown to increase Nrf2 gene transcription in humans, and experimental models of chronic liver disease have shown that coffee extracts enhance the antioxidant response and increase levels of antioxidant enzymes, most likely through modulation of the Nrf2/antioxidant responsive element (ARE) pathway [403].

In addition, it has been shown that caffeine can regulate metabolism and lipid accumulation in several experimental models [404]. Finally, caffeine and paraxanthine metabolites have antioxidant effects also through the modulation of the Nrf2 antioxidant pathway $[176,177]$. Protective effects of caffeine have been reported in several models, mainly through modulation of lipid metabolism [178]. Recent evidence has also shown that caffeine treatment promotes the conversion of SFAs to monounsaturated fatty acids (MUFAs) [405-407].

In addition, caffeine has been shown to improve mitochondrial function and lipid metabolism, in part through activation of AMPK, preventing hepatic steatosis and increasing fat oxidation [405]. Furthermore, it has been suggested that its protective effect against liver damage might be related to cyclic AMP-related pathways [406]. However, the exact molecular mechanisms of caffeine in relation to NAFLD protection have yet to be elucidated, as well as the potential link with the antioxidant response.

Coffee is also an important dietary source of natural antioxidants, particularly polyphenols. Among the polyphenols found in coffee is chlorogenic acid (CGA). The antioxidant properties of CGA have been widely reported. However, the experimental evidence that the protective effect of coffee components on NAFLD is related to antioxidant effects is still unclear [407]. It has been reported that in vitro CGA protects the ER from palmitate-induced stress and apoptosis. Furthermore, based on experimental models of high-fat-/highcarbohydrate-induced NAFLD, CGA has been reported to exhibit hepatoprotective effects, including improved metabolic function, inflammation, and liver histology. Interestingly, CGA protected against acute liver injury in animal models through activation of the Nrf2 pathway and inhibition of the NLRP3 inflammasome [408].

\subsection{Metformin}

Metformin, belonging to the biguanide class of antidiabetic drugs, is used in the treatment of type 2 diabetes due to its anti-hyperglycemic effects. The latter one is, as reported above, closely associated with NAFLD. In addition, several studies have shown that metformin treatment slows the progression of NAFLD due to the improvement of some metabolic parameters. For example, body weight and total body fat mass significantly decreased after 24 weeks of metformin monotherapy in diabetic patients with NAFLD [409]. However, metformin is not yet included in current guidelines for the clinical treatment of NAFLD.

More recently, additional mechanisms have been described to explain the protective effect of metformin in NAFLD, including modulation of gut microbiota composition and decreased levels of bacterial endotoxin [410]. There is also evidence showing that metformin can protect against liver damage by lowering the increase in serum cholesterol, LDL, high-density lipoprotein (HDL), glucose, ALT, and aspartate transaminase (AST) in the liver of HFD-fed mice. Metformin alleviates hepatic steatosis by restoring sirtuin 1 (SIRT1)-mediated autophagy through an AMP-activated protein kinase-independent pathway. These observations show that autophagy is induced by metformin through the protein kinase A (PRKA)-mammalian target of rapamycin (mTOR)-unc-51 like autophagy activating kinase 1 (ULK1) or SIRT1-forkhead box O (FOXO) signaling pathways. Ob/ob mice, after 4 weeks of metformin treatment, showed an increase in autophagy that was related to a decrease in the expression of the signaling adaptor protein sequestosome-1 (SQSTM1/p62). This protein can be degraded by selective autophagy and its protein level is often used as an indicator of autophagic flux [411]. 
Interestingly, metformin has been shown to protect rat primary hepatocytes from oxidative stress-induced apoptosis through induction of HO-1 and inhibition of JNK activation, suggesting a potential therapeutic option for OS-associated liver diseases. Further studies have shown that metformin also protects against palmitate-induced necrosis and apoptosis in primary rat hepatocytes and HepG2 cells, respectively. This protective effect is at least in part due to partial inhibition of mitochondrial complex I, resulting in increased SOD2 expression and reduced ROS production. Metformin has a beneficial effect on HFD-induced NAFLD in rats. This beneficial effect includes improved insulin resistance, reduced expression of phospholipase A2 gene, lowered serum levels of phospholipase A2 and lysophosphatidylcholine, and decreased inflammation and may be related to improved mitochondrial function [412].

Thus, metformin may be useful in the prevention and/or treatment of NAFLD, and its beneficial effects may be partly related to reduced ROS generation in mitochondria.

\subsection{Hesperetin}

Hesperetin is a flavonoid, and its derivatives are found in citrus fruits such as oranges and grapefruits. It has various biological activities, including antioxidant and anti-inflammatory properties in vitro and in vivo. Hesperetin has been shown to attenuate $\mathrm{H}_{2} \mathrm{O}_{2}$-induced damage through direct radical scavenging and by enhancing the antioxidant response through extracellular signal-regulated kinase (ERK)/Nrf2-mediated induction of $\mathrm{HO}-1$. In diabetic rats, antioxidant, anti-inflammatory, and antiangiogenic properties of hesperetin have been reported. Hesperetin significantly attenuated oxidative stress, lipid peroxidation, and ROS production in the brains of rats with $A \beta$-induced neurodegeneration. In addition, markers of apoptosis were significantly attenuated by hesperetin in HT22 cells [413].

Hesperetin has demonstrated hepatoprotective effects both in vitro and in vivo and is able to attenuate liver inflammation and fibrosis in vivo. Furthermore, a recent clinical study demonstrated that hesperidin (structurally related to hesperetin) improves hepatic steatosis, inflammation, and fibrosis, most likely through modulation of the NF-kB pathway [414].

There is also evidence that hesperetin protects primary rat hepatocytes and HepG2 cells from palmitate-induced cell death. High concentrations of hesperetin significantly increased the expression of glucose-regulated protein (GRP) 78 and the level of phospho eukaryotic initiation factor (p-eIF) $2 \alpha$, indicating that hesperetin may attenuate ER stress. Hesperetin has also been shown to reduce acetaminophen-induced phosphorylation of mitogen-activated protein kinases (MAPK) p38 and p65, resulting in decreased levels of the inflammatory cytokines TNF- $\alpha$ and IL-1 $\beta$ [415].

Therefore, hesperetin, by improving redox balance and relieving ER stress, is a potential therapy that could be used in the treatment of NAFLD.

\subsection{Silymarin}

Silymarin is a mixture of flavonolignans and polyphenolic compounds derived from the milk thistle plant, Silybum marianum, used for the treatment of various liver diseases. It has anti-inflammatory, antifibrotic, and antioxidant properties that may be beneficial also in patients with NAFLD [416]. Focusing on its antioxidative effects, they have been demonstrated both in animals and humans. More in detail, silymarin can scavenge ROS and enhance antioxidant enzymes, with an efficacy comparable or event greater than VitE [417]. From a clinical perspective, a meta-analysis of randomized control trials indicated that the compound causes significant reduction of AST and ALT levels [418].

Although other studies demonstrated that silymarin may be able to reduce liver disease progression in NASH [416] and that it could even improve-at least partly-NAFLDassociated cardiovascular disease risk factors (which remain the primary mortality cause in such patients) such as dyslipidemia, vascular dysfunction, hypertension, cardiac ischemia, 
and/or hypertrophy [419], these reports were not confirmed by others [420]. Therefore, routinary silymarin usage, alone or combined with VitE, is not yet recommended.

\subsection{Other Compounds}

There is a number of other drugs that have been tested for their influence on hepatic steatosis and that have still uncertain/elusive molecular mechanisms, with a possible beneficial role against NAFLD-related OS, such as ursodeoxycholic acid (UDCA), obeticholic acid, and cannabidiol [67]. There are also several other innovative agents currently undergoing phases II and III clinical trials with different targets [421].

\section{Conclusions}

Although the knowledge of NAFLD pathogenesis and natural history has greatly expanded in the last decade, many issues remain still unsolved. The purpose of this article was to summarize recent developments in the understanding of NAFLD, essentially focusing on OS as a major pathogenetic mechanism. Among different ROS generators, mitochondria could play a central role and contribute to liver injury caused by FA and/or a wide variety of their biologically active metabolites. Additionally, gut microbiota would be involved in inflammation and oxidation.

Starting from the assumption that OS would represent a trigger factor for NAFLD onset and evolution towards NASH and HCC, it is quite evident that the cornerstone of NAFLD treatment can be represented by the modulation of the balance between the antioxidants/oxidants, which is under the influence of individual genetic and epigenetic factors, as well. Various attempts to translate ROS scavenging by antioxidants into experimental and clinical studies have yielded mostly encouraging results. Among several antioxidants, the use of VitE has been particularly examined in Literature, although results obtained are somehow contradictory. Additionally, studies performed with natural polyphenols, which could be useful for NAFLD prevention and treatment thanks to their antioxidant activities, are quite satisfactory. In addition, probiotics/prebiotics, healthy diet, exercise, or fecal microbiota transplantation would represent new therapeutic approaches to modulate microbiota quality and diversity in order to prevent and/or avoid gut damage and consequent liver OS. Nevertheless, it must be said that most of the molecular targets and the exact cellular mechanisms of these compounds remain to be fully elucidated, and additional studies on their therapeutic potential are needed. Finally, given the importance of genetics in the NAFLD onset, precision medicine taking into consideration genetic/epigenetic factors will likely assist in targeting individualized, appropriate treatments.

As a final remark, it should be also highlighted that the finding of the role of any circulating factors in the NAFLD pathogenesis and evolution could open new frontiers for the early diagnosis of the disease and for the prognosis of patients. In this context, circulating EVs could represent the ideal candidate and would deserve further study.

In conclusion, at the current level of knowledge, the most important problem for OS in NAFLD remains the interpretation and correlation of some results obtained through experimental and clinical studies. A lot of these are difficult to translate into routine clinical practice, aimed at restoring a "healthy" lipid profile and/or reinforcing the antioxidant status, because of a loss of strong evidences that support their application in the therapy of this disease. Certainly, we must admit that the evolution in the comprehension of the mechanisms that support NAFLD has been very fast in the last decade, and, at the same time, the analyzed fields represent some of the most promising topics of scientific research of the future.

Author Contributions: Conceptualization, C.S., E.C. and D.D.B.; methodology, C.C.; software, V.C.; resources, C.S., E.C. and M.P.; data curation, C.S., E.C. and D.D.B.; writing - original draft preparation, C.S., E.G. and M.P.; writing-review and editing, C.S. and R.M.; visualization, E.G. and P.P.S.; supervision, M.P.; project administration, C.S. and V.C.; funding acquisition, C.S. and V.C. All authors have read and agreed to the published version of the manuscript. 
Funding: This research was (partially) supported by FAR (University fund for research)-2019 funding of Università del Piemonte Orientale and by the AGING Project-Departments of ExcellenceDepartment of Translational Medicine, Università del Piemonte Orientale.

Acknowledgments: Carlo Smirne is grateful to Gino Amisano and the Fondazione Valenza Anziani for partially funding his researcher position for studies in internal medicine/geriatric medicine.

Conflicts of Interest: The authors declare no conflict of interest. The funders had no role in the design of the study; in the collection, analyses, or interpretation of data; in the writing of the manuscript; or in the decision to publish the results.

\section{References}

1. $\quad$ Lazarus, J.V.; Mark, H.E.; Anstee, Q.M.; Arab, J.P.; Batterham, R.L.; Castera, L.; Cortez-Pinto, H.; Crespo, J.; Cusi, K.; Dirac, M.A.; et al. Advancing the global public health agenda for NAFLD: A consensus statement. Nat. Rev. Gastroenterol. Hepatol. 2022, 19, 60-78. [CrossRef] [PubMed]

2. Younossi, Z.M.; Marchesini, G.; Pinto-Cortez, H.; Petta, S. Epidemiology of Nonalcoholic Fatty Liver Disease and Nonalcoholic Steatohepatitis: Implications for Liver Transplantation. Transplantation 2019, 103, 22-27. [CrossRef] [PubMed]

3. Younossi, Z.M.; Koenig, A.B.; Abdelatif, D.; Fazel, Y.; Henry, L.; Wymer, M. Global epidemiology of nonalcoholic fatty liver disease-Meta-analytic assessment of prevalence, incidence, and outcomes. Hepatology 2016, 64, 73-84. [CrossRef] [PubMed]

4. Chalasani, N.; Younossi, Z.; Lavine, J.E.; Charlton, M.; Cusi, K.; Rinella, M.; Harrison, S.A.; Brunt, E.M.; Sanyal, A.J. The diagnosis and management of nonalcoholic fatty liver disease: Practice guidance from the American Association for the Study of Liver Diseases. Hepatology 2018, 67, 328-357. [CrossRef]

5. Caligiuri, A.; Gentilini, A.; Marra, F. Molecular Pathogenesis of NASH. Int. J. Mol. Sci. 2016, 17, 1575. [CrossRef]

6. Wong, R.J.; Aguilar, M.; Cheung, R.; Perumpail, R.B.; Harrison, S.A.; Younossi, Z.M.; Ahmed, A. Nonalcoholic steatohepatitis is the second leading etiology of liver disease among adults awaiting liver transplantation in the United States. Gastroenterology 2015, 148, 547-555. [CrossRef]

7. Khan, F.Z.; Perumpail, R.B.; Wong, R.J.; Ahmed, A. Advances in hepatocellular carcinoma: Nonalcoholic steatohepatitis-related hepatocellular carcinoma. World J. Hepatol. 2015, 7, 2155-2161. [CrossRef]

8. Hamaguchi, M.; Kojima, T.; Itoh, Y.; Harano, Y.; Fujii, K.; Nakajima, T.; Kato, T.; Takeda, N.; Okuda, J.; Ida, K.; et al. The severity of ultrasonographic findings in nonalcoholic fatty liver disease reflects the metabolic syndrome and visceral fat accumulation. Am. J. Gastroenterol. 2007, 102, 2708-2715. [CrossRef]

9. Shenoy-Bhangle, A.; Baliyan, V.; Kordbacheh, H.; Guimaraes, A.R.; Kambadakone, A. Diffusion weighted magnetic resonance imaging of liver: Principles, clinical applications and recent updates. World J. Hepatol. 2017, 9, 1081-1091. [CrossRef]

10. Kleiner, D.E.; Brunt, E.M.; Van Natta, M.; Behling, C.; Contos, M.J.; Cummings, O.W.; Ferrell, L.D.; Liu, Y.C.; Torbenson, M.S.; Unalp-Arida, A.; et al. Design and validation of a histological scoring system for nonalcoholic fatty liver disease. Hepatology 2005, 41, 1313-1321. [CrossRef]

11. Takaki, A.; Kawai, D.; Yamamoto, K. Multiple hits, including oxidative stress, as pathogenesis and treatment target in nonalcoholic steatohepatitis (NASH). Int. J. Mol. Sci. 2013, 14, 20704-20728. [CrossRef] [PubMed]

12. Noureddin, M.; Mato, J.M.; Lu, S.C. Nonalcoholic fatty liver disease: Update on pathogenesis, diagnosis, treatment and the role of S-adenosylmethionine. Exp. Biol. Med. 2015, 240, 809-820. [CrossRef] [PubMed]

13. Day, C.P.; James, O.F.W. Steatohepatitis: A tale of two "hits"? Gastroenterology 1998, 114, 842-845. [CrossRef]

14. Ni, M.; Zhang, B.; Zhao, J.; Feng, Q.; Peng, J.; Hu, Y.; Zhao, Y. Biological mechanisms and related natural modulators of liver X receptor in nonalcoholic fatty liver disease. Biomed. Pharmacother. 2019, 113, 108778. [CrossRef] [PubMed]

15. Donnelly, K.L.; Smith, C.I.; Schwarzenberg, S.J.; Jessurun, J.; Boldt, M.D.; Parks, E.J. Sources of fatty acids stored in liver and secreted via lipoproteins in patients with nonalcoholic fatty liver disease. J. Clin. Investig. 2005, 115, 1343-1351. [CrossRef]

16. Targher, G.; Marchesini, G.; Byrne, C.D. Risk of type 2 diabetes in patients with non-alcoholic fatty liver disease: Causal association or epiphenomenon? Diabetes Metab. 2016, 42, 142-156. [CrossRef]

17. Ballestri, S.; Zona, S.; Targher, G.; Romagnoli, D.; Baldelli, E.; Nascimbeni, F.; Roverato, A.; Guaraldi, G.; Lonardo, A. Nonalcoholic fatty liver disease is associated with an almost twofold increased risk of incident type 2 diabetes and metabolic syndrome. Evidence from a systematic review and meta-analysis. J. Gastroenterol. Hepatol. 2016, 31, 936-944. [CrossRef]

18. Dai, W.; Ye, L.; Liu, A.; Wen, S.W.; Deng, J.; Wu, X.; Lai, Z. Prevalence of nonalcoholic fatty liver disease in patients with type 2 diabetes mellitus: A meta-analysis. Medicine 2017, 96, e8179. [CrossRef]

19. Tesfay, M.; Goldkamp, W.J.; Neuschwander-Tetri, B.A. NASH: The Emerging Most Common Form of Chronic Liver Disease. Mo. Med. 2018, 115, 225.

20. Polimeni, L.; del Ben, M.; Baratta, F.; Perri, L.; Albanese, F.; Pastori, D.; Violi, F.; Angelico, F. Oxidative stress: New insights on the association of non-alcoholic fatty liver disease and atherosclerosis. World J. Hepatol. 2015, 7, 1325-1336. [CrossRef]

21. Vergara, D.; Casadei-Gardini, A.; Giudetti, A.M. Oxidative Molecular Mechanisms Underlying Liver Diseases: From Systems Biology to the Personalized Medicine. Oxid. Med. Cell. Longev. 2019, 2019, 7864316. [CrossRef] [PubMed]

22. Angulo, P. Nonalcoholic fatty liver disease. N. Engl. J. Med. 2002, 346, 1221-1231. [CrossRef] [PubMed] 
23. Hruszkewycz, A.M. Evidence for mitochondrial DNA damage by lipid peroxidation. Biochem. Biophys. Res. Commun. 1988, 153, 191-197. [CrossRef]

24. Chen, J.; Schenker, S.; Frosto, T.A.; Henderson, G.I. Inhibition of cytochrome c oxidase activity by 4-hydroxynonenal (HNE). Role of HNE adduct formation with the enzyme subunits. Biochim. Biophys. Acta 1998, 1380, 336-344. [CrossRef]

25. Sanyal, A.J.; Campbell-Sargent, C.; Mirshahi, F.; Rizzo, W.B.; Contos, M.J.; Sterling, R.K.; Luketic, V.A.; Shiffman, M.L.; Clore, J.N. Nonalcoholic steatohepatitis: Association of insulin resistance and mitochondrial abnormalities. Gastroenterology 2001, 120, 1183-1192. [CrossRef]

26. Gambino, R.; Musso, G.; Cassader, M. Redox balance in the pathogenesis of nonalcoholic fatty liver disease: Mechanisms and therapeutic opportunities. Antioxid. Redox Signal. 2011, 15, 1325-1365. [CrossRef]

27. Sastre, J.; Pallardó, F.V.; Llopis, J.; Furukawa, T.; Vinã, J.R.; Viña, J. Glutathione depletion by hyperphagia-induced obesity. Life Sci. 1989, 45, 183-187. [CrossRef]

28. Strauss, R.S.; Barlow, S.E.; Dietz, W.H. Prevelance of abnormal serum aminotransferase values in overweight and obese adolescents. J. Pediatr. 2000, 136, 727-733. [CrossRef]

29. Valenti, L.; Fracanzani, A.L.; Bugianesi, E.; Dongiovanni, P.; Galmozzi, E.; Vanni, E.; Canavesi, E.; Lattuada, E.; Roviaro, G.; Marchesini, G.; et al. HFE genotype, parenchymal iron accumulation, and liver fibrosis in patients with nonalcoholic fatty liver disease. Gastroenterology 2010, 138, 905-912. [CrossRef]

30. George, D.K.; Goldwurm, S.; Macdonald, G.A.; Cowley, L.L.; Walker, N.I.; Ward, P.J.; Jazwinska, E.C.; Powell, L.W. Increased hepatic iron concentration in nonalcoholic steatohepatitis is associated with increased fibrosis. Gastroenterology 1998, 114, 311-318. [CrossRef]

31. Chitturi, S.; Weltman, M.; Farrell, G.C.; McDonald, D.; Liddle, C.; Samarasinghe, D.; Lin, R.; Abeygunasekera, S.; George, J. HFE mutations, hepatic iron, and fibrosis: Ethnic-specific association of NASH with C282Y but not with fibrotic severity. Hepatology 2002, 36, 142-149. [CrossRef] [PubMed]

32. Adams, L.A.; Crawford, D.H.; Stuart, K.; House, M.J.; St. Pierre, T.G.; Webb, M.; Ching, H.L.I.; Kava, J.; Bynevelt, M.; Macquillan, G.C.; et al. The impact of phlebotomy in nonalcoholic fatty liver disease: A prospective, randomized, controlled trial. Hepatology 2015, 61, 1555-1564. [CrossRef] [PubMed]

33. Tarantino, G.; Caputi, A. JNKs, insulin resistance and inflammation: A possible link between NAFLD and coronary artery disease. World J. Gastroenterol. 2011, 17, 3785-3794. [CrossRef] [PubMed]

34. Park, S.H.; Lee, W.Y.; Lee, Y.S.; Rhee, E.J.; Kim, S.W. The relative effects of obesity and insulin resistance on cardiovascular risk factors in nondiabetic and normotensive men. Korean J. Intern. Med. 2004, 19, 75-80. [CrossRef]

35. Loomba, R.; Schork, N.; Chen, C.H.; Bettencourt, R.; Bhatt, A.; Ang, B.; Nguyen, P.; Hernandez, C.; Richards, L.; Salotti, J.; et al. Heritability of Hepatic Fibrosis and Steatosis Based on a Prospective Twin Study. Gastroenterology 2015, 149, 1784-1793. [CrossRef]

36. Eslam, M.; Valenti, L.; Romeo, S. Genetics and epigenetics of NAFLD and NASH: Clinical impact. J. Hepatol. 2018, 68, 268-279. [CrossRef]

37. Dongiovanni, P.; Romeo, S.; Valenti, L. Genetic Factors in the Pathogenesis of Nonalcoholic Fatty Liver and Steatohepatitis. Biomed Res. Int. 2015, 2015, 460190. [CrossRef]

38. Dongiovanni, P.; Valenti, L.; Rametta, R.; Daly, A.K.; Nobili, V.; Mozzi, E.; Leathart, J.B.S.; Pietrobattista, A.; Burt, A.D.; Maggioni, M.; et al. Genetic variants regulating insulin receptor signalling are associated with the severity of liver damage in patients with non-alcoholic fatty liver disease. Gut 2010, 59, 267-273. [CrossRef]

39. Wigg, A.J.; Roberts-Thomson, I.C.; Grose, R.H.; Cummins, A.G.; Dymock, R.B.; McCarthy, P.J. The role of small intestinal bacterial overgrowth, intestinal permeability, endotoxaemia, and tumour necrosis factor alpha in the pathogenesis of non-alcoholic steatohepatitis. Gut 2001, 48, 206-211. [CrossRef]

40. Miele, L.; Valenza, V.; La Torre, G.; Montalto, M.; Cammarota, G.; Ricci, R.; Mascianà, R.; Forgione, A.; Gabrieli, M.L.; Perotti, G.; et al. Increased intestinal permeability and tight junction alterations in nonalcoholic fatty liver disease. Hepatology 2009, 49, 1877-1887. [CrossRef]

41. Cope, K.; Risby, T.; Diehl, A.M. Increased gastrointestinal ethanol production in obese mice: Implications for fatty liver disease pathogenesis. Gastroenterology 2000, 119, 1340-1347. [CrossRef] [PubMed]

42. Roh, Y.S.; Seki, E. Toll-like receptors in alcoholic liver disease, non-alcoholic steatohepatitis and carcinogenesis. J. Gastroenterol. Hepatol. 2013, 28 (Suppl. 1), 38-42. [CrossRef] [PubMed]

43. Neish, A.S. Microbes in gastrointestinal health and disease. Gastroenterology 2009, 136, 65-80. [CrossRef] [PubMed]

44. Miura, K.; Kodama, Y.; Inokuchi, S.; Schnabl, B.; Aoyama, T.; Ohnishi, H.; Olefsky, J.M.; Brenner, D.A.; Seki, E. Toll-like receptor 9 promotes steatohepatitis by induction of interleukin-1beta in mice. Gastroenterology 2010, 139, 323-334.e7. [CrossRef] [PubMed]

45. Petrasek, J.; Dolganiuc, A.; Csak, T.; Kurtjones, E.A.; Szabo, G. Type I interferons protect from Toll-like receptor 9-associated liver injury and regulate IL-1 receptor antagonist in mice. Gastroenterology 2011, 140, 697-708.e4. [CrossRef] [PubMed]

46. Petrasek, J.; Csak, T.; Ganz, M.; Szabo, G. Differences in innate immune signaling between alcoholic and non-alcoholic steatohepatitis. J. Gastroenterol. Hepatol. 2013, 28, 93. [CrossRef]

47. Konerman, M.A.; Jones, J.C.; Harrison, S.A. Pharmacotherapy for NASH: Current and emerging. J. Hepatol. 2018, 68, 362-375 [CrossRef] 
48. Fernández-Sánchez, A.; Madrigal-Santillán, E.; Bautista, M.; Esquivel-Soto, J.; Morales-González, Á.; Esquivel-Chirino, C.; Durante-Montiel, I.; Sánchez-Rivera, G.; Valadez-Vega, C.; Morales-González, J.A. Inflammation, oxidative stress, and obesity. Int. J. Mol. Sci. 2011, 12, 3117-3132. [CrossRef]

49. Spahis, S.; Delvin, E.; Borys, J.M.; Levy, E. Oxidative Stress as a Critical Factor in Nonalcoholic Fatty Liver Disease Pathogenesis. Antioxid. Redox Signal. 2017, 26, 519-541. [CrossRef]

50. Masarone, M.; Rosato, V.; Dallio, M.; Gravina, A.G.; Aglitti, A.; Loguercio, C.; Federico, A.; Persico, M. Corrigendum to “Role of Oxidative Stress in Pathophysiology of Nonalcoholic Fatty Liver Disease". Oxid. Med. Cell. Longev. 2021, $2021,9757921$. [CrossRef]

51. Klisic, A.; Kavaric, N.; Ninic, A.; Kotur-Stevuljevic, J. Oxidative stress and cardiometabolic biomarkers in patients with nonalcoholic fatty liver disease. Sci. Rep. 2021, 11, S41598-S416021. [CrossRef] [PubMed]

52. Warolin, J.; Coenen, K.R.; Kantor, J.L.; Whitaker, L.E.; Wang, L.; Acra, S.A.; Roberts, L.J.; Buchowski, M.S. The relationship of oxidative stress, adiposity and metabolic risk factors in healthy Black and White American youth. Pediatr. Obes. 2014, 9, 43-52. [CrossRef] [PubMed]

53. Codoñer-Franch, P.; Tavárez-Alonso, S.; Murria-Estal, R.; Tortajada-Girbés, M.; Simó-Jordá, R.; Alonso-Iglesias, E. Elevated advanced oxidation protein products (AOPPs) indicate metabolic risk in severely obese children. Nutr. Metab. Cardiovasc. Dis. 2012, 22, 237-243. [CrossRef] [PubMed]

54. Hermsdorff, H.H.M.; Barbosa, K.B.; Volp, A.C.P.; Puchau, B.; Bressan, J.; Zulet, M.Á.; Martínez, J.A. Gender-specific relationships between plasma oxidized low-density lipoprotein cholesterol, total antioxidant capacity, and central adiposity indicators. Eur. $J$. Prev. Cardiol. 2014, 21, 884-891. [CrossRef]

55. Karaouzene, N.; Merzouk, H.; Aribi, M.; Merzouk, S.A.; Yahia Berrouiguet, A.; Tessier, C.; Narce, M. Effects of the association of aging and obesity on lipids, lipoproteins and oxidative stress biomarkers: A comparison of older with young men. Nutr. Metab. Cardiovasc. Dis. 2011, 21, 792-799. [CrossRef]

56. Gabbia, D.; Cannella, L.; Martin, S. De The Role of Oxidative Stress in NAFLD-NASH-HCC Transition-Focus on NADPH Oxidases. Biomedicines 2021, 9, 687. [CrossRef]

57. Sies, H.; Stahl, W.; Sevanian, A. Nutritional, dietary and postprandial oxidative stress. J. Nutr. 2005, 135, 96-972. [CrossRef]

58. Dandona, P.; Ghanim, H.; Chaudhuri, A.; Dhindsa, S.; Kim, S.S. Macronutrient intake induces oxidative and inflammatory stress: Potential relevance to atherosclerosis and insulin resistance. Exp. Mol. Med. 2010, 42, 245-253. [CrossRef]

59. Serra, D.; Mera, P.; Malandrino, M.I.; Mir, J.F.; Herrero, L. Mitochondrial fatty acid oxidation in obesity. Antioxid. Redox Signal. 2013, 19, 269-284. [CrossRef]

60. Fujii, J.; Homma, T.; Kobayashi, S.; Seo, H.G. Mutual interaction between oxidative stress and endoplasmic reticulum stress in the pathogenesis of diseases specifically focusing on non-alcoholic fatty liver disease. World J. Biol. Chem. 2018, 9, 1-15. [CrossRef]

61. Arroyave-Ospina, J.C.; Wu, Z.; Geng, Y.; Moshage, H. Role of Oxidative Stress in the Pathogenesis of Non-Alcoholic Fatty Liver Disease: Implications for Prevention and Therapy. Antioxidants 2021, 10, 174. [CrossRef] [PubMed]

62. Furukawa, S.; Fujita, T.; Shimabukuro, M.; Iwaki, M.; Yamada, Y.; Nakajima, Y.; Nakayama, O.; Makishima, M.; Matsuda, M.; Shimomura, I. Increased oxidative stress in obesity and its impact on metabolic syndrome. J. Clin. Investig. 2004, 114, 1752-1761. [CrossRef] [PubMed]

63. Mlinar, B.; Marc, J. New insights into adipose tissue dysfunction in insulin resistance. Clin. Chem. Lab. Med. 2011, 49, 1925-1935. [CrossRef] [PubMed]

64. Patel, C.; Ghanim, H.; Ravishankar, S.; Chang, L.S.; Viswanathan, P.; Mohanty, P.; Dandona, P. Prolonged reactive oxygen species generation and nuclear factor-kappaB activation after a high-fat, high-carbohydrate meal in the obese. J. Clin. Endocrinol. Metab. 2007, 92, 4476-4479. [CrossRef]

65. Bełtowski, J. Leptin and the regulation of endothelial function in physiological and pathological conditions. Clin. Exp. Pharmacol. Physiol. 2012, 39, 168-178. [CrossRef]

66. Bondia-Pons, I.; Ryan, L.; Martinez, J.A. Oxidative stress and inflammation interactions in human obesity. J. Physiol. Biochem. 2012, 68, 701-711. [CrossRef]

67. Delli Bovi, A.P.; Marciano, F.; Mandato, C.; Siano, M.A.; Savoia, M.; Vajro, P. Oxidative Stress in Non-alcoholic Fatty Liver Disease. An Updated Mini Review. Front. Med. 2021, 8, 595371. [CrossRef]

68. Chen, Z.; Tian, R.; She, Z.; Cai, J.; Li, H. Role of oxidative stress in the pathogenesis of nonalcoholic fatty liver disease. Free Radic. Biol. Med. 2020, 152, 116-141. [CrossRef]

69. Dandona, P.; Aljada, A.; Chaudhuri, A.; Mohanty, P.; Garg, R. Metabolic syndrome: A comprehensive perspective based on interactions between obesity, diabetes, and inflammation. Circulation 2005, 111, 1448-1454. [CrossRef]

70. Crujeiras, A.B.; Díaz-Lagares, A.; Carreira, M.C.; Amil, M.; Casanueva, F.F. Oxidative stress associated to dysfunctional adipose tissue: A potential link between obesity, type 2 diabetes mellitus and breast cancer. Free Radic. Res. 2013, 47, 243-256. [CrossRef]

71. Li, S.; Hong, M.; Tan, H.Y.; Wang, N.; Feng, Y. Insights into the Role and Interdependence of Oxidative Stress and Inflammation in Liver Diseases. Oxid. Med. Cell. Longev. 2016, 2016, 4234061. [CrossRef] [PubMed]

72. Karkucinska-Wieckowska, A.; Simoes, I.C.M.; Kalinowski, P.; Lebiedzinska-Arciszewska, M.; Zieniewicz, K.; Milkiewicz, P.; Górska-Ponikowska, M.; Pinton, P.; Malik, A.N.; Krawczyk, M.; et al. Mitochondria, oxidative stress and nonalcoholic fatty liver disease: A complex relationship. Eur. J. Clin. Investig. 2021, e13622. [CrossRef] [PubMed] 
73. Kanikowska, D.; Kanikowska, A.; Swora-Cwynar, E.; Grzymisławski, M.; Sato, M.; Bręborowicz, A.; Witowski, J.; Korybalska, K. Moderate Caloric Restriction Partially Improved Oxidative Stress Markers in Obese Humans. Antioxidants 2021, 10, 1018. [CrossRef] [PubMed]

74. Bigornia, S.J.; Mott, M.M.; Hess, D.T.; Apovian, C.M.; McDonnell, M.E.; Duess, M.A.; Kluge, M.A.; Fiscale, A.J.; Vita, J.A.; Gokce, N. Long-term successful weight loss improves vascular endothelial function in severely obese individuals. Obesity 2010, 18, 754-759. [CrossRef] [PubMed]

75. Świderska, M.; Maciejczyk, M.; Zalewska, A.; Pogorzelska, J.; Flisiak, R.; Chabowski, A. Oxidative stress biomarkers in the serum and plasma of patients with non-alcoholic fatty liver disease (NAFLD). Can plasma AGE be a marker of NAFLD? Oxidative stress biomarkers in NAFLD patients. Free Radic. Res. 2019, 53, 841-850. [CrossRef]

76. Kim, H.J.; Lee, Y.; Fang, S.; Kim, W.; Kim, H.J.; Kim, J. woo GPx7 ameliorates non-alcoholic steatohepatitis by regulating oxidative stress. BMB Rep. 2020, 53, 317-322. [CrossRef]

77. Simon, J.; Nuñez-García, M.; Fernández-Tussy, P.; Barbier-Torres, L.; Fernández-Ramos, D.; Gómez-Santos, B.; Buqué, X.; LopitzOtsoa, F.; Goikoetxea-Usandizaga, N.; Serrano-Macia, M.; et al. Targeting hepatic Glutaminase 1 ameliorates Non-Alcoholic Steatohepatitis by restoring Very-Low Density Lipoproteins triglyceride assembly. Cell Metab. 2020, 31, 605. [CrossRef]

78. Milaciu, M.V.; Vesa, S.C.; Bocșan, I.C.; Ciumărnean, L.; Sâmpelean, D.; Negrean, V.; Pop, R.M.; Matei, D.M.; Pașca, S.; Răchișan, A.L.; et al. Paraoxonase-1 Serum Concentration and PON1 Gene Polymorphisms: Relationship with Non-Alcoholic Fatty Liver Disease. J. Clin. Med. 2019, 8, 2200. [CrossRef]

79. Shin, S.K.; Cho, H.W.; Song, S.E.; Song, D.K. Catalase and nonalcoholic fatty liver disease. Pflugers Arch. 2018, 470, 1721-1737. [CrossRef]

80. Hwang, I.; Uddin, M.J.; Pak, E.S.; Kang, H.; Jin, E.J.; Jo, S.; Kang, D.; Lee, H.; Ha, H. The impaired redox balance in peroxisomes of catalase knockout mice accelerates nonalcoholic fatty liver disease through endoplasmic reticulum stress. Free Radic. Biol. Med. 2020, 148, 22-32. [CrossRef]

81. Nerstedt, A.; Kurhe, Y.; Cansby, E.; Caputo, M.; Gao, L.; Vorontsov, E.; Ståhlman, M.; Nuñez-Durán, E.; Borén, J.; Marschall, H.U.; et al. Lipid droplet-associated kinase STK25 regulates peroxisomal activity and metabolic stress response in steatotic liver. J. Lipid Res. 2020, 61, 178-191. [CrossRef] [PubMed]

82. St-Pierre, J.; Buckingham, J.A.; Roebuck, S.J.; Brand, M.D. Topology of superoxide production from different sites in the mitochondrial electron transport chain. J. Biol. Chem. 2002, 277, 44784-44790. [CrossRef] [PubMed]

83. Esterbauer, H.; Schaur, R.J.; Zollner, H. Chemistry and biochemistry of 4-hydroxynonenal, malonaldehyde and related aldehydes Free Radic. Biol. Med. 1991, 11, 81-128. [CrossRef]

84. Gardner, H.W. Oxygen radical chemistry of polyunsaturated fatty acids. Free Radic. Biol. Med. 1989, 7, 65-86. [CrossRef]

85. Demeilliers, C.; Maisonneuve, C.; Grodet, A.; Mansouri, A.; Nguyen, R.; Tinel, M.; Lettéron, P.; Degott, C.; Feldmann, G.; Pessayre, D.; et al. Impaired adaptive resynthesis and prolonged depletion of hepatic mitochondrial DNA after repeated alcohol binges in mice. Gastroenterology 2002, 123, 1278-1290. [CrossRef]

86. Pérez-Carreras, M.; Del Hoyo, P.; Martín, M.A.; Rubio, J.C.; Martín, A.; Castellano, G.; Colina, F.; Arenas, J.; Solis-Herruzo, J.A. Defective hepatic mitochondrial respiratory chain in patients with nonalcoholic steatohepatitis. Hepatology 2003, 38, 999-1007. [CrossRef]

87. Ayala, A.; Muñoz, M.F.; Argüelles, S. Lipid peroxidation: Production, metabolism, and signaling mechanisms of malondialdehyde and 4-hydroxy-2-nonenal. Oxid. Med. Cell. Longev. 2014, 2014, 360438. [CrossRef]

88. Lukosz, M.; Jakob, S.; Büchner, N.; Zschauer, T.C.; Altschmied, J.; Haendeler, J. Nuclear redox signaling. Antioxid. Redox Signal. 2010, 12, 713-742. [CrossRef]

89. Schafer, F.Q.; Buettner, G.R. Redox environment of the cell as viewed through the redox state of the glutathione disulfide/glutathione couple. Free Radic. Biol. Med. 2001, 30, 1191-1212. [CrossRef]

90. Ying, W. NAD+/NADH and NADP+/NADPH in cellular functions and cell death: Regulation and biological consequences Antioxid. Redox Signal. 2008, 10, 179-206. [CrossRef]

91. Sunny, N.E.; Parks, E.J.; Browning, J.D.; Burgess, S.C. Excessive hepatic mitochondrial TCA cycle and gluconeogenesis in humans with nonalcoholic fatty liver disease. Cell Metab. 2011, 14, 804-810. [CrossRef] [PubMed]

92. Serviddio, G.; Bellanti, F.; Tamborra, R.; Rollo, T.; Capitanio, N.; Romano, A.D.; Sastre, J.; Vendemiale, G.; Altomare, E. Uncoupling protein-2 (UCP2) induces mitochondrial proton leak and increases susceptibility of non-alcoholic steatohepatitis (NASH) liver to ischaemia-reperfusion injury. Gut 2008, 57, 957-965. [CrossRef] [PubMed]

93. Thomas, J.; Debeer, L.J.; Mannaerts, G.P.; De Schepper, P.J. Mitochondrial and peroxisomal fatty acid oxidation in liver homogenates from control and clofibrate-treated rats [proceedings]. Arch. Int. Physiol. Biochim. 1979, 87, 209-210. [PubMed]

94. Robertson, G.; Leclercq, I.; Farrell, G.C. Nonalcoholic steatosis and steatohepatitis. II. Cytochrome P-450 enzymes and oxidative stress. Am. J. Physiol. Gastrointest. Liver Physiol. 2001, 281, G1135-G1139. [CrossRef]

95. De Craemer, D.; Pauwels, M.; Van den Branden, C. Alterations of peroxisomes in steatosis of the human liver: A quantitative study. Hepatology 1995, 22, 744-752. [CrossRef]

96. Natarajan, S.K.; Eapen, C.E.; Pullimood, A.B.; Balasubramanian, K.A. Oxidative stress in experimental liver microvesicular steatosis: Role of mitochondria and peroxisomes. J. Gastroenterol. Hepatol. 2006, 21, 1240-1249. [CrossRef]

97. Katsiki, N.; Mikhailidis, D.P.; Mantzoros, C.S. Non-alcoholic fatty liver disease and dyslipidemia: An update. Metabolism 2016, 65, 1109-1123. [CrossRef] 
98. Machado, M.V.; Cortez-Pinto, H. Diet, Microbiota, Obesity, and NAFLD: A Dangerous Quartet. Int. J. Mol. Sci. 2016, 17, 481. [CrossRef]

99. Lonardo, A.; Ballestri, S.; Marchesini, G.; Angulo, P.; Loria, P. Nonalcoholic fatty liver disease: A precursor of the metabolic syndrome. Dig. Liver Dis. 2015, 47, 181-190. [CrossRef]

100. Aron-Wisnewsky, J.; Clement, K.; Pépin, J.L. Nonalcoholic fatty liver disease and obstructive sleep apnea. Metabolism 2016, 65, 1124-1135. [CrossRef]

101. Del Ben, M.; Polimeni, L.; Carnevale, R.; Bartimoccia, S.; Nocella, C.; Baratta, F.; Loffredo, L.; Pignatelli, P.; Violi, F.; Angelico, F. NOX2-generated oxidative stress is associated with severity of ultrasound liver steatosis in patients with non-alcoholic fatty liver disease. BMC Gastroenterol. 2014, 14, 81. [CrossRef]

102. De Minicis, S.; Bataller, R.; Brenner, D.A. NADPH oxidase in the liver: Defensive, offensive, or fibrogenic? Gastroenterology 2006, 131, 272-275. [CrossRef] [PubMed]

103. Jiang, J.X.; Venugopal, S.; Serizawa, N.; Chen, X.; Scott, F.; Li, Y.; Adamson, R.; Devaraj, S.; Shah, V.; Gershwin, M.E.; et al Reduced nicotinamide adenine dinucleotide phosphate oxidase 2 plays a key role in stellate cell activation and liver fibrogenesis in vivo. Gastroenterology 2010, 139, 1375-1384. [CrossRef] [PubMed]

104. Singh, C.K.; Chhabra, G.; Ndiaye, M.A.; Garcia-Peterson, L.M.; MacK, N.J.; Ahmad, N. The Role of Sirtuins in Antioxidant and Redox Signaling. Antioxid. Redox Signal. 2018, 28, 643-661. [CrossRef] [PubMed]

105. El-Benna, J.; Dang, P.M.C.; Gougerot-Pocidalo, M.A.; Marie, J.C.; Braut-Boucher, F. p47phox, the phagocyte NADPH oxidase/NOX2 organizer: Structure, phosphorylation and implication in diseases. Exp. Mol. Med. 2009, 41, 217-225. [CrossRef]

106. De Minicis, S.; Seki, E.; Oesterreicher, C.; Schnabl, B.; Schwabe, R.F.; Brenner, D.A. Reduced nicotinamide adenine dinucleotide phosphate oxidase mediates fibrotic and inflammatory effects of leptin on hepatic stellate cells. Hepatology 2008, 48, 2016-2026. [CrossRef]

107. Pastori, D.; Baratta, F.; Carnevale, R.; Cangemi, R.; Del Ben, M.; Bucci, T.; Polimeni, L.; Labbadia, G.; Nocella, C.; Scardella, L.; et al. Similar Reduction of Cholesterol-Adjusted Vitamin E Serum Levels in Simple Steatosis and Non-Alcoholic Steatohepatitis. Clin. Transl. Gastroenterol. 2015, 6, e113. [CrossRef]

108. Pastori, D.; Loffredo, L.; Perri, L.; Baratta, F.; Scardella, L.; Polimeni, L.; Pani, A.; Brancorsini, M.; Albanese, F.; Catasca, E.; et al. Relation of nonalcoholic fatty liver disease and Framingham Risk Score to flow-mediated dilation in patients with cardiometabolic risk factors. Am. J. Cardiol. 2015, 115, 1402-1406. [CrossRef]

109. Lin, X.; Zhang, X.; Guo, J.; Roberts, C.K.; McKenzie, S.; Wu, W.C.; Liu, S.; Song, Y. Effects of Exercise Training on Cardiorespiratory Fitness and Biomarkers of Cardiometabolic Health: A Systematic Review and Meta-Analysis of Randomized Controlled Trials. J. Am. Heart Assoc. 2015, 4, e002014. [CrossRef]

110. Violi, F.; Loffredo, L.; Carnevale, R.; Pignatelli, P.; Pastori, D. Atherothrombosis and Oxidative Stress: Mechanisms and Management in Elderly. Antioxid. Redox Signal. 2017, 27, 1083-1124. [CrossRef]

111. Kattoor, A.J.; Pothineni, N.V.K.; Palagiri, D.; Mehta, J.L. Oxidative Stress in Atherosclerosis. Curr. Atheroscler. Rep. $2017,19,42$. [CrossRef] [PubMed]

112. Libby, P. Inflammation in atherosclerosis. Nature 2002, 420, 868-874. [CrossRef] [PubMed]

113. Sanchez-Valle, V.; Chavez-Tapia, N.C.; Uribe, M.; Mendez-Sanchez, N. Role of oxidative stress and molecular changes in liver fibrosis: A review. Curr. Med. Chem. 2012, 19, 4850-4860. [CrossRef] [PubMed]

114. Sun, X.; Seidman, J.S.; Zhao, P.; Troutman, T.D.; Spann, N.J.; Que, X.; Zhou, F.; Liao, Z.; Pasillas, M.; Yang, X.; et al. Neutralization of Oxidized Phospholipids Ameliorates Non-alcoholic Steatohepatitis. Cell Metab. 2019, 31, 189-206.e8. [CrossRef]

115. Gan, L.T.; Van Rooyen, D.M.; Koina, M.E.; McCuskey, R.S.; Teoh, N.C.; Farrell, G.C. Hepatocyte free cholesterol lipotoxicity results from JNK1-mediated mitochondrial injury and is HMGB1 and TLR4-dependent. J. Hepatol. 2014, 61, 1376-1384. [CrossRef] [PubMed]

116. Shepard, C.R. TLR9 in MAFLD and NASH: At the Intersection of Inflammation and Metabolism. Front. Endocrinol. 2021, 11, 613639. [CrossRef] [PubMed]

117. Koliaki, C.; Szendroedi, J.; Kaul, K.; Jelenik, T.; Nowotny, P.; Jankowiak, F.; Herder, C.; Carstensen, M.; Krausch, M.; Knoefel, W.T.; et al. Adaptation of hepatic mitochondrial function in humans with non-alcoholic fatty liver is lost in steatohepatitis. Cell Metab. 2015, 21, 739-746. [CrossRef]

118. Ouyang, X.; Han, S.N.; Zhang, J.Y.; Nemeth, B.T.; Pacher, P.; Feng, D.; Bataller, R.; Cabezas, J.; Stärkel, P.; Caballeria, J.; et al. Digoxin Suppresses Pyruvate Kinase M2-Promoted HIF-1 $\alpha$ Transactivation in Steatohepatitis. Cell Metab. 2018, 27, 339-350.e3. [CrossRef]

119. Peters, K.M.; Wilson, R.B.; Borradaile, N.M. Non-parenchymal hepatic cell lipotoxicity and the coordinated progression of non-alcoholic fatty liver disease and atherosclerosis. Curr. Opin. Lipidol. 2018, 29, 417-422. [CrossRef]

120. Bataller, R.; Schwabe, R.F.; Choi, Y.H.; Yang, L.; Paik, Y.H.; Lindquist, J.; Qian, T.; Schoonhoven, R.; Hagedorn, C.H.; Lemasters, J.J.; et al. NADPH oxidase signal transduces angiotensin II in hepatic stellate cells and is critical in hepatic fibrosis. J. Clin. Investig. 2003, 112, 1383-1394. [CrossRef]

121. Paik, Y.H.; Iwaisako, K.; Seki, E.; Inokuchi, S.; Schnabl, B.; Österreicher, C.H.; Kisseleva, T.; Brenner, D.A. The nicotinamide adenine dinucleotide phosphate oxidase (NOX) homologues NOX1 and NOX2/gp91(phox) mediate hepatic fibrosis in mice. Hepatology 2011, 53, 1730-1741. [CrossRef] [PubMed] 
122. Thuy, L.T.T.; Hai, H.; Kawada, N. Role of cytoglobin, a novel radical scavenger, in stellate cell activation and hepatic fibrosis. Clin. Mol. Hepatol. 2020, 26, 280. [CrossRef] [PubMed]

123. Hammoutene, A.; Rautou, P.E. Role of liver sinusoidal endothelial cells in non-alcoholic fatty liver disease. J. Hepatol. 2019, 70, 1278-1291. [CrossRef] [PubMed]

124. Meijnikman, A.S.; Herrema, H.; Scheithauer, T.P.M.; Kroon, J.; Nieuwdorp, M.; Groen, A.K. Evaluating causality of cellular senescence in non-alcoholic fatty liver disease. JHEP Rep. Innov. Hepatol. 2021, 3, 100301. [CrossRef]

125. Oliveira-Marques, V.; Marinho, H.S.; Cyrne, L.; Antunes, F. Role of hydrogen peroxide in NF-kappaB activation: From inducer to modulator. Antioxid. Redox Signal. 2009, 11, 2223-2243. [CrossRef]

126. de Gregorio, E.; Colell, A.; Morales, A.; Marí, M. Relevance of SIRT1-NF-кB Axis as Therapeutic Target to Ameliorate Inflammation in Liver Disease. Int. J. Mol. Sci. 2020, 21, 3858. [CrossRef]

127. Komeili-Movahhed, T.; Bassirian, M.; Changizi, Z.; Moslehi, A. SIRT1/NFkB pathway mediates anti-inflammatory and antiapoptotic effects of rosmarinic acid on in a mouse model of nonalcoholic steatohepatitis (NASH). J. Recept. Signal Transduct. Res. 2021, 1-10. [CrossRef]

128. Vasileva, L.V.; Savova, M.S.; Amirova, K.M.; Dinkova-Kostova, A.T.; Georgiev, M.I. Obesity and NRF2-mediated cytoprotection: Where is the missing link? Pharmacol. Res. 2020, 156, 104760. [CrossRef]

129. Solano-Urrusquieta, A.; Morales-González, J.A.; Castro-Narro, G.E.; Cerda-Reyes, E.; Flores-Rangel, P.D.; Fierros-Oceguera, R NRF-2 and nonalcoholic fatty liver disease. Ann. Hepatol. 2020, 19, 458-465. [CrossRef]

130. Sharma, R.S.; Harrison, D.J.; Kisielewski, D.; Cassidy, D.M.; McNeilly, A.D.; Gallagher, J.R.; Walsh, S.V.; Honda, T.; McCrimmon, R.J.; Dinkova-Kostova, A.T.; et al. Experimental Nonalcoholic Steatohepatitis and Liver Fibrosis Are Ameliorated by Pharmacologic Activation of Nrf2 (NF-E2 p45-Related Factor 2). Cell. Mol. Gastroenterol. Hepatol. 2017, 5, 367-398. [CrossRef]

131. Meakin, P.J.; Chowdhry, S.; Sharma, R.S.; Ashford, F.B.; Walsh, S.V.; McCrimmon, R.J.; Dinkova-Kostova, A.T.; Dillon, J.F.; Hayes, J.D.; Ashford, M.L.J. Susceptibility of Nrf2-null mice to steatohepatitis and cirrhosis upon consumption of a high-fat diet is associated with oxidative stress, perturbation of the unfolded protein response, and disturbance in the expression of metabolic enzymes but not with insulin resistance. Mol. Cell. Biol. 2014, 34, 3305-3320. [CrossRef] [PubMed]

132. Mohs, A.; Otto, T.; Schneider, K.M.; Peltzer, M.; Boekschoten, M.; Holland, C.H.; Hudert, C.A.; Kalveram, L.; Wiegand, S.; Saez-Rodriguez, J.; et al. Hepatocyte-specific NRF2 activation controls fibrogenesis and carcinogenesis in steatohepatitis. J. Hepatol. 2021, 74, 638-648. [CrossRef] [PubMed]

133. Yu, H.; Jiang, X.; Dong, F.; Zhang, F.; Ji, X.; Xue, M.; Yang, F.; Chen, J.; Hu, X.; Bao, Z. Lipid accumulation-induced hepatocyte senescence regulates the activation of hepatic stellate cells through the Nrf2-antioxidant response element pathway. Exp. Cell Res. 2021, 405, 112689. [CrossRef] [PubMed]

134. Das, D.; Paul, A.; Lahiri, A.; Adak, M.; Maity, S.K.; Sarkar, A.; Paul, S.; Chakrabarti, P. Proteasome dysfunction under compromised redox metabolism dictates liver injury in NASH through ASK1/PPAR $\gamma$ binodal complementary modules. Redox Biol. 2021, 45, 102043. [CrossRef]

135. Liu, G.H.; Qu, J.; Shen, X. NF-kappaB/p65 antagonizes Nrf2-ARE pathway by depriving CBP from Nrf2 and facilitating recruitment of HDAC3 to MafK. Biochim. Biophys. Acta 2008, 1783, 713-727. [CrossRef]

136. Saha, S.; Buttari, B.; Panieri, E.; Profumo, E.; Saso, L. An Overview of Nrf2 Signaling Pathway and Its Role in Inflammation. Molecules 2020, 25, 5474. [CrossRef]

137. Tacke, F. Targeting hepatic macrophages to treat liver diseases. J. Hepatol. 2017, 66, 1300-1312. [CrossRef]

138. Friedman, S.L.; Neuschwander-Tetri, B.A.; Rinella, M.; Sanyal, A.J. Mechanisms of NAFLD development and therapeutic strategies. Nat. Med. 2018, 24, 908-922. [CrossRef]

139. Tang, Y.; Bian, Z.; Zhao, L.; Liu, Y.; Liang, S.; Wang, Q.; Han, X.; Peng, Y.; Chen, X.; Shen, L.; et al. Interleukin-17 exacerbates hepatic steatosis and inflammation in non-alcoholic fatty liver disease. Clin. Exp. Immunol. 2011, 166, 281-290. [CrossRef]

140. Luo, X.Y.; Takahara, T.; Kawai, K.; Fujino, M.; Sugiyama, T.; Tsuneyama, K.; Tsukada, K.; Nakae, S.; Zhong, L.; Li, X.K. IFN- $\gamma$ deficiency attenuates hepatic inflammation and fibrosis in a steatohepatitis model induced by a methionine- and choline-deficient high-fat diet. Am. J. Physiol. Gastrointest. Liver Physiol. 2013, 305, G891-G899. [CrossRef]

141. Wolf, M.J.; Adili, A.; Piotrowitz, K.; Abdullah, Z.; Boege, Y.; Stemmer, K.; Ringelhan, M.; Simonavicius, N.; Egger, M.; Wohlleber, D.; et al. Metabolic activation of intrahepatic CD8+ T cells and NKT cells causes nonalcoholic steatohepatitis and liver cancer via cross-talk with hepatocytes. Cancer Cell 2014, 26, 549-564. [CrossRef]

142. Wikenheiser, D.J.; Stumhofer, J.S. ICOS Co-Stimulation: Friend or Foe? Front. Immunol. 2016, 7, 304. [CrossRef] [PubMed]

143. Li, D.Y.; Xiong, X.Z. ICOS + Tregs: A Functional Subset of Tregs in Immune Diseases. Front. Immunol. 2020, 11, 2104. [CrossRef] [PubMed]

144. Tang, G.; Qin, Q.; Zhang, P.; Wang, G.; Liu, M.; Ding, Q.; Qin, Y.; Shen, Q. Reverse signaling using an inducible costimulator to enhance immunogenic function of dendritic cells. Cell. Mol. Life Sci. 2009, 66, 3067-3080. [CrossRef] [PubMed]

145. Occhipinti, S.; Dianzani, C.; Chiocchetti, A.; Boggio, E.; Clemente, N.; Gigliotti, C.L.; Soluri, M.F.; Minelli, R.; Fantozzi, R.; Yagi, J.; et al. Triggering of B7h by the ICOS modulates maturation and migration of monocyte-derived dendritic cells. J. Immunol. 2013, 190, 1125-1134. [CrossRef]

146. Gigliotti, C.L.; Boggio, E.; Clemente, N.; Shivakumar, Y.; Toth, E.; Sblattero, D.; D'Amelio, P.; Isaia, G.C.; Dianzani, C.; Yagi, J.; et al. ICOS-Ligand Triggering Impairs Osteoclast Differentiation and Function In Vitro and In Vivo. J. Immunol. 2016, 197, 3905-3916. [CrossRef] 
147. Koh, K.H.; Cao, Y.; Mangos, S.; Tardi, N.J.; Dande, R.R.; Lee, H.W.; Samelko, B.; Altintas, M.M.; Schmitz, V.P.; Lee, H.; et al. Nonimmune cell-derived ICOS ligand functions as a renoprotective $\alpha \mathrm{v} \beta 3$ integrin-selective antagonist. J. Clin. Investig. 2019, 129, 1713-1726. [CrossRef]

148. Ramavath, N.N.; Gadipudiaik, L.I.; Provera, A.; Gigliotti, L.C.; Boggio, E.; Clemente, N.; Dianzani, U.; Albano, E.; Sutti, S. Co-stimulatory signals mediated by ICOS/ICOS-L dyad influence the differentiation of liver NASH-associated macrophages (NAMs). In Abstracts of The International Liver Congress ${ }^{\mathrm{TM}}$ 2021, Proceedings of the International Liver Congress (ILC), Digital, 23-26 June 2021. J. Hepatol. 2021, 75, S598.

149. Wei, Y.; Rector, R.S.; Thyfault, J.P.; Ibdah, J.A. Nonalcoholic fatty liver disease and mitochondrial dysfunction. World J. Gastroenterol. 2008, 14, 193-199. [CrossRef]

150. Nassir, F.; Ibdah, J.A. Role of mitochondria in nonalcoholic fatty liver disease. Int. J. Mol. Sci. 2014, 15, 8713-8742. [CrossRef]

151. Dornas, W.; Schuppan, D. Mitochondrial oxidative injury: A key player in nonalcoholic fatty liver disease. Am. J. Physiol. Gastrointest. Liver Physiol. 2020, 319, G400-G411. [CrossRef] [PubMed]

152. Mantena, S.K.; King, A.L.; Andringa, K.K.; Eccleston, H.B.; Bailey, S.M. Mitochondrial dysfunction and oxidative stress in the pathogenesis of alcohol- and obesity-induced fatty liver diseases. Free Radic. Biol. Med. 2008, 44, 1259-1272. [CrossRef] [PubMed]

153. Simões, I.C.M.; Fontes, A.; Pinton, P.; Zischka, H.; Wieckowski, M.R. Mitochondria in non-alcoholic fatty liver disease. Int. J. Biochem. Cell Biol. 2018, 95, 93-99. [CrossRef] [PubMed]

154. Meex, R.C.R.; Blaak, E.E. Mitochondrial Dysfunction is a Key Pathway that Links Saturated Fat Intake to the Development and Progression of NAFLD. Mol. Nutr. Food Res. 2021, 65, e1900942. [CrossRef]

155. Begriche, K.; Massart, J.; Robin, M.A.; Bonnet, F.; Fromenty, B. Mitochondrial adaptations and dysfunctions in nonalcoholic fatty liver disease. Hepatology 2013, 58, 1497-1507. [CrossRef]

156. Satapati, S.; Kucejova, B.; Duarte, J.A.G.; Fletcher, J.A.; Reynolds, L.; Sunny, N.E.; He, T.; Arya Nair, L.; Livingston, K.; Fu, X.; et al. Mitochondrial metabolism mediates oxidative stress and inflammation in fatty liver. J. Clin. Investig. 2015, 125, 4447-4462. [CrossRef]

157. Satapati, S.; Sunny, N.E.; Kucejova, B.; Fu, X.; He, T.T.; Méndez-Lucas, A.; Shelton, J.M.; Perales, J.C.; Browning, J.D.; Burgess, S.C. Elevated TCA cycle function in the pathology of diet-induced hepatic insulin resistance and fatty liver. J. Lipid Res. 2012, 53, 1080-1092. [CrossRef]

158. Grossini, E.; Garhwal, D.P.; Calamita, G.; Romito, R.; Rigamonti, C.; Minisini, R.; Smirne, C.; Surico, D.; Bellan, M.; Pirisi, M. Exposure to Plasma from Non-alcoholic Fatty Liver Disease Patients Affects Hepatocyte Viability, Generates Mitochondrial Dysfunction, and Modulates Pathways Involved in Fat Accumulation and Inflammation. Front. Med. 2021, 8, 693997. [CrossRef]

159. Besse-Patin, A.; Léveillé, M.; Oropeza, D.; Nguyen, B.N.; Prat, A. Estrogen Signals Through Peroxisome Proliferator-Activated Receptor- $\gamma$ Coactivator $1 \alpha$ to Reduce Oxidative Damage Associated with Diet-Induced Fatty Liver Disease. Gastroenterology 2017, 152, 243-256. [CrossRef]

160. Paradies, G.; Paradies, V.; Ruggiero, F.M.; Petrosillo, G. Role of Cardiolipin in Mitochondrial Function and Dynamics in Health and Disease: Molecular and Pharmacological Aspects. Cells 2019, 8, 728. [CrossRef]

161. Pfeiffer, K.; Gohil, V.; Stuart, R.A.; Hunte, C.; Brandt, U.; Greenberg, M.L.; Schägger, H. Cardiolipin stabilizes respiratory chain supercomplexes. J. Biol. Chem. 2003, 278, 52873-52880. [CrossRef] [PubMed]

162. Sullivan, E.M.; Pennington, E.R.; Green, W.D.; Beck, M.A.; Brown, D.A.; Shaikh, S.R. Mechanisms by Which Dietary Fatty Acids Regulate Mitochondrial Structure-Function in Health and Disease. Adv. Nutr. 2018, 9, 247-262. [CrossRef] [PubMed]

163. Kroemer, G.; Galluzzi, L.; Brenner, C. Mitochondrial membrane permeabilization in cell death. Physiol. Rev. 2007, 87, 99-163. [CrossRef] [PubMed]

164. Paradies, G.; Petrosillo, G.; Pistolese, M.; Ruggiero, F.M. Reactive oxygen species affect mitochondrial electron transport complex I activity through oxidative cardiolipin damage. Gene 2002, 286, 135-141. [CrossRef]

165. Paradies, G.; Paradies, V.; Ruggiero, F.M.; Petrosillo, G. Oxidative stress, cardiolipin and mitochondrial dysfunction in nonalcoholic fatty liver disease. World J. Gastroenterol. 2014, 20, 14205-14218. [CrossRef]

166. Petrosillo, G.; Ruggiero, F.M.; Pistolese, M.; Paradies, G. Reactive oxygen species generated from the mitochondrial electron transport chain induce cytochrome c dissociation from beef-heart submitochondrial particles via cardiolipin peroxidation. Possible role in the apoptosis. FEBS Lett. 2001, 509, 435-438. [CrossRef]

167. Peng, K.Y.; Watt, M.J.; Rensen, S.; Willem Greve, J.; Huynh, K.; Jayawardana, K.S.; Meikle, P.J.; Meex, R.C.R. Mitochondrial dysfunction-related lipid changes occur in nonalcoholic fatty liver disease progression. J. Lipid Res. 2018, 59, 1977-1986. [CrossRef]

168. Sullivan, E.M.; Fix, A.; Crouch, M.J.; Sparagna, G.C.; Zeczycki, T.N.; Brown, D.A.; Shaikh, S.R. Murine diet-induced obesity remodels cardiac and liver mitochondrial phospholipid acyl chains with differential effects on respiratory enzyme activity. $J$. Nutr. Biochem. 2017, 45, 94-103. [CrossRef]

169. Han, X.; Yang, J.; Yang, K.; Zhongdan, Z.; Abendschein, D.R.; Gross, R.W. Alterations in myocardial cardiolipin content and composition occur at the very earliest stages of diabetes: A shotgun lipidomics study. Biochemistry 2007, 46, 6417-6428. [CrossRef]

170. Di Ciaula, A.; Calamita, G.; Shanmugam, H.; Khalil, M.; Bonfrate, L.; Wang, D.Q.H.; Baffy, G.; Portincasa, P. Mitochondria Matter: Systemic Aspects of Nonalcoholic Fatty Liver Disease (NAFLD) and Diagnostic Assessment of Liver Function by Stable Isotope Dynamic Breath Tests. Int. J. Mol. Sci. 2021, 22, 7702. [CrossRef] 
171. Marí, M.; Caballero, F.; Colell, A.; Morales, A.; Caballeria, J.; Fernandez, A.; Enrich, C.; Fernandez-Checa, J.C.; García-Ruiz, C. Mitochondrial free cholesterol loading sensitizes to TNF- and Fas-mediated steatohepatitis. Cell Metab. 2006, 4, 185-198. [CrossRef] [PubMed]

172. Afolabi, P.; Wright, M.; Wootton, S.A.; Jackson, A.A. Clinical utility of 13C-liver-function breath tests for assessment of hepatic function. Dig. Dis. Sci. 2013, 58, 33-41. [CrossRef] [PubMed]

173. Gorowska-Kowolik, K.; Chobot, A.; Kwiecien, J. 13 C Methacetin Breath Test for Assessment of Microsomal Liver Function: Methodology and Clinical Application. Gastroenterol. Res. Pract. 2017, 2017, 7397840. [CrossRef] [PubMed]

174. Afolabi, P.R.; Scorletti, E.; Smith, D.E.; Almehmadi, A.A.; Calder, P.C.; Byrne, C.D. The characterisation of hepatic mitochondrial function in patients with non-alcoholic fatty liver disease (NAFLD) using the 13 C-ketoisocaproate breath test. J. Breath Res. 2018, 12, 046002. [CrossRef]

175. Campo, L.; Eiseler, S.; Apfel, T.; Pyrsopoulos, N. Fatty Liver Disease and Gut Microbiota: A Comprehensive Update. J. Clin. Transl. Hepatol. 2019, 7, 56-60. [CrossRef]

176. Lau, E.; Carvalho, D.; Freitas, P. Gut Microbiota: Association with NAFLD and Metabolic Disturbances. Biomed Res. Int. 2015, 2015, 979515. [CrossRef]

177. Zhou, J.; Tripathi, M.; Sinha, R.A.; Singh, B.K.; Yen, P.M. Gut microbiota and their metabolites in the progression of non-alcoholic fatty liver disease. Hepatoma Res. 2021, 7, 11. [CrossRef]

178. Samuel, B.S.; Shaito, A.; Motoike, T.; Rey, F.E.; Backhed, F.; Manchester, J.K.; Hammer, R.E.; Williams, S.C.; Crowley, J.; Yanagisawa, M.; et al. Effects of the gut microbiota on host adiposity are modulated by the short-chain fatty-acid binding $\mathrm{G}$ protein-coupled receptor, Gpr41. Proc. Natl. Acad. Sci. USA 2008, 105, 16767-16772. [CrossRef]

179. Bäckhed, F.; Manchester, J.K.; Semenkovich, C.F.; Gordon, J.I. Mechanisms underlying the resistance to diet-induced obesity in germ-free mice. Proc. Natl. Acad. Sci. USA 2007, 104, 979-984. [CrossRef]

180. Burz, S.D.; Monnoye, M.; Philippe, C.; Farin, W.; Ratziu, V.; Strozzi, F.; Paillarse, J.M.; Chêne, L.; Blottière, H.M.; Gérard, P. Fecal Microbiota Transplant from Human to Mice Gives Insights into the Role of the Gut Microbiota in Non-Alcoholic Fatty Liver Disease (NAFLD). Microorganisms 2021, 9, 199. [CrossRef]

181. Vrieze, A.; Van Nood, E.; Holleman, F.; Salojärvi, J.; Kootte, R.S.; Bartelsman, J.F.W.M.; Dallinga-Thie, G.M.; Ackermans, M.T.; Serlie, M.J.; Oozeer, R.; et al. Transfer of intestinal microbiota from lean donors increases insulin sensitivity in individuals with metabolic syndrome. Gastroenterology 2012, 143, 913-916.e7. [CrossRef] [PubMed]

182. Witjes, J.J.; Smits, L.P.; Pekmez, C.T.; Prodan, A.; Meijnikman, A.S.; Troelstra, M.A.; Bouter, K.E.C.; Herrema, H.; Levin, E.; Holleboom, A.G.; et al. Donor Fecal Microbiota Transplantation Alters Gut Microbiota and Metabolites in Obese Individuals With Steatohepatitis. Hepatol. Commun. 2020, 4, 1578-1590. [CrossRef] [PubMed]

183. Hrncir, T.; Hrncirova, L.; Kverka, M.; Hromadka, R.; Machova, V.; Trckova, E.; Kostovcikova, K.; Kralickova, P.; Krejsek, J.; Tlaskalova-Hogenova, H. Gut Microbiota and NAFLD: Pathogenetic Mechanisms, Microbiota Signatures, and Therapeutic Interventions. Microorganisms 2021, 9, 957. [CrossRef] [PubMed]

184. Jennison, E.; Byrne, C.D. The role of the gut microbiome and diet in the pathogenesis of non-alcoholic fatty liver disease. Clin. Mol. Hepatol. 2021, 27, 22-43. [CrossRef]

185. Bakhshimoghaddam, F.; Alizadeh, M. Contribution of gut microbiota to nonalcoholic fatty liver disease: Pathways of mechanisms. Clin. Nutr. ESPEN 2021, 44, 61-68. [CrossRef]

186. Compare, D.; Coccoli, P.; Rocco, A.; Nardone, O.M.; De Maria, S.; Cartenì, M.; Nardone, G. Gut-Liver axis: The impact of gut microbiota on non alcoholic fatty liver disease. Nutr. Metab. Cardiovasc. Dis. 2012, 22, 471-476. [CrossRef]

187. Mouries, J.; Brescia, P.; Silvestri, A.; Spadoni, I.; Sorribas, M.; Wiest, R.; Mileti, E.; Galbiati, M.; Invernizzi, P.; Adorini, L.; et al. Microbiota-driven gut vascular barrier disruption is a prerequisite for non-alcoholic steatohepatitis development. J. Hepatol. 2019, 71, 1216-1228. [CrossRef]

188. Nicoletti, A.; Ponziani, F.R.; Biolato, M.; Valenza, V.; Marrone, G.; Sganga, G.; Gasbarrini, A.; Miele, L.; Grieco, A. Intestinal permeability in the pathogenesis of liver damage: From non-alcoholic fatty liver disease to liver transplantation. World $J$. Gastroenterol. 2019, 25, 4814-4834. [CrossRef]

189. Auguet, T.; Bertran, L.; Binetti, J. Intestinal Dysbiosis and Non-Alcoholic Fatty Liver Disease. In Human Microbiome; Beloborodova, N.V., Grechko, A.V., Eds.; Intech Open Limited: London, UK, 2020; pp. 1-24. [CrossRef]

190. Ley, R.E.; Turnbaugh, P.J.; Klein, S.; Gordon, J.I. Microbial ecology: Human gut microbes associated with obesity. Nature 2006, 444, 1022-1023. [CrossRef] [PubMed]

191. Jumpertz, R.; Le, D.S.; Turnbaugh, P.J.; Trinidad, C.; Bogardus, C.; Gordon, J.I.; Krakoff, J. Energy-balance studies reveal associations between gut microbes, caloric load, and nutrient absorption in humans. Am. J. Clin. Nutr. 2011, 94, 58-65. [CrossRef] [PubMed]

192. Jasirwan, O.M.C.; Muradi, A.; Hasan, I.; Simadibrata, M.; Rinaldi, I. Correlation of gut Firmicutes/Bacteroidetes ratio with fibrosis and steatosis stratified by body mass index in patients with non-alcoholic fatty liver disease. Biosci. Microbiota Food Health 2021, 40, 50-58. [CrossRef] [PubMed]

193. Zhu, L.; Baker, R.D.; Baker, S.S. Gut microbiome and nonalcoholic fatty liver diseases. Pediatr. Res. 2015, 77, 245-251. [CrossRef] [PubMed]

194. Ji, Y.; Yin, Y.; Li, Z.; Zhang, W. Gut Microbiota-Derived Components and Metabolites in the Progression of Non-Alcoholic Fatty Liver Disease (NAFLD). Nutrients 2019, 11, 1712. [CrossRef] [PubMed] 
195. Eswaran, S.; Babbar, A.; Drescher, H.K.; Hitch, T.C.A.; Clavel, T.; Muschaweck, M.; Ritz, T.; Kroy, D.C.; Trautwein, C.; Wagner, N.; et al. Upregulation of Anti-Oxidative Stress Response Improves Metabolic Changes in L-Selectin-Deficient Mice but Does Not Prevent NAFLD Progression or Fecal Microbiota Shifts. Int. J. Mol. Sci. 2021, 22, 7314. [CrossRef] [PubMed]

196. Wang, W.; Li, Q.; Chai, W.; Sun, C.; Zhang, T.; Zhao, C.; Yuan, Y.; Wang, X.; Liu, H.; Ye, H. Lactobacillus paracasei Jlus66 extenuate oxidative stress and inflammation via regulation of intestinal flora in rats with non alcoholic fatty liver disease. Food Sci. Nutr. 2019, 7, 2636-2646. [CrossRef]

197. Park, E.; Jeong, J.J.; Won, S.M.; Sharma, S.P.; Gebru, Y.A.; Ganesan, R.; Gupta, H.; Suk, K.T.; Kim, D.J. Gut Microbiota-Related Cellular and Molecular Mechanisms in the Progression of Nonalcoholic Fatty Liver Disease. Cells 2021, 10, 2634. [CrossRef]

198. Shen, J.; Obin, M.S.; Zhao, L. The gut microbiota, obesity and insulin resistance. Mol. Asp. Med. 2013, 34, 39-58. [CrossRef]

199. Diamant, M.; Blaak, E.E.; de Vos, W.M. Do nutrient-gut-microbiota interactions play a role in human obesity, insulin resistance and type 2 diabetes? Obes. Rev. 2011, 12, 272-281. [CrossRef] [PubMed]

200. Cassard, A.-M.; Gérard, P.; Perlemuter, G. Microbiota, Liver Diseases, and Alcohol. Microbiol. Spectr. 2017, 5. [CrossRef]

201. Kullisaar, T.; Songisepp, E.; Mikelsaar, M.; Zilmer, K.; Vihalemm, T.; Zilmer, M. Antioxidative probiotic fermented goats' milk decreases oxidative stress-mediated atherogenicity in human subjects. Br. J. Nutr. 2003, 90, 449-456. [CrossRef] [PubMed]

202. Arora, T.; Singh, S.; Sharma, R.K. Probiotics: Interaction with gut microbiome and antiobesity potential. Nutrition 2013, 29, 591-596. [CrossRef] [PubMed]

203. Park, D.Y.; Ahn, Y.T.; Huh, C.S.; Mcgregor, R.A.; Choi, M.S. Dual probiotic strains suppress high fructose-induced metabolic syndrome. World J. Gastroenterol. 2013, 19, 274-283. [CrossRef] [PubMed]

204. Castillo, V.; Figueroa, F.; González-Pizarro, K.; Jopia, P.; Ibacache-Quiroga, C. Probiotics and Prebiotics as a Strategy for NonAlcoholic Fatty Liver Disease, a Narrative Review. Foods 2021, 10, 1719. [CrossRef] [PubMed]

205. Moszak, M.; Szulińska, M.; Walczak-Gałęzewska, M.; Bogdański, P. Nutritional Approach Targeting Gut Microbiota in NAFLD-To Date. Int. J. Environ. Res. Public Health 2021, 18, 1616. [CrossRef]

206. Nagashimada, M.; Honda, M. Effect of Microbiome on Non-Alcoholic Fatty Liver Disease and the Role of Probiotics, Prebiotics, and Biogenics. Int. J. Mol. Sci. 2021, 22, 8008. [CrossRef]

207. Khan, A.; Ding, Z.; Ishaq, M.; Bacha, A.S.; Khan, I.; Hanif, A.; Li, W.; Guo, X. Understanding the Effects of Gut Microbiota Dysbiosis on Nonalcoholic Fatty Liver Disease and the Possible Probiotics Role: Recent Updates. Int. J. Biol. Sci. 2021, 17, 818-833. [CrossRef]

208. Rives, C.; Fougerat, A.; Ellero-Simatos, S.; Loiseau, N.; Guillou, H.; Gamet-Payrastre, L.; Wahli, W. Oxidative Stress in NAFLD: Role of Nutrients and Food Contaminants. Biomolecules 2020, 10, 1702. [CrossRef]

209. Porras, D.; Nistal, E.; Martínez-Flórez, S.; González-Gallego, J.; García-Mediavilla, M.V.; Sánchez-Campos, S. Intestinal Microbiota Modulation in Obesity-Related Non-alcoholic Fatty Liver Disease. Front. Physiol. 2018, 9, 1813. [CrossRef]

210. Lim, J.S.; Mietus-Snyder, M.; Valente, A.; Schwarz, J.M.; Lustig, R.H. The role of fructose in the pathogenesis of NAFLD and the metabolic syndrome. Nat. Rev. Gastroenterol. Hepatol. 2010, 7, 251-264. [CrossRef]

211. Jensen, T.; Abdelmalek, M.F.; Sullivan, S.; Nadeau, K.J.; Green, M.; Roncal, C.; Nakagawa, T.; Kuwabara, M.; Sato, Y.; Kang, D.H.; et al. Fructose and sugar: A major mediator of non-alcoholic fatty liver disease. J. Hepatol. 2018, 68, 1063-1075. [CrossRef]

212. Jegatheesan, P.; De Bandt, J.P. Fructose and NAFLD: The Multifaceted Aspects of Fructose Metabolism. Nutrients 2017, 9 , 230. [CrossRef] [PubMed]

213. Roeb, E.; Weiskirchen, R. Fructose and Non-Alcoholic Steatohepatitis. Front. Pharmacol. 2021, 12, 634344. [CrossRef] [PubMed]

214. Ouyang, X.; Cirillo, P.; Sautin, Y.; McCall, S.; Bruchette, J.L.; Diehl, A.M.; Johnson, R.J.; Abdelmalek, M.F. Fructose consumption as a risk factor for non-alcoholic fatty liver disease. J. Hepatol. 2008, 48, 993-999. [CrossRef] [PubMed]

215. Lambertz, J.; Weiskirchen, S.; Landert, S.; Weiskirchen, R. Fructose: A Dietary Sugar in Crosstalk with Microbiota Contributing to the Development and Progression of Non-Alcoholic Liver Disease. Front. Immunol. 2017, 8, 1159. [CrossRef]

216. Xie, C.; Halegoua-Demarzio, D. Role of Probiotics in Non-alcoholic Fatty Liver Disease: Does Gut Microbiota Matter? Nutrients 2019, 11, 2837. [CrossRef]

217. Nabavi, S.; Rafraf, M.; Somi, M.H.; Homayouni-Rad, A.; Asghari-Jafarabadi, M. Effects of probiotic yogurt consumption on metabolic factors in individuals with nonalcoholic fatty liver disease. J. Dairy Sci. 2014, 97, 7386-7393. [CrossRef]

218. Famouri, F.; Shariat, Z.; Hashemipour, M.; Keikha, M.; Kelishadi, R. Effects of Probiotics on Nonalcoholic Fatty Liver Disease in Obese Children and Adolescents. J. Pediatr. Gastroenterol. Nutr. 2017, 64, 413-417. [CrossRef]

219. Ahn, S.B.; Jun, D.W.; Kang, B.K.; Lim, J.H.; Lim, S.; Chung, M.J. Randomized, Double-blind, Placebo-controlled Study of a Multispecies Probiotic Mixture in Nonalcoholic Fatty Liver Disease. Sci. Rep. 2019, 9, 5688. [CrossRef]

220. Javadi, L.; Khoshbaten, M.; Safaiyan, A.; Ghavami, M.; Abbasi, M.M.; Gargari, B.P. Pro- and prebiotic effects on oxidative stress and inflammatory markers in non-alcoholic fatty liver disease. Asia Pac. J. Clin. Nutr. 2018, 27, 1031-1039. [CrossRef]

221. Lei, K.; Li, Y.L.; Wang, Y.; Wen, J.; Wu, H.Z.; Yu, D.Y.; Li, W.F. Effect of dietary supplementation of Bacillus subtilis B10 on biochemical and molecular parameters in the serum and liver of high-fat diet-induced obese mice. J. Zhejiang Univ. Sci. B 2015, 16, 487-495. [CrossRef]

222. Kozmus, C.E.P.; Moura, E.; Serrão, M.P.; Real, H.; Guimarães, J.T.; Guedes-de-Pinho, P.; Duarte, B.P.; Marques, F.; Martins, M.J.; Vieira-Coelho, M.A. Influence of dietary supplementation with dextrin or oligofructose on the hepatic redox balance in rats. Mol. Nutr. Food Res. 2011, 55, 1735-1739. [CrossRef] [PubMed] 
223. Ekhlasi, G.; Zarrati, M.; Agah, S.; Hosseini, A.F.; Hosseini, S.; Shidfar, S.; Aarbshahi, S.S.S.; Razmpoosh, E.; Shidfar, F. Effects of symbiotic and vitamin $\mathrm{E}$ supplementation on blood pressure, nitric oxide and inflammatory factors in non-alcoholic fatty liver disease. EXCLI J. 2017, 16, 278-290. [CrossRef] [PubMed]

224. Zhang, H.; Tsao, R. Dietary polyphenols, oxidative stress and antioxidant and anti-inflammatory effects. Curr. Opin. Food Sci. 2016, 8, 33-42. [CrossRef]

225. Wang, Z.; Zeng, M.; Wang, Z.; Qin, F.; Chen, J.; He, Z. Dietary Polyphenols to Combat Nonalcoholic Fatty Liver Disease via the Gut-Brain-Liver Axis: A Review of Possible Mechanisms. J. Agric. Food Chem. 2021, 69, 3585-3600. [CrossRef]

226. Abenavoli, L.; Larussa, T.; Corea, A.; Procopio, A.C.; Boccuto, L.; Dallio, M.; Federico, A.; Luzza, F. Dietary Polyphenols and Non-Alcoholic Fatty Liver Disease. Nutrients 2021, 13, 494. [CrossRef]

227. Houghton, D.; Stewart, C.J.; Day, C.P.; Trenell, M. Gut Microbiota and Lifestyle Interventions in NAFLD. Int. J. Mol. Sci. 2016, 17, 447. [CrossRef]

228. Evans, C.C.; LePard, K.J.; Kwak, J.W.; Stancukas, M.C.; Laskowski, S.; Dougherty, J.; Moulton, L.; Glawe, A.; Wang, Y.; Leone, V.; et al. Exercise prevents weight gain and alters the gut microbiota in a mouse model of high fat diet-induced obesity. PLoS ONE 2014, 9, e92193. [CrossRef]

229. Campbell, S.C.; Wisniewski, P.J.; Noji, M.; McGuinness, L.R.; Häggblom, M.M.; Lightfoot, S.A.; Joseph, L.B.; Kerkhof, L.J. The Effect of Diet and Exercise on Intestinal Integrity and Microbial Diversity in Mice. PLoS ONE 2016, 11, e0150502. [CrossRef]

230. Petriz, B.A.; Castro, A.P.; Almeida, J.A.; Gomes, C.P.C.; Fernandes, G.R.; Kruger, R.H.; Pereira, R.W.; Franco, O.L. Exercise induction of gut microbiota modifications in obese, non-obese and hypertensive rats. BMC Genomics 2014, 15, 511. [CrossRef]

231. Lambert, J.E.; Myslicki, J.P.; Bomhof, M.R.; Belke, D.D.; Shearer, J.; Reimer, R.A. Exercise training modifies gut microbiota in normal and diabetic mice. Appl. Physiol. Nutr. Metab. 2015, 40, 749-752. [CrossRef]

232. Carbajo-Pescador, S.; Porras, D.; Garcia-Mediavilla, M.V.; Martinez-Florez, S.; Juarez-Fernandez, M.; Cuevas, M.J.; Mauriz, J.L.; Gonzalez-Gallego, J.; Nistal, E.; Sanchez-Campos, S. Beneficial effects of exercise on gut microbiota functionality and barrier integrity, and gut-liver crosstalk in an in vivo model of early obesity and non-alcoholic fatty liver disease. Dis. Model. Mech. 2019, 12, dmm039206. [CrossRef] [PubMed]

233. Winn, N.C.; Liu, Y.; Rector, R.S.; Parks, E.J.; Ibdah, J.A.; Kanaley, J.A. Energy-matched moderate and high intensity exercise training improves nonalcoholic fatty liver disease risk independent of changes in body mass or abdominal adiposity-A randomized trial. Metabolism 2018, 78, 128-140. [CrossRef] [PubMed]

234. Yaribeygi, H.; Atkin, S.L.; Simental-Mendía, L.E.; Sahebkar, A. Molecular mechanisms by which aerobic exercise induces insulin sensitivity. J. Cell. Physiol. 2019, 234, 12385-12392. [CrossRef] [PubMed]

235. Houttu, V.; Boulund, U.; Grefhorst, A.; Soeters, M.R.; Pinto-Sietsma, S.J.; Nieuwdorp, M.; Holleboom, A.G. The role of the gut microbiome and exercise in non-alcoholic fatty liver disease. Therap. Adv. Gastroenterol. 2020, 13, 1756284820941745. [CrossRef] [PubMed]

236. Uchida, D.; Takaki, A.; Oyama, A.; Adachi, T.; Wada, N.; Onishi, H.; Okada, H. Oxidative Stress Management in Chronic Liver Diseases and Hepatocellular Carcinoma. Nutrients 2020, 12, 1576. [CrossRef] [PubMed]

237. Poetsch, A.R. The genomics of oxidative DNA damage, repair, and resulting mutagenesis. Comput. Struct. Biotechnol. J. 2020, 18, 207-219. [CrossRef]

238. McLoughlin, M.R.; Orlicky, D.J.; Prigge, J.R.; Krishna, P.; Talago, E.A.; Cavigli, I.R.; Eriksson, S.; Miller, C.G.; Kundert, J.A.; Sayin, V.I.; et al. TrxR1, Gsr, and oxidative stress determine hepatocellular carcinoma malignancy. Proc. Natl. Acad. Sci. USA. 2019, 116, 11408-11417. [CrossRef]

239. Hayes, J.D.; Dinkova-Kostova, A.T.; Tew, K.D. Oxidative Stress in Cancer. Cancer Cell 2020, 38, 167-197. [CrossRef]

240. Cho, E.S.; Cha, Y.H.; Kim, H.S.; Kim, N.H.; Yook, J.I. The Pentose Phosphate Pathway as a Potential Target for Cancer Therapy. Biomol. Ther. 2018, 26, 29-38. [CrossRef]

241. Denicola, G.M.; Karreth, F.A.; Humpton, T.J.; Gopinathan, A.; Wei, C.; Frese, K.; Mangal, D.; Yu, K.H.; Yeo, C.J.; Calhoun, E.S.; et al. Oncogene-induced Nrf2 transcription promotes ROS detoxification and tumorigenesis. Nature 2011, 475, 106-110. [CrossRef]

242. Tao, J.; Krutsenko, Y.; Moghe, A.; Singh, S.; Poddar, M.; Bell, A.; Oertel, M.; Singhi, A.D.; Geller, D.; Chen, X.; et al. Nuclear factor erythroid 2-related factor 2 and $\beta$-Catenin Coactivation in Hepatocellular Cancer: Biological and Therapeutic Implications. Hepatology 2021, 74, 741-759. [CrossRef]

243. Taniguchi, K.; Karin, M. NF-кB, inflammation, immunity and cancer: Coming of age. Nat. Rev. Immunol. 2018, 18, 309-324. [CrossRef]

244. Luedde, T.; Schwabe, R.F. NF-кB in the liver-linking injury, fibrosis and hepatocellular carcinoma. Nat. Rev. Gastroenterol. Hepatol. 2011, 8, 108-118. [CrossRef]

245. Tomita, K.; Teratani, T.; Suzuki, T.; Oshikawa, T.; Yokoyama, H.; Shimamura, K.; Nishiyama, K.; Mataki, N.; Irie, R.; Minamino, T.; et al. P53/p66Shc-mediated signaling contributes to the progression of non-alcoholic steatohepatitis in humans and mice. J. Hepatol. 2012, 57, 837-843. [CrossRef]

246. Wilson, G.K.; Tennant, D.A.; McKeating, J.A. Hypoxia inducible factors in liver disease and hepatocellular carcinoma: Current understanding and future directions. J. Hepatol. 2014, 61, 1397-1406. [CrossRef]

247. Longo, M.; Paolini, E.; Meroni, M.; Dongiovanni, P. Remodeling of Mitochondrial Plasticity: The Key Switch from NAFLD/NASH to HCC. Int. J. Mol. Sci. 2021, 22, 4173. [CrossRef] 
248. Huang, Y.; Zhang, Y.; Ge, L.; Lin, Y.; Kwok, H.F. The Roles of Protein Tyrosine Phosphatases in Hepatocellular Carcinoma. Cancers 2018, 10, 82. [CrossRef]

249. Grohmann, M.; Wiede, F.; Dodd, G.T.; Gurzov, E.N.; Ooi, G.J.; Butt, T.; Rasmiena, A.A.; Kaur, S.; Gulati, T.; Goh, P.K.; et al. Obesity Drives STAT-1-Dependent NASH and STAT-3-Dependent HCC. Cell 2018, 175, 1289-1306. [CrossRef]

250. Wu, Y.; Cain-Hom, C.; Choy, L.; Hagenbeek, T.J.; De Leon, G.P.; Chen, Y.; Finkle, D.; Venook, R.; Wu, X.; Ridgway, J.; et al. Therapeutic antibody targeting of individual Notch receptors. Nature 2010, 464, 1052-1057. [CrossRef]

251. Zhu, C.; Ho, Y.J.; Salomao, M.A.; Dapito, D.H.; Bartolome, A.; Schwabe, R.F.; Lee, J.S.; Lowe, S.W.; Pajvani, U.B. Notch activity characterizes a common hepatocellular carcinoma subtype with unique molecular and clinicopathologic features. J. Hepatol. 2021, 74, 613-626. [CrossRef]

252. Pervez, M.A.; Khan, D.A.; Slehria, A.U.R.; Ijaz, A. Delta-tocotrienol supplementation improves biochemical markers of hepatocellular injury and steatosis in patients with nonalcoholic fatty liver disease: A randomized, placebo-controlled trial. Complement. Ther. Med. 2020, 52, 102494. [CrossRef]

253. Zhang, S.; Yang, Y.; Liang, Z.; Duan, W.; Yang, J.; Yan, J.; Wang, N.; Feng, W.; Ding, M.; Nie, Y.; et al. Silybin-mediated inhibition of Notch signaling exerts antitumor activity in human hepatocellular carcinoma cells. PLoS ONE 2013, 8, e83699. [CrossRef]

254. Bootcov, M.R.; Bauskin, A.R.; Valenzuela, S.M.; Moore, A.G.; Bansal, M.; He, X.Y.; Zhang, H.P.; Donnellan, M.; Mahler, S.; Pryor, K.; et al. MIC-1, a novel macrophage inhibitory cytokine, is a divergent member of the TGF-beta superfamily. Proc. Natl. Acad. Sci. USA 1997, 94, 11514-11519. [CrossRef]

255. Tzikas, S.; Vassilikos, V.; Keller, T. GDF-15 as a risk stratification biomarker for cardiovascular disease. Int. J. Cardiol. 2019, 292, 246-247. [CrossRef]

256. Ago, T.; Sadoshima, J. GDF15, a cardioprotective TGF-beta superfamily protein. Circ. Res. 2006, 98, 294-297. [CrossRef]

257. Emmerson, P.J.; Wang, F.; Du, Y.; Liu, Q.; Pickard, R.T.; Gonciarz, M.D.; Coskun, T.; Hamang, M.J.; Sindelar, D.K.; Ballman, K.K.; et al. The metabolic effects of GDF15 are mediated by the orphan receptor GFRAL. Nat. Med. 2017, 23, 1215-1219. [CrossRef]

258. Lin, Y.F.; Schulz, A.M.; Pellegrino, M.W.; Lu, Y.; Shaham, S.; Haynes, C.M. Maintenance and propagation of a deleterious mitochondrial genome by the mitochondrial unfolded protein response. Nature 2016, 533, 416-419. [CrossRef]

259. Chung, H.K.; Kim, J.T.; Kim, H.W.; Kwon, M.; Kim, S.Y.; Shong, M.; Kim, K.S.; Yi, H.S. GDF15 deficiency exacerbates chronic alcohol- and carbon tetrachloride-induced liver injury. Sci. Rep. 2017, 7, 17238. [CrossRef]

260. Lee, H.Y.; Nga, H.T.; Tian, J.; Yi, H.S. Mitochondrial Metabolic Signatures in Hepatocellular Carcinoma. Cells $2021,10,1901$. [CrossRef]

261. Si, Y.; Liu, X.; Cheng, M.; Wang, M.; Gong, Q.; Yang, Y.; Wang, T.; Yang, W. Growth differentiation factor 15 is induced by hepatitis $C$ virus infection and regulates hepatocellular carcinoma-related genes. PLoS ONE 2011, 6, e19967. [CrossRef]

262. Liu, X.; Chi, X.; Gong, Q.; Gao, L.; Niu, Y.; Chi, X.; Cheng, M.; Si, Y.; Wang, M.; Zhong, J.; et al. Association of serum level of growth differentiation factor 15 with liver cirrhosis and hepatocellular carcinoma. PLoS ONE 2015, 10, e0127518. [CrossRef] [PubMed]

263. Lee, E.S.; Kim, S.H.; Kim, H.J.; Kim, K.H.; Lee, B.S.; Ku, B.J. Growth Differentiation Factor 15 Predicts Chronic Liver Disease Severity. Gut Liver 2017, 11, 276-282. [CrossRef] [PubMed]

264. Koo, B.K.; Um, S.H.; Seo, D.S.; Joo, S.K.; Bae, J.M.; Park, J.H.; Chang, M.S.; Kim, J.H.; Lee, J.; Jeong, W., II; et al. Growth differentiation factor 15 predicts advanced fibrosis in biopsy-proven non-alcoholic fatty liver disease. Liver Int. 2018, 38, 695-705. [CrossRef] [PubMed]

265. Govaere, O.; Cockell, S.; Tiniakos, D.; Queen, R.; Younes, R.; Vacca, M.; Alexander, L.; Ravaioli, F.; Palmer, J.; Petta, S.; et al Transcriptomic profiling across the nonalcoholic fatty liver disease spectrum reveals gene signatures for steatohepatitis and fibrosis. Sci. Transl. Med. 2020, 12, eaba4448. [CrossRef]

266. Smirne, C.; Rigamonti, C.; De Benedittis, C.; Sainaghi, P.P.; Bellan, M.; Burlone, M.E.; Castello, L.M.; Avanzi, G.C. Gas6/TAM Signaling Components as Novel Biomarkers of Liver Fibrosis. Dis. Markers 2019, 2019, 2304931. [CrossRef]

267. Day, C.P. From fat to inflammation. Gastroenterology 2006, 130, 207-210. [CrossRef]

268. Roskams, T.; Yang, S.Q.; Koteish, A.; Durnez, A.; DeVos, R.; Huang, X.; Achten, R.; Verslype, C.; Diehl, A.M. Oxidative stress and oval cell accumulation in mice and humans with alcoholic and nonalcoholic fatty liver disease. Am. J. Pathol. 2003, 163, 1301-1311. [CrossRef]

269. Richardson, M.M.; Jonsson, J.R.; Powell, E.E.; Brunt, E.M.; Neuschwander-Tetri, B.A.; Bhathal, P.S.; Dixon, J.B.; Weltman, M.D.; Tilg, H.; Moschen, A.R.; et al. Progressive fibrosis in nonalcoholic steatohepatitis: Association with altered regeneration and a ductular reaction. Gastroenterology 2007, 133, 80-90. [CrossRef]

270. Lafdil, F.; Chobert, M.N.; Couchie, D.; Brouillet, A.; Zafrani, E.S.; Mavier, P.; Laperche, Y. Induction of Gas6 protein in CCl4induced rat liver injury and anti-apoptotic effect on hepatic stellate cells. Hepatology 2006, 44, 228-239. [CrossRef]

271. Couchie, D.; Lafdil, F.; Martin-Garcia, N.; Laperche, Y.; Zafrani, E.S.; Mavier, P. Expression and role of Gas6 protein and of its receptor Axl in hepatic regeneration from oval cells in the rat. Gastroenterology 2005, 129, 1633-1642. [CrossRef]

272. Lafdil, F.; Chobert, M.N.; Deveaux, V.; Zafrani, E.S.; Mavier, P.; Nakano, T.; Laperche, Y.; Brouillet, A. Growth arrest-specific protein 6 deficiency impairs liver tissue repair after acute toxic hepatitis in mice. J. Hepatol. 2009, 51, 55-66. [CrossRef] [PubMed]

273. Fourcot, A.; Couchie, D.; Chobert, M.N.; Zafrani, E.S.; Mavier, P.; Laperche, Y.; Brouillet, A. Gas6 deficiency prevents liver inflammation, steatohepatitis, and fibrosis in mice. Am. J. Physiol. Gastrointest. Liver Physiol. 2011, 300, G1043-G1053. [CrossRef] [PubMed] 
274. Gogoi-Tiwari, J.; Köhn-Gaone, J.; Giles, C.; Schmidt-Arras, D.; Gratte, F.D.; Elsegood, C.L.; McCaughan, G.W.; Ramm, G.A.; Olynyk, J.K.; Tirnitz-Parker, J.E.E. The Murine Choline-Deficient, Ethionine-Supplemented (CDE) Diet Model of Chronic Liver Injury. J. Vis. Exp. 2017, 128, 56138. [CrossRef] [PubMed]

275. Soret, P.A.; Magusto, J.; Housset, C.; Gautheron, J. In Vitro and In Vivo Models of Non-Alcoholic Fatty Liver Disease: A Critical Appraisal. J. Clin. Med. 2020, 10, 36. [CrossRef]

276. Eng, J.M.; Estall, J.L. Diet-Induced Models of Non-Alcoholic Fatty Liver Disease: Food for Thought on Sugar, Fat, and Cholesterol. Cells 2021, 10, 1805. [CrossRef]

277. Rinella, M.E.; Elias, M.S.; Smolak, R.R.; Fu, T.; Borensztajn, J.; Green, R.M. Mechanisms of hepatic steatosis in mice fed a lipogenic methionine choline-deficient diet. J. Lipid Res. 2008, 49, 1068-1076. [CrossRef]

278. Rivera, C.A.; Adegboyega, P.; van Rooijen, N.; Tagalicud, A.; Allman, M.; Wallace, M. Toll-like receptor-4 signaling and Kupffer cells play pivotal roles in the pathogenesis of non-alcoholic steatohepatitis. J. Hepatol. 2007, 47, 571-579. [CrossRef]

279. Tomita, K.; Tamiya, G.; Ando, S.; Ohsumi, K.; Chiyo, T.; Mizutani, A.; Kitamura, N.; Toda, K.; Kaneko, T.; Horie, Y.; et al Tumour necrosis factor alpha signalling through activation of Kupffer cells plays an essential role in liver fibrosis of non-alcoholic steatohepatitis in mice. Gut 2006, 55, 415-424. [CrossRef]

280. Stienstra, R.; Saudale, F.; Duval, C.; Keshtkar, S.; Groener, J.E.M.; Van Rooijen, N.; Staels, B.; Kersten, S.; Müller, M. Kupffer cells promote hepatic steatosis via interleukin-1beta-dependent suppression of peroxisome proliferator-activated receptor alpha activity. Hepatology 2010, 51, 511-522. [CrossRef]

281. Maquoi, E.; Vörös, G.; Carmeliet, P.; Collen, D.; Lijnen, H.R. Role of Gas-6 in adipogenesis and nutritionally induced adipose tissue development in mice. Arterioscler. Thromb. Vasc. Biol. 2005, 25, 1002-1007. [CrossRef]

282. Castrillo, A.; Tontonoz, P. Nuclear receptors in macrophage biology: At the crossroads of lipid metabolism and inflammation. Annu. Rev. Cell Dev. Biol. 2004, 20, 455-480. [CrossRef] [PubMed]

283. Gonzalez, N.; Bensinger, S.J.; Hong, C.; Beceiro, S.; Bradley, M.N.; Zelcer, N.; Deniz, J.; Ramirez, C.; Díaz, M.; Gallardo, G.; et al. Apoptotic cells promote their own clearance and immune tolerance through activation of the nuclear receptor LXR. Immunity 2009, 31, 245-258. [CrossRef] [PubMed]

284. Zizzo, G.; Cohen, P.L. The PPAR- $\gamma$ antagonist GW9662 elicits differentiation of M2c-like cells and upregulation of the MerTK/Gas6 axis: A key role for PPAR- $\gamma$ in human macrophage polarization. J. Inflamm. 2015, 12, 36. [CrossRef] [PubMed]

285. Nagy, L.; Tontonoz, P.; Alvarez, J.G.A.; Chen, H.; Evans, R.M. Oxidized LDL regulates macrophage gene expression through ligand activation of PPARgamma. Cell 1998, 93, 229-240. [CrossRef]

286. Szanto, A.; Roszer, T. Nuclear receptors in macrophages: A link between metabolism and inflammation. FEBS Lett. 2008, 582, 106-116. [CrossRef]

287. Repa, J.J.; Mangelsdorf, D.J. The liver X receptor gene team: Potential new players in atherosclerosis. Nat. Med. 2002, 8, $1243-1248$. [CrossRef]

288. Pastore, M.; Grimaudo, S.; Pipitone, R.M.; Lori, G.; Raggi, C.; Petta, S.; Marra, F. Role of Myeloid-Epithelial-Reproductive Tyrosine Kinase and Macrophage Polarization in the Progression of Atherosclerotic Lesions Associated With Nonalcoholic Fatty Liver Disease. Front. Pharmacol. 2019, 10, 604. [CrossRef]

289. Ait-Oufella, H.; Pouresmail, V.; Simon, T.; Blanc-Brude, O.; Kinugawa, K.; Merval, R.; Offenstadt, G.; Lesèche, G.; Cohen, P.L.; Tedgui, A.; et al. Defective mer receptor tyrosine kinase signaling in bone marrow cells promotes apoptotic cell accumulation and accelerates atherosclerosis. Arterioscler. Thromb. Vasc. Biol. 2008, 28, 1429-1431. [CrossRef]

290. Garbin, U.; Baggio, E.; Stranieri, C.; Pasini, A.; Manfro, S.; Mozzini, C.; Vallerio, P.; Lipari, G.; Merigo, F.; Guidi, G.; et al. Expansion of necrotic core and shedding of Mertk receptor in human carotid plaques: A role for oxidized polyunsaturated fatty acids? Cardiovasc. Res. 2013, 97, 125-133. [CrossRef]

291. Kamada, Y.; Ono, M.; Hyogo, H.; Fujii, H.; Sumida, Y.; Yamada, M.; Mori, K.; Tanaka, S.; Maekawa, T.; Ebisutani, Y.; et al. Use of Mac-2 binding protein as a biomarker for nonalcoholic fatty liver disease diagnosis. Hepatol. Commun. 2017, 1, 780-791. [CrossRef]

292. Hayashi, S.; Nagaoka, K.; Tanaka, Y. Blood-Based Biomarkers in Hepatitis B Virus-Related Hepatocellular Carcinoma, Including the Viral Genome and Glycosylated Proteins. Int. J. Mol. Sci. 2021, 22, 11051. [CrossRef] [PubMed]

293. Bellan, M.; Castello, L.M.; Pirisi, M. Candidate Biomarkers of Liver Fibrosis: A Concise, Pathophysiology-oriented Review. J. Clin. Transl. Hepatol. 2018, 6, 317-325. [CrossRef] [PubMed]

294. Abe, M.; Miyake, T.; Kuno, A.; Imai, Y.; Sawai, Y.; Hino, K.; Hara, Y.; Hige, S.; Sakamoto, M.; Yamada, G.; et al. Association between Wisteria floribunda agglutinin-positive Mac-2 binding protein and the fibrosis stage of non-alcoholic fatty liver disease. J. Gastroenterol. 2015, 50, 776-784. [CrossRef] [PubMed]

295. Sugiura, T.; Dohi, Y.; Takase, H.; Yamashita, S.; Murai, S.; Tsuzuki, Y.; Ogawa, S.; Tanaka, Y.; Ohte, N. Serum levels of Mac-2 binding protein increase with cardiovascular risk and reflect silent atherosclerosis. Atherosclerosis 2016, 251, 192-196. [CrossRef]

296. Sugiura, T.; Dohi, Y.; Takase, H.; Yamashita, S.; Tsuzuki, Y.; Ogawa, S.; Tanaka, Y.; Ohte, N. Factors associated with longitudinal changes in serum concentrations of Mac-2 binding protein: A prospective 3-year observational study. Nutr. Metab. Cardiovasc. Dis. 2019, 29, 1337-1344. [CrossRef]

297. Arai, T.; Atsukawa, M.; Tsubota, A.; Kawano, T.; Koeda, M.; Yoshida, Y.; Tanabe, T.; Okubo, T.; Hayama, K.; Iwashita, A.; et al. Factors influencing subclinical atherosclerosis in patients with biopsy-proven nonalcoholic fatty liver disease. PLoS ONE 2019, 14, e0224184. [CrossRef] 
298. Oh, S.; Tsujimoto, T.; Kim, B.; Uchida, F.; Suzuki, H.; Iizumi, S.; Isobe, T.; Sakae, T.; Tanaka, K.; Shoda, J. Weight-loss-independent benefits of exercise on liver steatosis and stiffness in Japanese men with NAFLD. JHEP Rep. Innov. Hepatol. 2021, $3,100253$. [CrossRef]

299. Ban, L.A.; Shackel, N.A.; McLennan, S.V. Extracellular Vesicles: A New Frontier in Biomarker Discovery for Non-Alcoholic Fatty Liver Disease. Int. J. Mol. Sci. 2016, 17, 376. [CrossRef]

300. Garcia-Martinez, I.; Alen, R.; Rada, P.; Valverde, A.M. Insights Into Extracellular Vesicles as Biomarker of NAFLD Pathogenesis. Front. Med. 2020, 7, 395. [CrossRef]

301. Masyuk, A.I.; Masyuk, T.V.; Larusso, N.F. Exosomes in the pathogenesis, diagnostics and therapeutics of liver diseases. J. Hepatol. 2013, 59, 621-625. [CrossRef]

302. Szabo, G.; Momen-Heravi, F. Extracellular vesicles in liver disease and potential as biomarkers and therapeutic targets. Nat. Rev. Gastroenterol. Hepatol. 2017, 14, 455-466. [CrossRef] [PubMed]

303. Moratti, E.; Vezzalini, M.; Tomasello, L.; Giavarina, D.; Sorio, C. Identification of protein tyrosine phosphatase receptor gamma extracellular domain (sPTPRG) as a natural soluble protein in plasma. PLoS ONE 2015, 10, e0119110. [CrossRef] [PubMed]

304. Hirsova, P.; Ibrahim, S.H.; Krishnan, A.; Verma, V.K.; Bronk, S.F.; Werneburg, N.W.; Charlton, M.R.; Shah, V.H.; Malhi, H.; Gores, G.J. Lipid-Induced Signaling Causes Release of Inflammatory Extracellular Vesicles from Hepatocytes. Gastroenterology 2016, 150, 956-967. [CrossRef]

305. Ibrahim, S.H.; Hirsova, P.; Tomita, K.; Bronk, S.F.; Werneburg, N.W.; Harrison, S.A.; Goodfellow, V.S.; Malhi, H.; Gores, G.J. Mixed lineage kinase 3 mediates release of C-X-C motif ligand 10-bearing chemotactic extracellular vesicles from lipotoxic hepatocytes. Hepatology 2016, 63, 731-744. [CrossRef]

306. Zhao, Y.; Zhao, M.F.; Jiang, S.; Wu, J.; Liu, J.; Yuan, X.W.; Shen, D.; Zhang, J.Z.; Zhou, N.; He, J.; et al. Liver governs adipose remodelling via extracellular vesicles in response to lipid overload. Nat. Commun. 2020, 11, 719. [CrossRef]

307. Ore, A.; Akinloye, O.A. Oxidative Stress and Antioxidant Biomarkers in Clinical and Experimental Models of Non-Alcoholic Fatty Liver Disease. Medicina 2019, 55, 26. [CrossRef]

308. Korish, A.A.; Arafah, M.M. Camel milk ameliorates steatohepatitis, insulin resistance and lipid peroxidation in experimental non-alcoholic fatty liver disease. BMC Complement. Altern. Med. 2013, 13, 264. [CrossRef]

309. Schröder, T.; Kucharczyk, D.; Bär, F.; Pagel, R.; Derer, S.; Jendrek, S.T.; Sünderhauf, A.; Brethack, A.K.; Hirose, M.; Möller, S.; et al. Mitochondrial gene polymorphisms alter hepatic cellular energy metabolism and aggravate diet-induced non-alcoholic steatohepatitis. Mol. Metab. 2016, 5, 283-295. [CrossRef]

310. Elshazly, S.M. Ameliorative effect of nicorandil on high fat diet induced non-alcoholic fatty liver disease in rats. Eur. J. Pharmacol. 2015, 748, 123-132. [CrossRef]

311. Sugatani, J.; Wada, T.; Osabe, M.; Yamakawa, K.; Yoshinari, K.; Miwa, M. Dietary inulin alleviates hepatic steatosis and xenobioticsinduced liver injury in rats fed a high-fat and high-sucrose diet: Association with the suppression of hepatic cytochrome P450 and hepatocyte nuclear factor 4alpha expression. Drug Metab. Dispos. 2006, 34, 1677-1687. [CrossRef]

312. Li, W.; Lu, Y. Hepatoprotective Effects of Sophoricoside against Fructose-Induced Liver Injury via Regulating Lipid Metabolism, Oxidation, and Inflammation in Mice. J. Food Sci. 2018, 83, 552-558. [CrossRef]

313. García-Ruiz, I.; Rodríguez-Juan, C.; Díaz-Sanjuan, T.; Del Hoyo, P.; Colina, F.; Muñoz-Yagüe, T.; Solís-Herruzo, J.A. Uric acid and anti-TNF antibody improve mitochondrial dysfunction in ob/ob mice. Hepatology 2006, 44, 581-591. [CrossRef]

314. Verbeek, J.; Spincemaille, P.; Vanhorebeek, I.; Van Den Berghe, G.; Vander Elst, I.; Windmolders, P.; Van Pelt, J.; Van Der Merwe, S.; Bedossa, P.; Nevens, F.; et al. Dietary intervention, but not losartan, completely reverses non-alcoholic steatohepatitis in obese and insulin resistant mice. Lipids Health Dis. 2017, 16, 46. [CrossRef]

315. Ciapaite, J.; Bakker, S.J.L.; Van Eikenhorst, G.; Wagner, M.J.; Teerlink, T.; Schalkwijk, C.G.; Fodor, M.; Ouwens, D.M.; Diamant, M.; Heine, R.J.; et al. Functioning of oxidative phosphorylation in liver mitochondria of high-fat diet fed rats. Biochim. Biophys. Acta 2007, 1772, 307-316. [CrossRef]

316. Janevski, M.; Antonas, K.N.; Sullivan-Gunn, M.J.; McGlynn, M.A.; Lewandowski, P.A. The effect of cocoa supplementation on hepatic steatosis, reactive oxygen species and LFABP in a rat model of NASH. Comp. Hepatol. 2011, 10, 10. [CrossRef]

317. García-Ruiz, I.; Fernández-Moreira, D.; Solís-Muñoz, P.; Rodríguez-Juan, C.; Díaz-Sanjuán, T.; Muñoz-Yagüe, T.; Solís-Herruzo, J.A. Mitochondrial complex I subunits are decreased in murine nonalcoholic fatty liver disease: Implication of peroxynitrite. $J$. Proteome Res. 2010, 9, 2450-2459. [CrossRef]

318. Mantena, S.K.; Vaughn, D.P.; Andringa, K.K.; Eccleston, H.B.; King, A.L.; Abrams, G.A.; Doeller, J.E.; Kraus, D.W.; Darley-Usmar, V.M.; Bailey, S.M. High fat diet induces dysregulation of hepatic oxygen gradients and mitochondrial function in vivo. Biochem. J. 2009, 417, 183-193. [CrossRef]

319. Lieber, C.S.; Leo, M.A.; Mak, K.M.; Xu, Y.; Cao, Q.; Ren, C.; Ponomarenko, A.; DeCarli, L.M. Model of nonalcoholic steatohepatitis. Am. J. Clin. Nutr. 2004, 79, 502-509. [CrossRef]

320. Cardoso, A.R.; Kakimoto, P.A.H.B.; Kowaltowski, A.J. Diet-sensitive sources of reactive oxygen species in liver mitochondria: Role of very long chain acyl-CoA dehydrogenases. PLoS ONE 2013, 8, e77088. [CrossRef]

321. Kathirvel, E.; Chen, P.; Morgan, K.; French, S.W.; Morgan, T.R. Oxidative stress and regulation of anti-oxidant enzymes in cytochrome P4502E1 transgenic mouse model of non-alcoholic fatty liver. J. Gastroenterol. Hepatol. 2010, 25, 1136-1143. [CrossRef] 
322. Yoshioka, S.; Hamada, A.; Jobu, K.; Yokota, J.; Onogawa, M.; Kyotani, S.; Miyamura, M.; Saibara, T.; Onishi, S.; Nishioka, Y. Effects of Eriobotrya japonica seed extract on oxidative stress in rats with non-alcoholic steatohepatitis. J. Pharm. Pharmacol. 2010, 62, 241-246. [CrossRef]

323. Chung, M.Y.; Park, H.J.; Manautou, J.E.; Koo, S.I.; Bruno, R.S. Green tea extract protects against nonalcoholic steatohepatitis in $\mathrm{ob} / \mathrm{ob}$ mice by decreasing oxidative and nitrative stress responses induced by proinflammatory enzymes. J. Nutr. Biochem. 2012, 23, 361-367. [CrossRef]

324. Song, L.; Qu, D.; Zhang, Q.; Jiang, J.; Zhou, H.; Jiang, R.; Li, Y.; Zhang, Y.; Yan, H. Phytosterol esters attenuate hepatic steatosis in rats with non-alcoholic fatty liver disease rats fed a high-fat diet. Sci. Rep. 2017, 7, 41604. [CrossRef]

325. Stiuso, P.; Scognamiglio, I.; Murolo, M.; Ferranti, P.; De Simone, C.; Rizzo, M.R.; Tuccillo, C.; Caraglia, M.; Loguercio, C.; Federico, A. Serum oxidative stress markers and lipidomic profile to detect NASH patients responsive to an antioxidant treatment: A pilot study. Oxid. Med. Cell. Longev. 2014, 2014, 169216. [CrossRef]

326. Leghi, G.E.; Domenici, F.A.; Vannucchi, H. Influence of oxidative stress and obesity in patients with nonalcoholic steatohepatitis. Arq. Gastroenterol. 2015, 52, 228-233. [CrossRef]

327. Videla, L.A.; Rodrigo, R.; Orellana, M.; Fernandez, V.; Tapia, G.; Quiñones, L.; Varela, N.; Contreras, J.; Lazarte, R.; Csendes, A.; et al. Oxidative stress-related parameters in the liver of non-alcoholic fatty liver disease patients. Clin. Sci. 2004, 106, 261-268. [CrossRef]

328. Loguercio, C.; De Girolamo, V.; De Sio, I.; Tuccillo, C.; Ascione, A.; Baldi, F.; Budillon, G.; Cimino, L.; Di Carlo, A.; Pia Di Marino, M.; et al. Non-alcoholic fatty liver disease in an area of southern Italy: Main clinical, histological, and pathophysiological aspects. J. Hepatol. 2001, 35, 568-574. [CrossRef]

329. Seki, S.; Kitada, T.; Yamada, T.; Sakaguchi, H.; Nakatani, K.; Wakasa, K. In situ detection of lipid peroxidation and oxidative DNA damage in non-alcoholic fatty liver diseases. J. Hepatol. 2002, 37, 56-62. [CrossRef]

330. Oliveira, C.P.M.S.; Faintuch, J.; Rascovski, A.; Furuya, C.K.; Do Socorro Bastos, M.; Matsuda, M.; Della Nina, B.I.; Yahnosi, K.; Abdala, D.S.P.; Vezozzo, D.C.P.; et al. Lipid peroxidation in bariatric candidates with nonalcoholic fatty liver disease (NAFLD)-Preliminary findings. Obes. Surg. 2005, 15, 502-505. [CrossRef]

331. Dasarathy, S.; Yang, Y.; McCullough, A.J.; Marczewski, S.; Bennett, C.; Kalhan, S.C. Elevated hepatic fatty acid oxidation, high plasma fibroblast growth factor 21, and fasting bile acids in nonalcoholic steatohepatitis. Eur. J. Gastroenterol. Hepatol. 2011, 23, 382-388. [CrossRef]

332. Lu, Y.; Liu, X.; Jiao, Y.; Xiong, X.; Wang, E.; Wang, X.; Zhang, Z.; Zhang, H.; Pan, L.; Guan, Y.; et al. Periostin promotes liver steatosis and hypertriglyceridemia through downregulation of PPAR $\alpha$. J. Clin. Investig. 2014, 124, 3501-3513. [CrossRef] [PubMed]

333. Zhu, J.Z.; Zhu, H.T.; Dai, Y.N.; Li, C.X.; Fang, Z.Y.; Zhao, D.J.; Wan, X.Y.; Wang, Y.M.; Wang, F.; Yu, C.H.; et al. Serum periostin is a potential biomarker for non-alcoholic fatty liver disease: A case-control study. Endocrine 2016, 51, 91-100. [CrossRef] [PubMed]

334. Yang, Z.; Zhang, H.; Niu, Y.; Zhang, W.; Zhu, L.; Li, X.; Lu, S.; Fan, J.; Li, X.; Ning, G.; et al. Circulating periostin in relation to insulin resistance and nonalcoholic fatty liver disease among overweight and obese subjects. Sci. Rep. 2016, 6, 37886. [CrossRef] [PubMed]

335. Luo, Y.; Qu, H.; Wang, H.; Wei, H.; Wu, J.; Duan, Y.; Liu, D.; Deng, H. Plasma Periostin Levels Are Increased in Chinese Subjects with Obesity and Type 2 Diabetes and Are Positively Correlated with Glucose and Lipid Parameters. Mediators Inflamm. 2016, 2016, 6423637. [CrossRef] [PubMed]

336. Dongiovanni, P.; Anstee, Q.; Valenti, L. Genetic predisposition in NAFLD and NASH: Impact on severity of liver disease and response to treatment. Curr. Pharm. Des. 2013, 19, 5219-5238. [CrossRef]

337. Salomone, F.; Li Volti, G.; Rosso, C.; Grosso, G.; Bugianesi, E. Unconjugated bilirubin, a potent endogenous antioxidant, is decreased in patients with non-alcoholic steatohepatitis and advanced fibrosis. J. Gastroenterol. Hepatol. 2013, 28, 1202-1208. [CrossRef]

338. Chtioui, H.; Semela, D.; Ledermann, M.; Zimmermann, A.; Dufour, J.F. Expression and activity of the cytochrome P450 2E1 in patients with nonalcoholic steatosis and steatohepatitis. Liver Int. 2007, 27, 764-771. [CrossRef]

339. Marcolin, É.; Forgiarini, L.F.; Tieppo, J.; Dias, A.S.; de Freitas, L.A.R.; Marroni, N.P. Methionine- and choline-deficient diet induces hepatic changes characteristic of non-alcoholic steatohepatitis. Arq. Gastroenterol. 2011, 48, 72-79. [CrossRef]

340. Nosrati, N.; Aghazadeh, S.; Yazdanparast, R. Effects of Teucrium polium on Insulin Resistance in Nonalcoholic Steatohepatitis. J. Acupunct. Meridian Stud. 2010, 3, 104-110. [CrossRef]

341. Rector, R.S.; Thyfault, J.P.; Uptergrove, G.M.; Morris, E.M.; Naples, S.P.; Borengasser, S.J.; Mikus, C.R.; Laye, M.J.; Laughlin, M.H.; Booth, F.W.; et al. Mitochondrial dysfunction precedes insulin resistance and hepatic steatosis and contributes to the natural history of non-alcoholic fatty liver disease in an obese rodent model. J. Hepatol. 2010, 52, 727-736. [CrossRef]

342. Marcolin, E.; San-Miguel, B.; Vallejo, D.; Tieppo, J.; Marroni, N.; González-Gallego, J.; Tuñón, M.J. Quercetin treatment ameliorates inflammation and fibrosis in mice with nonalcoholic steatohepatitis. J. Nutr. 2012, 142, 1821-1828. [CrossRef] [PubMed]

343. Kumar, A.; Sharma, A.; Duseja, A.; Das, A.; Dhiman, R.K.; Chawla, Y.K.; Kohli, K.K.; Bhansali, A. Patients with Nonalcoholic Fatty Liver Disease (NAFLD) have Higher Oxidative Stress in Comparison to Chronic Viral Hepatitis. J. Clin. Exp. Hepatol. 2013, 3, 12-18. [CrossRef] [PubMed]

344. Koruk, M.; Taysi, S.; Savas, M.C.; Yilmaz, O.; Akcay, F.K.M. Oxidative stress and enzymatic antioxidant status in patients with nonalcoholic steatohepatitis. Ann. Clin. Lab. Sci. 2004, 34, 57-62. [PubMed] 
345. Sumida, Y.; Nakashima, T.; Yoh, T.; Furutani, M.; Hirohama, A.; Kakisaka, Y.; Nakajima, Y.; Ishikawa, H.; Mitsuyoshi, H.; Okanoue, T.; et al. Serum thioredoxin levels as a predictor of steatohepatitis in patients with nonalcoholic fatty liver disease. J. Hepatol. 2003, 38, 32-38. [CrossRef]

346. Köroğlu, E.; Canbakan, B.; Atay, K.; Hatemi, I.; Tuncer, M.; Dobrucali, A.; Sonsuz, A.; Gültepe, I.; Şentürk, H. Role of oxidative stress and insulin resistance in disease severity of non-alcoholic fatty liver disease. Turk. J. Gastroenterol. 2016, 27, 361-366. [CrossRef] [PubMed]

347. Yesilova, Z.; Yaman, H.; Oktenli, C.; Ozcan, A.; Uygun, A.; Cakir, E.; Sanisoglu, S.Y.; Erdil, A.; Ates, Y.; Aslan, M.; et al. Systemic markers of lipid peroxidation and antioxidants in patients with nonalcoholic Fatty liver disease. Am. J. Gastroenterol. 2005, 100, 850-855. [CrossRef] [PubMed]

348. Osterreicher, C.H.; Brenner, D.A. The genetics of nonalcoholic fatty liver disease. Ann Hepatol. 2007, 6, 83-88. [CrossRef]

349. Willner, I.R.; Waters, B.; Patil, S.R.; Reuben, A.; Morelli, J.; Riely, C.A. Ninety patients with nonalcoholic steatohepatitis: Insulin resistance, familial tendency, and severity of disease. Am. J. Gastroenterol. 2001, 96, 2957-2961. [CrossRef]

350. Schwimmer, J.B.; Celedon, M.A.; Lavine, J.E.; Salem, R.; Campbell, N.; Schork, N.J.; Shiehmorteza, M.; Yokoo, T.; Chavez, A.; Middleton, M.S.; et al. Heritability of nonalcoholic fatty liver disease. Gastroenterology 2009, 136, 1585-1592. [CrossRef] [PubMed]

351. Dabravolski, S.A.; Bezsonov, E.E.; Baig, M.S.; Popkova, T.V.; Nedosugova, L.V.; Starodubova, A.V.; Orekhov, A.N. Mitochondrial Mutations and Genetic Factors Determining NAFLD Risk. Int. J. Mol. Sci. 2021, 22, 4459. [CrossRef] [PubMed]

352. Oliveira, C.P.; Stefano, J.T. Genetic polymorphisms and oxidative stress in non-alcoholic steatohepatitis (NASH): A mini review. Clin. Res. Hepatol. Gastroenterol. 2015, 39 (Suppl. 1), S35-S40. [CrossRef] [PubMed]

353. Di Rosa, M.; Malaguarnera, L. Genetic variants in candidate genes influencing NAFLD progression. J. Mol. Med. 2012, 90, 105-118. [CrossRef] [PubMed]

354. Taliento, A.E.; Dallio, M.; Federico, A.; Prati, D.; Valenti, L. Novel Insights into the Genetic Landscape of Nonalcoholic Fatty Liver Disease. Int. J. Environ. Res. Public Health 2019, 16, 2755. [CrossRef] [PubMed]

355. Wispe', J.R.; Clark, J.C.; Burhans, M.S.; Kropp, K.E.; Korfhagen, T.R.; Whitsett, J.A. Synthesis and processing of the precursor for human mangano-superoxide dismutase. Biochim. Biophys. Acta 1989, 994, 30-36. [CrossRef]

356. Sutton, A.; Imbert, A.; Igoudjil, A.; Descatoire, V.; Cazanave, S.; Pessayre, D.; Degoul, F. The manganese superoxide dismutase Ala16Val dimorphism modulates both mitochondrial import and mRNA stability. Pharmacogenet. Genomics 2005, 15, 311-319. [CrossRef]

357. Meroni, M.; Longo, M.; Dongiovanni, P. Genetic and metabolic factors: The perfect combination to treat metabolic associated fatty liver disease. Explor. Med. 2020, 1, 218-243. [CrossRef]

358. Al-Serri, A.; Anstee, Q.M.; Valenti, L.; Nobili, V.; Leathart, J.B.S.; Dongiovanni, P.; Patch, J.; Fracanzani, A.; Fargion, S.; Day, C.P.; et al. The SOD2 C47T polymorphism influences NAFLD fibrosis severity: Evidence from case-control and intra-familial allele association studies. J. Hepatol. 2012, 56, 448-454. [CrossRef]

359. Namikawa, C.; Shu-Ping, Z.; Vyselaar, J.R.; Nozaki, Y.; Nemoto, Y.; Ono, M.; Akisawa, N.; Saibara, T.; Hiroi, M.; Enzan, H.; et al. Polymorphisms of microsomal triglyceride transfer protein gene and manganese superoxide dismutase gene in non-alcoholic steatohepatitis. J. Hepatol. 2004, 40, 781-786. [CrossRef]

360. Schrauwen, P.; Xia, J.; Walder, K.; Snitker, S.; Ravussin, E. A novel polymorphism in the proximal UCP3 promoter region: Effect on skeletal muscle UCP3 mRNA expression and obesity in male non-diabetic Pima Indians. Int. J. Obes. Relat. Metab. Disord. 1999, 23, 1242-1245. [CrossRef]

361. Aller, R.; De Luis, D.A.; Izaola, O.; González Sagrado, M.; Conde, R.; Alvarez, T.; Pacheco, D.V.M. Role of -55CT polymorphism of UCP3 gene on non alcoholic fatty liver disease and insulin resistance in patients with obesity. Nutr. Hosp. 2010, 25, 572-576.

362. Fares, R.; Petta, S.; Lombardi, R.; Grimaudo, S.; Dongiovanni, P.; Pipitone, R.; Rametta, R.; Fracanzani, A.L.; Mozzi, E.; Craxì, A.; et al. The UCP2-866 G>A promoter region polymorphism is associated with nonalcoholic steatohepatitis. Liver Int. 2015, 35, 1574-1580. [CrossRef]

363. Dong, C.; Della-Morte, D.; Wang, L.; Cabral, D.; Beecham, A.; McClendon, M.S.; Luca, C.C.; Blanton, S.H.; Sacco, R.L.; Rundek, T. Association of the sirtuin and mitochondrial uncoupling protein genes with carotid plaque. PLoS ONE 2011, 6, e27157. [CrossRef]

364. Oliveira, C.P.M.S.; Stefano, J.T.; Cavaleiro, A.M.; Zanella Fortes, M.A.H.; Vieira, S.M.; Rodrigues Lima, V.M.; Santos, T.E.; Santos, V.N.; De Azevedo Salgado, A.L.F.; Parise, É.R.; et al. Association of polymorphisms of glutamate-cystein ligase and microsomal triglyceride transfer protein genes in non-alcoholic fatty liver disease. J. Gastroenterol. Hepatol. 2010, 25, 357-361. [CrossRef]

365. Hashemi, M.; Hoseini, H.; Yaghmaei, P.; Moazeni-Roodi, A.; Bahari, A.; Hashemzehi, N.; Shafieipour, S. Association of polymorphisms in glutamate-cysteine ligase catalytic subunit and microsomal triglyceride transfer protein genes with nonalcoholic fatty liver disease. DNA Cell Biol. 2011, 30, 569-575. [CrossRef]

366. Emdin, C.A.; Haas, M.E.; Khera, A.V.; Aragam, K.; Chaffin, M.; Klarin, D.; Hindy, G.; Jiang, L.; Wei, W.Q.; Feng, Q.; et al. A missense variant in Mitochondrial Amidoxime Reducing Component 1 gene and protection against liver disease. PLoS Genet. 2020, 16, e1008629. [CrossRef]

367. Sparacino-Watkins, C.E.; Tejero, J.; Sun, B.; Gauthier, M.C.; Thomas, J.; Ragireddy, V.; Merchan, B.A.; Wang, J.; Azarov, I.; Basu, P.; et al. Nitrite reductase and nitric-oxide synthase activity of the mitochondrial molybdopterin enzymes mARC1 and mARC2. J. Biol. Chem. 2014, 289, 10345-10358. [CrossRef]

368. Schneider, J.; Girreser, U.; Havemeyer, A.; Bittner, F.; Clement, B. Detoxification of Trimethylamine N-Oxide by the Mitochondrial Amidoxime Reducing Component mARC. Chem. Res. Toxicol. 2018, 31, 447-453. [CrossRef] 
369. Wang, C.; Gong, J.; Wu, H. Development of gene polymorphisms in meditators of nonalcoholic fatty liver disease. Biomed. Rep. 2017, 7, 95-104. [CrossRef]

370. Lin, Y.C.; Wu, C.C.; Ni, Y.H. New Perspectives on Genetic Prediction for Pediatric Metabolic Associated Fatty Liver Disease. Front. Pediatr. 2020, 8, 603654. [CrossRef]

371. Nobili, V.; Carpino, G.; Alisi, A.; De Vito, R.; Franchitto, A.; Alpini, G.; Onori, P.; Gaudio, E. Role of docosahexaenoic acid treatment in improving liver histology in pediatric nonalcoholic fatty liver disease. PLoS ONE 2014, 9, e88005. [CrossRef]

372. Lin, Y.C.; Chang, P.F.; Hu, F.C.; Chang, M.H.; Ni, Y.H. Variants in the UGT1A1 gene and the risk of pediatric nonalcoholic fatty liver disease. Pediatrics 2009, 124, e1221-e1227. [CrossRef]

373. Puri, K.; Nobili, V.; Melville, K.; Corte, C.D.; Sartorelli, M.R.; Lopez, R.; Feldstein, A.E.; Alkhouri, N. Serum bilirubin level is inversely associated with nonalcoholic steatohepatitis in children. J. Pediatr. Gastroenterol. Nutr. 2013, 57, 114-118. [CrossRef]

374. Drummond, G.S.; Baum, J.; Greenberg, M.; Lewis, D.; Abraham, N.G. HO-1 overexpression and underexpression: Clinical implications. Arch. Biochem. Biophys. 2019, 673, 108073. [CrossRef]

375. Soyal, S.; Krempler, F.; Oberkofler, H.; Patsch, W. PGC-1alpha: A potent transcriptional cofactor involved in the pathogenesis of type 2 diabetes. Diabetologia 2006, 49, 1477-1488. [CrossRef]

376. Lin, Y.C.; Chang, P.F.; Chang, M.H.; Ni, Y.H. A common variant in the peroxisome proliferator-activated receptor- $\gamma$ coactivator- $1 \alpha$ gene is associated with nonalcoholic fatty liver disease in obese children. Am. J. Clin. Nutr. 2013, 97, 326-331. [CrossRef]

377. Ladero, J.M.; Martínez, C.; García-Martin, E.; Fernández-Arquero, M.; López-Alonso, G.; De La Concha, E.G.; Díaz-Rubio, M.; Agúndez, J.A.G. Polymorphisms of the glutathione S-transferases mu-1 (GSTM1) and theta-1 (GSTT1) and the risk of advanced alcoholic liver disease. Scand. J. Gastroenterol. 2005, 40, 348-353. [CrossRef]

378. Stickel, F.; Österreicher, C.H.; Datz, C.; Ferenci, P.; Wölfel, M.; Norgauer, W.; Kraus, M.R.; Wrba, F.; Hellerbrand, C.; Schuppan, D. Prediction of progression to cirrhosis by a glutathione S-transferase P1 polymorphism in subjects with hereditary hemochromatosis. Arch. Intern. Med. 2005, 165, 1835-1840. [CrossRef]

379. Reynolds, W.F.; Patel, K.; Pianko, S.; Blatt, L.M.; Nicholas, J.J.; McHutchison, J.G. A genotypic association implicates myeloperoxidase in the progression of hepatic fibrosis in chronic hepatitis C virus infection. Genes Immun. 2002, 3, 345-349. [CrossRef]

380. Österreicher, C.H.; Datz, C.; Stickel, F.; Hellerbrand, C.; Penz, M.; Hofer, H.; Wrba, F.; Penner, E.; Schuppan, D.; Ferenci, P. Association of myeloperoxidase promotor polymorphism with cirrhosis in patients with hereditary hemochromatosis. J. Hepatol. 2005, 42, 914-919. [CrossRef]

381. Sonzogni, L.; Silvestri, L.; De Silvestri, A.; Gritti, C.; Foti, L.; Zavaglia, C.; Bottelli, R.; Mondelli, M.U.; Civardi, E.; Silini, E.M. Polymorphisms of microsomal epoxide hydrolase gene and severity of HCV-related liver disease. Hepatology 2002, 36, 195-201. [CrossRef]

382. Cicero, A.F.G.; Colletti, A.; Bellentani, S. Nutraceutical Approach to Non-Alcoholic Fatty Liver Disease (NAFLD): The Available Clinical Evidence. Nutrients 2018, 10, 1153. [CrossRef] [PubMed]

383. Li, S.; Tan, H.Y.; Wang, N.; Cheung, F.; Hong, M.; Feng, Y. The Potential and Action Mechanism of Polyphenols in the Treatment of Liver Diseases. Oxid. Med. Cell. Longev. 2018, 2018, 8394818. [CrossRef] [PubMed]

384. Rafiei, H.; Omidian, K.; Bandy, B. Dietary Polyphenols Protect Against Oleic Acid-Induced Steatosis in an in Vitro Model of NAFLD by Modulating Lipid Metabolism and Improving Mitochondrial Function. Nutrients 2019, 11, 541. [CrossRef] [PubMed]

385. Musso, G.; Cassader, M.; Gambino, R. Non-alcoholic steatohepatitis: Emerging molecular targets and therapeutic strategies. Nat. Rev. Drug Discov. 2016, 15, 249-274. [CrossRef]

386. Hodges, J.K.; Sasaki, G.Y.; Bruno, R.S. Anti-inflammatory activities of green tea catechins along the gut-liver axis in nonalcoholic fatty liver disease: Lessons learned from preclinical and human studies. J. Nutr. Biochem. 2020, 85, 108478. [CrossRef]

387. Xia, H.M.; Wang, J.; Xie, X.J.; Xu, L.J.; Tang, S.Q. Green tea polyphenols attenuate hepatic steatosis, and reduce insulin resistance and inflammation in high-fat diet-induced rats. Int. J. Mol. Med. 2019, 44, 1523-1530. [CrossRef]

388. Yang, J.P.; Shin, J.H.; Seo, S.H.; Kim, S.G.; Lee, S.H.; Shin, E.H. Effects of Antioxidants in Reducing Accumulation of Fat in Hepatocyte. Int. J. Mol. Sci. 2018, 19, 2563. [CrossRef]

389. Li, S.; Tan, H.Y.; Wang, N.; Zhang, Z.J.; Lao, L.; Wong, C.W.; Feng, Y. The Role of Oxidative Stress and Antioxidants in Liver Diseases. Int. J. Mol. Sci. 2015, 16, 26087-26124. [CrossRef]

390. Ivancovsky-Wajcman, D.; Fliss-Isakov, N.; Salomone, F.; Webb, M.; Shibolet, O.; Kariv, R.; Zelber-Sagi, S. Dietary vitamin E and C intake is inversely associated with the severity of nonalcoholic fatty liver disease. Dig. Liver Dis. 2019, 51, 1698-1705. [CrossRef]

391. Perumpail, B.; Li, A.; John, N.; Sallam, S.; Shah, N.; Kwong, W.; Cholankeril, G.; Kim, D.; Ahmed, A. The Role of Vitamin E in the Treatment of NAFLD. Diseases 2018, 6, 86. [CrossRef]

392. Vilar-Gomez, E.; Vuppalanchi, R.; Gawrieh, S.; Ghabril, M.; Saxena, R.; Cummings, O.W.; Chalasani, N. Vitamin E Improves Transplant-Free Survival and Hepatic Decompensation Among Patients with Nonalcoholic Steatohepatitis and Advanced Fibrosis. Hepatology 2020, 71, 495-509. [CrossRef] [PubMed]

393. Raso, G.M.; Esposito, E.; Iacono, A.; Pacilio, M.; Cuzzocrea, S.; Canani, R.B.; Calignano, A.; Meli, R. Comparative therapeutic effects of metformin and vitamin $\mathrm{E}$ in a model of non-alcoholic steatohepatitis in the young rat. Eur. J. Pharmacol. 2009, 604, 125-131. [CrossRef] [PubMed]

394. Podszun, M.C.; Frank, J. Impact of vitamin E on redox biomarkers in non-alcoholic fatty liver disease. Redox Biol. 2021, $42,101937$. [CrossRef] [PubMed] 
395. Mishra, P.; Paital, B.; Jena, S.; Swain, S.S.; Kumar, S.; Yadav, M.K.; Chainy, G.B.N.; Samanta, L. Possible activation of NRF2 by Vitamin E/Curcumin against altered thyroid hormone induced oxidative stress via NFkB/AKT/mTOR/KEAP1 signalling in rat heart. Sci. Rep. 2019, 9, 7408. [CrossRef]

396. He, W.; Xu, Y.; Ren, X.; Xiang, D.; Lei, K.; Zhang, C.; Liu, D. Vitamin E Ameliorates Lipid Metabolism in Mice with Nonalcoholic Fatty Liver Disease via Nrf2/CES1 Signaling Pathway. Dig. Dis. Sci. 2019, 64, 3182-3191. [CrossRef]

397. Podszun, M.C.; Alawad, A.S.; Lingala, S.; Morris, N.; Huang, W.C.A.; Yang, S.; Schoenfeld, M.; Rolt, A.; Ouwerkerk, R.; Valdez, K.; et al. Vitamin E treatment in NAFLD patients demonstrates that oxidative stress drives steatosis through upregulation of de-novo lipogenesis. Redox Biol. 2020, 37, 101710. [CrossRef]

398. Wei, J.; Lei, G.H.; Fu, L.; Zeng, C.; Yang, T.; Peng, S.F. Association between Dietary Vitamin C Intake and Non-Alcoholic Fatty Liver Disease: A Cross-Sectional Study among Middle-Aged and Older Adults. PLoS ONE 2016, 11, e0147985. [CrossRef]

399. Oliveira, C.P.M.S.; Da Costa Gayotto, L.C.; Tatai, C.; Della Nina, B.I.; Lima, E.S.; Abdalla, D.S.P.; Lopasso, F.P.; Laurindo, F.R.M.; Carrilho, F.J. Vitamin C and Vitamin E in Prevention of Nonalcoholic Fatty Liver Disease (NAFLD) in Choline Deficient Diet Fed Rats. Nutr. J. 2003, 2, 9. [CrossRef]

400. Lee, H.; Ahn, J.; Shin, S.S.; Yoon, M. Ascorbic acid inhibits visceral obesity and nonalcoholic fatty liver disease by activating peroxisome proliferator-activated receptor $\alpha$ in high-fat-diet-fed C57BL/6J mice. Int. J. Obes. 2019, 43, 1620-1630. [CrossRef]

401. Kolb, H.; Kempf, K.; Martin, S. Health Effects of Coffee: Mechanism Unraveled? Nutrients 2020, 12, 1842. [CrossRef]

402. Wijarnpreecha, K.; Thongprayoon, C.; Ungprasert, P. Coffee consumption and risk of nonalcoholic fatty liver disease: A systematic review and meta-analysis. Eur. J. Gastroenterol. Hepatol. 2017, 29, e8-e12. [CrossRef] [PubMed]

403. Boettler, U.; Volz, N.; Teller, N.; Haupt, L.M.; Bakuradze, T.; Eisenbrand, G.; Bytof, G.; Lantz, I.; Griffiths, L.R.; Marko, D. Induction of antioxidative Nrf2 gene transcription by coffee in humans: Depending on genotype? Mol. Biol. Rep. 2012, 39, 7155-7162. [CrossRef] [PubMed]

404. Priftis, A.; Angeli-Terzidou, A.E.; Veskoukis, A.S.; Spandidos, D.A.; Kouretas, D. Cell-specific and roasting-dependent regulation of the Keap1/Nrf2 pathway by coffee extracts. Mol. Med. Rep. 2018, 17, 8325-8331. [CrossRef] [PubMed]

405. Du, X.; Huang, Q.; Guan, Y.; Lv, M.; He, X.; Fang, C.; Wang, X.; Sheng, J. Caffeine promotes conversion of palmitic acid to palmitoleic acid by inducing expression of fat-5 in Caenorhabditis elegans and scd1 in mice. Front. Pharmacol. $2018,9,321$. [CrossRef]

406. Foretz, M.; Even, P.C.; Viollet, B. AMPK Activation Reduces Hepatic Lipid Content by Increasing Fat Oxidation In Vivo. Int. J. Mol. Sci. 2018, 19, 2826. [CrossRef]

407. Wang, Q.; Dai, X.; Yang, W.; Wang, H.; Zhao, H.; Yang, F.; Yang, Y.; Li, J.; Lv, X. Caffeine protects against alcohol-induced liver fibrosis by dampening the cAMP/PKA/CREB pathway in rat hepatic stellate cells. Int. Immunopharmacol. 2015, 25, 340-352. [CrossRef]

408. Bhandarkar, N.S.; Brown, L.; Panchal, S.K. Chlorogenic acid attenuates high-carbohydrate, high-fat diet-induced cardiovascular, liver, and metabolic changes in rats. Nutr. Res. 2019, 62, 78-88. [CrossRef]

409. Mazza, A.; Fruci, B.; Garinis, G.A.; Giuliano, S.; Malaguarnera, R.; Belfiore, A. The role of metformin in the management of NAFLD. Exp. Diabetes Res. 2012, 2012, 716404. [CrossRef]

410. Brandt, A.; Hernández-Arriaga, A.; Kehm, R.; Sánchez, V.; Jin, C.J.; Nier, A.; Baumann, A.; Camarinha-Silva, A.; Bergheim, I. Metformin attenuates the onset of non-alcoholic fatty liver disease and affects intestinal microbiota and barrier in small intestine. Sci. Rep. 2019, 9, 6668. [CrossRef]

411. Song, Y.M.; Lee, Y.H.; Kim, J.W.; Ham, D.S.; Kang, E.S.; Cha, B.S.; Lee, H.C.; Lee, B.W. Metformin alleviates hepatosteatosis by restoring SIRT1-mediated autophagy induction via an AMP-activated protein kinase-independent pathway. Autophagy 2015, 11, 46-59. [CrossRef]

412. Rouabhia, S.; Milic, N.; Abenavoli, L. Metformin in the treatment of non-alcoholic fatty liver disease: Safety, efficacy and mechanism. Expert Rev. Gastroenterol. Hepatol. 2014, 8, 343-349. [CrossRef]

413. Parhiz, H.; Roohbakhsh, A.; Soltani, F.; Rezaee, R.; Iranshahi, M. Antioxidant and anti-inflammatory properties of the citrus flavonoids hesperidin and hesperetin: An updated review of their molecular mechanisms and experimental models. Phytother. Res. 2015, 29, 323-331. [CrossRef]

414. Ikram, M.; Muhammad, T.; Rehman, S.U.; Khan, A.; Jo, M.G.; Ali, T.; Kim, M.O. Hesperetin Confers Neuroprotection by Regulating Nrf2/TLR4/NF-кB Signaling in an A $\beta$ Mouse Model. Mol. Neurobiol. 2019, 56, 6293-6309. [CrossRef]

415. Geng, Y.; Wu, Z.; Buist-Homan, M.; Blokzijl, H.; Moshage, H. Hesperetin protects against palmitate-induced cellular toxicity via induction of GRP78 in hepatocytes. Toxicol. Appl. Pharmacol. 2020, 404, 115183. [CrossRef]

416. Wah Kheong, C.; Nik Mustapha, N.R.; Mahadeva, S. A Randomized Trial of Silymarin for the Treatment of Nonalcoholic Steatohepatitis. Clin. Gastroenterol. Hepatol. 2017, 15, 1940-1949.e8. [CrossRef]

417. Herrero, M.; Cifuentes, A.; Ibañez, E. Sub- and supercritical fluid extraction of functional ingredients from different natural sources: Plants, food-by-products, algae and microalgae: A review. Food Chem. 2006, 98, 136-148. [CrossRef]

418. Zhong, S.; Fan, Y.; Yan, Q.; Fan, X.; Wu, B.; Han, Y.; Zhang, Y.; Chen, Y.; Zhang, H.; Niu, J. The therapeutic effect of silymarin in the treatment of nonalcoholic fatty disease: A meta-analysis (PRISMA) of randomized control trials. Medicine 2017, 96 , e9061. [CrossRef]

419. Taleb, A.; Ahmad, K.A.; Ihsan, A.U.; Qu, J.; Lin, N.; Hezam, K.; Koju, N.; Hui, L.; Qilong, D. Antioxidant effects and mechanism of silymarin in oxidative stress induced cardiovascular diseases. Biomed. Pharmacother. 2018, 102, 689-698. [CrossRef] 
420. Navarro, V.J.; Belle, S.H.; D’Amato, M.; Adfhal, N.; Brunt, E.M.; Fried, M.W.; Rajender Reddy, K.; Wahed, A.S.; Harrison, S. Silymarin in non-cirrhotics with non-alcoholic steatohepatitis: A randomized, double-blind, placebo controlled trial. PLoS ONE 2019, 14, e0221683. [CrossRef]

421. Tang, J.T.; Mao, Y.M. Development of new drugs for the treatment of nonalcoholic steatohepatitis. J. Dig. Dis. 2020, $21,3-11$. [CrossRef] 